Cochrane Database of Systematic Reviews

\title{
Face-to-face interventions for informing or educating parents about early childhood vaccination (Review)
}

Kaufman J, Ryan R, Walsh L, Horey D, Leask J, Robinson P, Hill S

Kaufman J, Ryan R, Walsh L, Horey D, Leask J, Robinson P, Hill S.

Face-to-face interventions for informing or educating parents about early childhood vaccination.

Cochrane Database of Systematic Reviews 2018, Issue 5. Art. No.: CD010038.

DOI: 10.1002/14651858.CD010038.pub3.

www.cochranelibrary.com 
TABLE OF CONTENTS

HEADER 1

ABSTRACT

PLAIN LANGUAGE SUMMARY

SUMMARY OF FINDINGS

BACKGROUND

OBJECTIVES

METHODS

RESULTS

Figure 1.

Figure 2.

Figure 3.

DISCUSSION

AUTHORS' CONCLUSIONS

ACKNOWLEDGEMENTS

REFERENCES

CHARACTERISTICS OF STUDIES

DATA AND ANALYSES

Analysis 1.1. Comparison 1 Face-to-face education versus control or non-face-to-face education (all), Outcome 1 Vaccination status (stratified by length).

Analysis 1.2. Comparison 1 Face-to-face education versus control or non-face-to-face education (all), Outcome 2 Vaccination status (stratified by number of vaccines delivered).

Analysis 1.3. Comparison 1 Face-to-face education versus control or non-face-to-face education (all), Outcome 3 Knowledge.

Analysis 1.4. Comparison 1 Face-to-face education versus control or non-face-to-face education (all), Outcome 4 Attitudes necessity.

Analysis 1.5. Comparison 1 Face-to-face education versus control or non-face-to-face education (all), Outcome 5 Intention to vaccinate.

Analysis 1.6. Comparison 1 Face-to-face education versus control or non-face-to-face education (all), Outcome 6 Adverse effects (anxiety).

ADDITIONAL TABLES

APPENDICES

WHAT'S NEW

CONTRIBUTIONS OF AUTHORS

DECLARATIONS OF INTEREST

SOURCES OF SUPPORT

DIFFERENCES BETWEEN PROTOCOL AND REVIEW

INDEX TERMS 
[Intervention Review]

\section{Face-to-face interventions for informing or educating parents about early childhood vaccination}

Jessica Kaufman ${ }^{1}$, Rebecca Ryan ${ }^{1}$, Louisa Walsh ${ }^{1}$, Dell Horey², Julie Leask ${ }^{3}$, Priscilla Robinson ${ }^{4}$, Sophie Hill1

${ }^{1}$ Centre for Health Communication and Participation, School of Psychology and Public Health, La Trobe University, Bundoora, Australia. ${ }^{2}$ College of Science, Health and Engineering, La Trobe University, Bundoora, Australia. ${ }^{3}$ Sydney Nursing School, The University of Sydney, Sydney, Australia. " Department of Public Health, School of Psychology and Public Health, La Trobe University, Bundoora, Australia

Contact address: Jessica Kaufman, Centre for Health Communication and Participation, School of Psychology and Public Health, La Trobe University, Bundoora, VIC, 3086, Australia. j.kaufman@latrobe.edu.au.

Editorial group: Cochrane Consumers and Communication Group.

Publication status and date: New search for studies and content updated (conclusions changed), published in Issue 5, 2018.

Citation: Kaufman J, Ryan R, Walsh L, Horey D, Leask J, Robinson P, Hill S. Face-to-face interventions for informing or educating parents about early childhood vaccination. Cochrane Database of Systematic Reviews 2018, Issue 5. Art. No.: CD010038. DOI: 10.1002/14651858.CD010038.pub3.

Copyright ( 2018 The Authors. Cochrane Database of Systematic Reviews published by John Wiley \& Sons, Ltd. on behalf of The Cochrane Collaboration. This is an open access article under the terms of the Creative Commons Attribution-Non-Commercial Licence, which permits use, distribution and reproduction in any medium, provided the original work is properly cited and is not used for commercial purposes.

\section{A B S T R A C T}

\section{Background}

Early childhood vaccination is an essential global public health practice that saves two to three million lives each year, but many children do not receive all the recommended vaccines. To achieve and maintain appropriate coverage rates, vaccination programmes rely on people having sufficient awareness and acceptance of vaccines.

Face-to-face information or educational interventions are widely used to help parents understand why vaccines are important; explain where, how and when to access services; and address hesitancy and concerns about vaccine safety or efficacy. Such interventions are interactive, and can be adapted to target particular populations or identified barriers.

This is an update of a review originally published in 2013.

\section{Objectives}

To assess the effects of face-to-face interventions for informing or educating parents about early childhood vaccination on vaccination status and parental knowledge, attitudes and intention to vaccinate.

\section{Search methods}

We searched the CENTRAL, MEDLINE, Embase, five other databases, and two trial registries (July and August 2017). We screened reference lists of relevant articles, and contacted authors of included studies and experts in the field. We had no language or date restrictions.

\section{Selection criteria}

We included randomised controlled trials (RCTs) and cluster-RCTs evaluating the effects of face-to-face interventions delivered to parents or expectant parents to inform or educate them about early childhood vaccination, compared with control or with another face-to-face intervention. The World Health Organization recommends that children receive all early childhood vaccines, with the exception of human papillomavirus vaccine (HPV), which is delivered to adolescents. 


\section{Data collection and analysis}

We used standard methodological procedures expected by Cochrane. Two authors independently reviewed all search results, extracted data and assessed the risk of bias of included studies.

\section{Main results}

In this update, we found four new studies, for a total of ten studies. We included seven RCTs and three cluster-RCTs involving a total of 4527 participants, although we were unable to pool the data from one cluster-RCT. Three of the ten studies were conducted in low- or middleincome countries.

All included studies compared face-to-face interventions with control. Most studies evaluated the effectiveness of a single intervention session delivered to individual parents. The interventions were an even mix of short (ten minutes or less) and longer sessions (15 minutes to several hours).

Overall, elements of the study designs put them at moderate to high risk of bias. All studies but one were at low risk of bias for sequence generation (i.e. used a random number sequence). For allocation concealment (i.e. the person randomising participants was unaware of the study group to which participant would be allocated), three were at high risk and one was judged at unclear risk of bias. Due to the educational nature of the intervention, blinding of participants and personnel was not possible in any studies. The risk of bias due to blinding of outcome assessors was judged as low for four studies. Most studies were at unclear risk of bias for incomplete outcome data and selective reporting. Other potential sources of bias included failure to account for clustering in a cluster-RCT and significant unexplained baseline differences between groups. One cluster-RCT was at high risk for selective recruitment of participants.

We judged the certainty of the evidence to be low for the outcomes of children's vaccination status, parents' attitudes or beliefs, intention to vaccinate, adverse effects (e.g. anxiety), and immunisation cost, and moderate for parents' knowledge or understanding. All studies had limitations in design. We downgraded the certainty of the evidence where we judged that studies had problems with randomisation or allocation concealment, or when outcomes were self-reported by participants who knew whether they'd received the intervention or not. We also downgraded the certainty for inconsistency (vaccination status), imprecision (intention to vaccinate and adverse effects), and indirectness (attitudes or beliefs, and cost).

Low-certainty evidence from seven studies (3004 participants) suggested that face-to-face interventions to inform or educate parents may improve vaccination status (risk ratio (RR) 1.20, 95\% confidence interval (CI) 1.04 to 1.37). Moderate-certainty evidence from four studies (657 participants) found that face-to-face interventions probably slightly improved parent knowledge (standardised mean difference (SMD) $0.19,95 \% \mathrm{Cl} 0.00$ to 0.38 ), and low-certainty evidence from two studies (179 participants) suggested they may slightly improve intention to vaccinate (SMD $0.55,95 \% \mathrm{Cl} 0.24$ to 0.85 ). Low-certainty evidence found the interventions may lead to little or no change in parent attitudes or beliefs about vaccination (SMD $0.03,95 \% \mathrm{Cl}-0.20$ to 0.27 ; three studies, 292 participants), or in parents' anxiety (mean difference (MD) $-1.93,95 \% \mathrm{Cl}-7.27$ to 3.41 ; one study, 90 participants). Only one study (365 participants) measured the intervention cost of a case management strategy, reporting that the estimated additional cost per fully immunised child for the intervention was approximately eight times higher than usual care (low-certainty evidence). No included studies reported outcomes associated with parents' experience of the intervention (e.g. satisfaction).

\section{Authors' conclusions}

There is low- to moderate-certainty evidence suggesting that face-to-face information or education may improve or slightly improve children's vaccination status, parents' knowledge, and parents' intention to vaccinate.

Face-to-face interventions may be more effective in populations where lack of awareness or understanding of vaccination is identified as a barrier (e.g. where people are unaware of new or optional vaccines). The effect of the intervention in a population where concerns about vaccines or vaccine hesitancy is the primary barrier is less clear. Reliable and validated scales for measuring more complex outcomes, such as attitudes or beliefs, are necessary in order to improve comparisons of the effects across studies.

\section{PLAIN LANGUAGE SUMMARY}

\section{Face-to-face interventions to inform or educate parents about early childhood vaccination}

\section{Review question}

The aim of this Cochrane Review was to find out whether face-to-face information or education delivered to parents or expectant parents improved vaccination status, parental knowledge or understanding of vaccination, attitudes or beliefs about vaccination, or intention to vaccinate. We also looked for evidence about any negative impacts of the intervention, such as anxiety, and evidence about cost and parents' experiences of the intervention.

This is an update of a review originally published in 2013. In this update, we found four new studies, for a total of ten studies.

\section{Background}


Childhood vaccination is an important and effective way to reduce childhood illness and death. However, many children do not receive the recommended vaccines, because their parents or caregivers do not know why vaccination is important, do not understand how, where, or when to get their children vaccinated, or have concerns or doubts about vaccine safety and efficacy.

One way to inform or educate parents about vaccination is through face-to-face discussions, either one-on-one, or in groups. This strategy can be used and adapted in any setting.

\section{Study characteristics}

We included trials published up to July 2017. We found ten studies with a total of 4527 participants that looked at the effects of face-toface information or education for parents. Seven studies were from high-income countries, and three were from low- or middle-income countries. The interventions were a mix of short (under ten minutes) and longer sessions (15 minutes to several hours) that were delivered to new or expectant parents.

\section{Key results}

We analysed data on the effects of face-to-face information or education on seven different outcomes. According to the included studies, face-to-face information or education may have improved children's vaccination status, probably slightly improved parents' knowledge or understanding of vaccination, and may slightly have improved parents' intention to vaccinate. These interventions may have led to little or no difference in parental attitudes or anxiety related to the intervention. Only one study measured the cost of a face-to-face case management strategy. In this study, the cost of fully immunising one additional child was eight times the cost of usual care, but the intervention was complex, and the study was older, and not widely generalisable. No studies measured parents' satisfaction with the faceto-face intervention.

\section{Certainty of the evidence}

We judged the certainty of the evidence to be moderate for parents' knowledge or understanding, but low for all other outcomes. We downgraded the certainty of the evidence where studies were judged to have problems with bias from different sources (e.g. the way in which participants were assigned to study groups), where there was a lot of variability in results or imprecise estimates, or where we had misgivings about the choice of outcomes measures.

\section{Conclusions}

This review suggests that immunisation-focused educational messages may be sufficient to improve vaccination coverage and, to a small degree, knowledge, particularly where awareness is identified as a barrier to vaccination. 


\section{SUMMARY OF FINDINGS}

\section{Summary of findings for the main comparison.}

Face-to-face interventions directed to parents for informing or educating parents about early childhood vaccination, as compared with control

Patient or population: parents of preschool-aged children or expectant parents

Settings: clinics, antenatal classes, or the mother's home

Intervention: face-to-face information or educational interventions

Comparison: control (no education, other education, or control not described)

\begin{tabular}{|c|c|c|c|c|c|c|}
\hline \multirow[t]{3}{*}{ Outcomes } & \multicolumn{2}{|c|}{ Illustrative comparative risks* $(95 \% \mathrm{CI})$} & \multirow{3}{*}{$\begin{array}{l}\text { Relative effect } \\
(95 \% \mathrm{CI})\end{array}$} & \multirow{3}{*}{$\begin{array}{l}\text { No of Partici- } \\
\text { pants } \\
\text { (studies) }\end{array}$} & \multirow{3}{*}{$\begin{array}{l}\text { Quality of the } \\
\text { evidence } \\
\text { (GRADE) }\end{array}$} & \multirow[t]{3}{*}{ Comments } \\
\hline & $\begin{array}{l}\text { Assumed } \\
\text { (baseline) risk }\end{array}$ & $\begin{array}{l}\text { Corresponding (interven- } \\
\text { tion) risk }\end{array}$ & & & & \\
\hline & $\begin{array}{l}\text { Control (no } \\
\text { face-to-face in- } \\
\text { formation or } \\
\text { education) }\end{array}$ & $\begin{array}{l}\text { Face-to-face information } \\
\text { or education }\end{array}$ & & & & \\
\hline $\begin{array}{l}\text { Vaccination status } \\
\text { Final time point }(3,6 \text {, or } 12 \\
\text { months post-intervention) }\end{array}$ & 55 per $100^{1}$ & $\begin{array}{l}\mathbf{6 6} \text { per } 100 \\
(57 \text { to } 75)\end{array}$ & $\begin{array}{l}\text { RR 1.20 (1.04 to } \\
1.37)\end{array}$ & 3004 (7 studies) & $\begin{array}{l}\oplus \oplus \oplus \ominus \\
\text { low } 2\end{array}$ & $\begin{array}{l}\text { The results for this outcome } \\
\text { were variable, so the true } \\
\text { result may be substantially } \\
\text { higher or lower than this esti- } \\
\text { mate. }\end{array}$ \\
\hline
\end{tabular}

Knowledge or understanding

The mean knowledge score in the intervention group

657 (4 studies)

$\oplus \oplus \oplus \odot$

was 0.19 standard devia-

moderate

One further study (Quinlivan 2003) of 124 participants did not report individual group mean scores as data were

Different measures used by

standard deviations higher)

skewed. The authors reported

that there were no significant differences in the knowledge

vaccine-preventable diseases,

vaccines, contraindications

scores of the intervention and

tion, on varying scales)

Final time point ( 3 or 6

months post-intervention) ${ }^{3}$

control groups (MD 0.85, 95\%

Cl: -0.06 to 1.76$)$.

A standard deviation of 0.2 represents a small difference between groups (based on 


\begin{tabular}{|c|c|c|c|c|c|c|}
\hline 仓旅 & & & & & & $\begin{array}{l}\text { Cohen's effect sizes; Cohen } \\
\text { 1988). }\end{array}$ \\
\hline 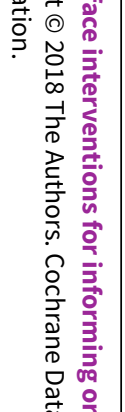 & $\begin{array}{l}\text { Attitudes or beliefs } \\
\text { (Different measures used by } \\
\text { the studies: perceived severi- } \\
\text { ty of vaccine-preventable dis- } \\
\text { eases, perceived necessity of } \\
\text { vaccines, or a combination, } \\
\text { on varying scales) } \\
\text { Final time point ( } 3 \text { or } 6 \\
\text { months post-intervention) }\end{array}$ & & $\begin{array}{l}\text { The mean score for per- } \\
\text { ceived severity of diseases, } \\
\text { necessity of vaccines, or } \\
\text { both, in the intervention } \\
\text { group was } 0.03 \text { standard de- } \\
\text { viations higher ( } 0.20 \text { stan- } \\
\text { dard deviations lower to } \\
0.27 \text { standard deviations } \\
\text { higher) }\end{array}$ & 292 (3 studies) & $\begin{array}{l}\oplus \oplus \ominus \ominus \\
\text { low }^{5}\end{array}$ & $\begin{array}{l}\text { A standard deviation of } 0.2 \\
\text { represents a small difference } \\
\text { between groups (based on } \\
\text { Cohen's effect sizes; Cohen } \\
\text { 1988). }\end{array}$ \\
\hline 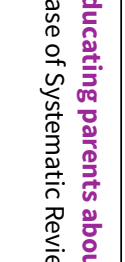 & $\begin{array}{l}\text { Intention to vaccinate } \\
1 \text { to } 7 \text { ( } 1 \text { = definitely do not } \\
\text { intend to vaccinate; } 7=\text { defi- } \\
\text { nitely do intend to vaccinate) } \\
3 \text { months post-intervention }\end{array}$ & $\begin{array}{l}\text { The mean in- } \\
\text { tention to vac- } \\
\text { cinate in the } \\
\text { control group } \\
\text { was } 5.58 \text { (SD } \\
2.13)^{6}\end{array}$ & $\begin{array}{l}\text { The mean intention to vac- } \\
\text { cinate in the intervention } \\
\text { groups was on average } 1.17 \\
\text { points higher ( } 0.51 \text { to } 1.81 \\
\text { points higher) }\end{array}$ & 179 (2 studies) & $\begin{array}{l}\oplus \oplus \odot \odot \\
\text { low }^{7}\end{array}$ & \\
\hline 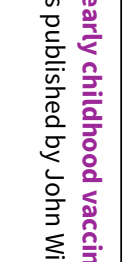 & $\begin{array}{l}\text { Adverse effects (anxiety as- } \\
\text { sociated with intervention) } \\
20 \text { (low anxiety) to } 80 \text { (high } \\
\text { anxiety) } \\
3 \text { months post-intervention }\end{array}$ & $\begin{array}{l}\text { The mean anx- } \\
\text { iety in the con- } \\
\text { trol group was } \\
33.9 \text { (SD 13.53) }\end{array}$ & $\begin{array}{l}\text { The mean anxiety in the in- } \\
\text { tervention group was } 1.93 \\
\text { points lower ( } 7.27 \text { lower to } \\
3.41 \text { higher) }\end{array}$ & 90 (1 study) & $\begin{array}{l}\oplus \oplus \oplus \ominus \\
\text { low }^{8}\end{array}$ & $\begin{array}{l}\text { The study authors note that a } \\
\text { normal score is in the range of } \\
34 \text { to } 36 \text { on this scale. }\end{array}$ \\
\hline 足 & $\begin{array}{l}\text { Parent experience of the in- } \\
\text { tervention }\end{array}$ & No studies mea & ed this outcome. & & & \\
\hline 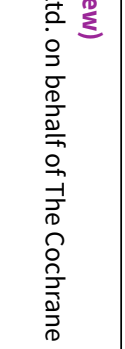 & $\begin{array}{l}\text { Cost } \\
\text { (personnel, supplies, travel, } \\
\text { office space, and orientation } \\
\text { costs of intervention) }\end{array}$ & $\begin{array}{l}\text { Effect of interve } \\
\text { gle study report } \\
\text { cost of usual car } \\
\text { USD } 1587 \text {, or US } \\
\text { high-risk. }{ }^{9} \text { The } \\
\text { fully immunised } \\
\text { proximately } 8 \text { ti } \\
\text { all children, anc } \\
\text { children. }\end{array}$ & $\begin{array}{l}\text { on was very uncertain. A sin- } \\
\text { that the estimated mean } \\
\text { per fully immunised child was } \\
1273 \text { for children defined as } \\
\text { imated additional cost per } \\
\text { ild per intervention was ap- } \\
\text { s higher than usual care for } \\
\text { times higher for high-risk }\end{array}$ & $\begin{array}{l}365^{10} \\
\text { (1 study) }\end{array}$ & $\begin{array}{l}\oplus \oplus \odot \odot \\
\text { low } 11\end{array}$ & $\begin{array}{l}\text { Did not include potential } \\
\text { costs arising from non-im- } \\
\text { munisation. Costs calculated } \\
\text { per individual took account } \\
\text { of indirect case management } \\
\text { costs (frequency and time } \\
\text { taken for case managers to } \\
\text { complete client-related con- } \\
\text { tact tasks). }\end{array}$ \\
\hline & $\begin{array}{l}{ }^{*} \text { The basis for the assumed ris } \\
\text { based on the assumed risk in th } \\
\text { Cl: Confidence interval; RR: Ris }\end{array}$ & $\begin{array}{l}\text { e.g. the media } \\
\text { comparison g } \\
\text { Ratio }\end{array}$ & $\begin{array}{l}\text { trol group risk across studie } \\
\text { ind the relative effect of the }\end{array}$ & $\begin{array}{l}\text { es. The corr } \\
5 \% \mathrm{Cl}) \text {. }\end{array}$ & & $95 \%$ confidence interval) is \\
\hline
\end{tabular}


GRADE Working Group grades of evidence

High quality: Further research is very unlikely to change our confidence in the estimate of effect.

Moderate quality: Further research is likely to have an important impact on our confidence in the estimate of effect and may change the estimate.

Low quality: Further research is very likely to have an important impact on our confidence in the estimate of effect and is likely to change the estimate.

Very low quality: We are very uncertain about the estimate.

${ }^{1}$ Assumed risk based on median control group risk across studies

2We downgraded the evidence for this outcome for risk of bias (-1). One trial was at unclear risk for sequence generation, two trials were at high, and one at unclear risk of bias for allocation concealment. We also downgraded for inconsistency $(-1)$ because, while the nature of the interventions and participants were relatively similar across studies, there was considerable statistical heterogeneity that was not easily explained $\left(\mathrm{I}^{2}=85 \%, \mathrm{Chi}^{2} \mathrm{P}<0.00001\right)$

30ne study measured this outcome at 15 months postpartum. The intervention included multiple sessions at varying times, so the time between the final session and outcome assessment was not known.

${ }^{4}$ We downgraded the evidence for this outcome for risk of bias $(-1)$. One trial was at unclear risk for sequence generation and one trial was at high risk of bias for allocation concealment.

5We downgraded the evidence for this outcome for indirectness (-1). There are many aspects of attitudes that are important to decision making. The specific attitudes measured in this outcome were only part of what could be measured, and therefore this outcome was a somewhat incomplete or indirect indication of attitudes. We also downgraded for risk of bias (-1), because lack of blinding may have impacted this subjective outcome.

${ }^{6}$ Assumed risk based on control group score from Jackson 2011, as this was the only validated scale.

${ }^{7}$ We downgraded the evidence for this outcome for imprecision (-1). The sample size for this outcome was relatively small and the effect estimate showed potentially appreciable benefit (i.e. the $\mathrm{Cl}$ of the pooled effect estimate crossed 0.5 ). We also downgraded for risk of bias (-1), because lack of blinding may have impacted this subjective outcome.

8 We downgraded the evidence for this outcome for risk of bias (-1), because only one study contributed data and it was at unclear risk of bias for sequence generation. We also downgraded for imprecision (-1) because the total sample size was small ( $\mathrm{N}=135$ participants).

${ }^{9}$ High-risk subgroup defined as those children who received only $3 / 5$ or fewer well-child visits.

10Includes high-risk subgroup (86 participants).

11We downgraded the evidence for this outcome for risk of bias (-1), because it was at high risk of bias for allocation concealment. We also downgraded for indirectness (-1), because the evaluated intervention was multi-component and included telephone reminders in addition to education. 


\section{B A C K G R O U N D}

This review originated as a part of the Communicate to Vaccinate (COMMVAC) project (2010-2016), which sought to build evidence for communication interventions related to childhood vaccination (Lewin 2011). This topic was selected through an international priority setting exercise because face-to-face communication is widely used around the world, can be implemented in a range of settings and can be adapted or tailored for different populations. A second review topic was also selected from this exercise (information or education aimed at communities (Saeterdal 2014)).

Since 2013, when the review was originally published, there have been a number of developments in the field of vaccination communication research. Most notably, research related to vaccine hesitancy has highlighted the relevance and importance of face-toface communication in countries of all income levels (Ames 2017; Henrikson 2015; Jarrett 2015; Leask 2015; Opel 2013). Therefore, in recognition of the progress of the field and the potentially wider audience for this review, we have revised the Background to strengthen the explanation of the intervention's theoretical underpinnings and situate this review within the landscape of evidence published since 2013. Some information from the original review, such as the detailed definition of the terms 'inform' and 'educate', is now presented in the supporting Appendices (Appendix 1).

\section{Description of the condition}

Early childhood vaccination is an essential public health practice, carried out in every country in the world and saving two to three million lives every year (WHO 2016). In addition to reducing preventable premature mortality, the practice of vaccination is cost-effective, increasing parent or carer productivity, and lowering health care costs by reducing childhood morbidity (Ozawa 2012; WHO 2018). Childhood vaccination also has a broader social benefit of promoting health equity by ensuring the distribution of health within populations, and contributes to the public good by supporting disease containment (Luyten 2016).

Nevertheless, over 19 million children per year do not receive all the recommended basic vaccines (WHO 2018), and coverage levels fluctuate in individual countries or populations, and for specific vaccines (Nandy 2016; Smith 2008; UNICEF 2014). While the burden of vaccine-preventable disease is greatest in low- and middleincome countries (LMICs; Oyo-Ita 2016; Sutter 2006), outbreaks occur all over the world, including in countries with relatively high coverage (e.g. Belgium, Italy, Ireland, Australia, USA; Barrett 2016; Filia 2017; Grammens 2017; Townsville-Mackay 2013; Zipprich 2015). Therefore, improving and maintaining global childhood vaccination rates is an ongoing public health goal, prioritised by major international health strategies and agreements, such as the UN Millennium Development Goals (UN Millennium Project 2006), the WHO-UNICEF Global Immunization Vision and Strategy (WHO 2009), and the Global Vaccine Action Plan 2011 to 2020 (WHO 2012).

The major factors influencing vaccination coverage relate to 1 ) availability of the vaccine, 2) awareness of recommendations, 3) accessibility of the services, 4) acceptance of the vaccines, and 5) activation to trigger the action of getting a vaccine (Thomson 2016). Face-to-face interventions to inform or educate parents specifically target two of these factors: awareness and acceptance.
Enhancing awareness of vaccination and its importance is critical to address barriers associated with limited or incorrect understanding of the value of vaccines, the risks of vaccine-preventable diseases, or the vaccine schedule itself, which evolves and changes over time (Esposito 2014). People are unable to seek on-time vaccination if they do not know where to go, how to access services, when or which vaccines are due, or why they are important.

Vaccine acceptance and the issue of vaccine hesitancy have become a major global focus in recent years (WHO SAGE Working Group on Vaccine Hesitancy 2014a). On the continuum from complete vaccine acceptance to total refusal, hesitant individuals are more likely to refuse or delay some or all vaccines (Dubé 2016). People may feel hesitant because they don't believe vaccines are necessary - a conundrum created by vaccination is that as its uptake becomes more widespread, the diseases it prevents become less visible, and people can feel less urgency to vaccinate (Smith 2015). Vaccine hesitancy is also influenced by concerns about the safety of vaccines, highlighting the critical importance of appropriate responses to safety-related events or rumours (WHO SAGE Working Group on Vaccine Hesitancy 2014). Although more commonly discussed and researched in high-income countries (HICs), vaccine hesitancy is a worldwide phenomenon (Dubé 2014), with notable anti-vaccine campaigns and safety scares taking hold in the UK (Brown 2012), Pakistan (Murakami 2014), and Nigeria (Kaufmann 2009). Ensuring that parents can access, understand, and judge the quality of information sources is critical, as misinformation and rumours can take root and spread particularly rapidly in a population with a high degree of hesitancy towards vaccines (Salmon 2015).

Successful vaccination programmes rely on people having appropriate information, and sufficient knowledge, awareness, and acceptance of vaccination to make the decision to participate (Dubé 2016; Shahrabani 2009; Thomson 2016; Zyngier 2011). Interventions to inform or educate may not necessarily be sufficient to change behaviour in all cases, but this does not negate their importance (Dubé 2015; Leask 2011). Ensuring that people are informed and knowledgeable about their health is a UNcodified human right and a principal tenet of patient-centred care (Dwamena 2012; Hill 2011; Rodriguez-Osorio 2008; United Nations 2008; WHO 2007). Information is fundamental to valid consent, and extensive qualitative evidence indicates that parents want more or different information about vaccines (Ames 2017).

\section{Description of the intervention}

Information and education can be provided in various ways, but this review focuses specifically on face-to-face communication interventions (Kaufman 2017b). Face-to-face communication can be interactive, adaptable, and efficient, and already accompanies the delivery of nearly every vaccine injection or drop around the world. It allows for real-time dialogue, during which parents are able to explain their concerns or preferences and ask personallyrelevant questions. It can take place in one-on-one interactions, or with small groups of people. Face-to-face communication is particularly useful when people are semi-literate, or not literate in either their language or the majority language of their country.

Face-to-face information or education can be delivered by a range of individuals (e.g. volunteers, advocates, peers), but it is particularly relevant in the context of the healthcare encounter. Healthcare providers (e.g. doctors, nurses, community health 
workers, Indigenous health workers) are the primary source of information for parents about routine childhood vaccination (Freed 2011; Jones 2012). Parents trust the recommendations of their providers over other sources of information about vaccination, and communication that is respectful and builds trust can help hesitant parents work through their concerns (Freed 2011; Jones 2012; Leask 2015). Conversely, poor provider communication experiences can cause parents to feel confused, disrespected, or mistrustful, and potentially make them less likely to return for their child's next vaccination appointment (Brown 2010; Leask 2012). Face-to-face delivery of vaccination information or education to parents is clearly influential, but the most effective messages and communication styles are not yet established. Some evidence supports a participatory communication approach for increasing vaccine acceptance (Opel 2015), while other research suggests a more presumptive communication style may be more effective at increasing uptake (Brewer 2017).

In addition to one-on-one discussions with providers, face-to-face interventions to inform or educate may include oral presentations, individual or group classes or seminars, information sessions, or home outreach visits. Such interventions may be undertaken on their own, or combined with other interventions (e.g. telephone contact). This review focused on face-to-face communication with parents or guardians of preschool-aged children, either individually or in groups. Interventions directed to adolescents were not included, as our focus was on early childhood vaccines. Interventions directed to communities are addressed by a separate review (Saeterdal 2014). Interventions directed to healthcare providers, such as professional education or communication training interventions, were also outside the scope of this review.

After a thorough investigation of the definitions of the words 'information' and 'education' (see Appendix 2), we determined that there was no reliable way to distinguish between the two across studies. A recent comprehensive table of definitions of educationand training-related terms developed by the World Federation of Public Health Associations working group on Public Health Education and Training supports the conclusion that 'education' and 'information' are largely considered coterminous (WFPHA 2017). Therefore, we included any trial evaluating an intervention that aimed to inform, educate, or both, in this review.

\section{How the intervention might work}

While creating a generally informed and health literate populace is an important public health goal, most information or educational interventions aim to change or support specific health behaviours. The interventions in this review targeted the parental health behaviour of vaccinating their young children on time, and with all recommended vaccines.

Behaviour change is complex, and a number of theories outline potential factors and antecedents that may predict or influence an individual's behaviour (see Appendix 2 for an overview of several relevant theories). The Health Belief Model (HBM) is a key behaviour change theory that is particularly relevant for vaccination, as it was developed to explain people's participation in preventive health programmes, including vaccination (Champion 2008; Janz 1984). According to the HBM, the decision to take action - or not - is a product of a number of variables: perceived severity (of vaccine-preventable diseases (VPDs)); perceived susceptibility (of one's child to VPDs); perceived benefits (of vaccination); perceived barriers (to getting vaccinated); and self-efficacy (perceived ability to act). Each of these variables may be influenced by an information or educational intervention.

Several other health behaviour change theories (e.g. the Theory of Reasoned Action (TRA), Theory of Planned Behaviour (TPB), Integrated Behavior Model (IBM) share the idea that the most important determinant of behavioural action is behavioural intention (Ajzen 1985; Ajzen 1991; Montaño 2008). These theories suggest that intention is based on a combination of attitudes (i.e. how a person feels about the behaviour), subjective norms (i.e. social pressure related to the behaviour), and perceived behavioural control (i.e. whether the person feels able to act). The IBM also explicitly recognises the importance of a person having sufficient knowledge and skills to perform the behaviour. Again, information or educational interventions can potentially impact vaccination behaviours by targeting any of the contributing factors identified in these models. For instance, learning about vaccine safety and efficacy may foster positive attitudes towards vaccines. Interventions could increase parents' perceived behavioural control by helping them to understand how, where, and when to vaccinate their children.

Interventions that intend to inform or educate do not necessarily mean just passively giving people information. While this may be adequate when the primary barrier to vaccination uptake is a lack of knowledge or a lack of access to necessary information, there is considerable evidence to suggest that interventions that just provide information are not necessarily sufficient to change behaviour (Goldstein 2015; Ryan 2014). In some cases, this may be because external barriers still exist, such as barriers to availability of the vaccine and access to the service. In other cases, people may not actually receive the intended information, they may not be able to understand it, they may not trust it, or it may be inaccurate. For certain individuals with firmly-rooted opposing beliefs, receiving factual information may actually backfire, and further entrench their opposing views (Nyhan 2014; Nyhan 2015). Therefore, it is important to recognise that information or educational interventions can involve much more than information provision - they can be interactive, tailored, and targeted. Increasingly, interventions are designed with a theoretical underpinning, and are supported by qualitative data (Corace 2016; Jones 2014; Leask 2012). An appropriately designed information or educational intervention can potentially influence not only parents' knowledge, but also their attitudes, perceptions about their peers, sense of selfefficacy, intention to vaccinate, and ultimately, their vaccination behaviours.

\section{Why it is important to do this review}

Interventions whose manifest purpose is to inform or educate people about vaccination are extremely common, reflecting a focus on information-giving and the provider-parent communication encounter as potential strategies to influence vaccination decision making. Despite this, few trials and no systematic reviews of randomised controlled trials (RCT) have evaluated the effects of face-to-face communication, and most research is qualitative or observational. In addition, many trials in the vaccination communication area do not measure key intermediate outcomes that help decision-makers understand whether, and how, an intervention works (Kaufman 2016). Therefore, there is an urgent need to establish a rigorous evidence base that considers the full 
range of relevant outcomes to guide implementation decisions and practice guidelines (Leask 2014).

This review's comprehensive, global approach includes faceto-face communication that aims to address both awareness and acceptance of vaccination. While much of the research about vaccine hesitancy and provider-parent communication focuses exclusively on HIC settings, face-to-face communication is a globally-relevant strategy that is widely used in LMICs as well as HICs. This topic was identified as important by vaccination programme managers, policymakers, researchers and other stakeholders from LMICs in deliberative forums that informed the original review (Lewin 2011). It is critical to determine the effects of face-to-face interventions - including their content, format and timing - so that valuable resources can be allocated appropriately.

\section{Relationship to other reviews}

Since this review's original publication in 2013, there have been a number of new or updated systematic reviews published on related topics. In Table 1, we briefly summarised several relevant non-Cochrane reviews. These reviews generally differ from ours in that they included a broader range of intervention types or study designs; they did not incorporate risk of bias assessment in the presentation of their results; they included vaccinations for adolescents or adults as well as children; or they focused exclusively on LMICs. While there was some variation in the conclusions drawn by the authors of these reviews, most agreed that there was a shortage of high-quality RCT evidence on the effects of information or educational interventions for childhood vaccination.

In addition to the relevant non-Cochrane reviews outlined in Table 1 , this review is also closely related to three Cochrane reviews (Ames 2017; Oyo-Ita 2016; Saeterdal 2014). Authors of each of these reviews include members of the COMMVAC project team.

The Oyo-Ita 2016 review considered all interventions evaluated in LMICs to improve vaccination coverage. This included interventions such as incentives, education, supportive supervision, or outreach directed at parents, caregivers, and communities. The review found fourteen studies conducted in LMICs, thirteen of which were assessed to be at high risk of bias. The majority involved a communication element (e.g. health education, home visits, information campaigns). There was generally low- to moderatecertainty evidence that health education and information campaigns improved vaccination coverage in LMIC settings. Our review is global in scope and focuses on face-to-face communication only, while the Oyo-Ita review included all intervention types, but focused on studies conducted only in LMICs. Three studies appeared in both reviews, but these studies were contextualised in different ways, based on the scope of the respective reviews (Bolam 1998; Usman 2009; Usman 2011).

Saeterdal 2014 included vaccination communication interventions aimed at communities, which we did not include in this review. The authors defined 'community-aimed' interventions as 1) interventions directed at a geographic area, 2) interventions directed to groups of people who shared at least one common social or cultural characteristic, or both. Our review focused on interventions directed to parents, individually or in groups, whereas Saeterdal 2014 included interventions directed to groups, which may or may not have included parents. The authors found low-certainty evidence from two cluster-RCTs that interventions aimed at communities may improve attitudes towards vaccination, and probably increased vaccination uptake under some circumstances, when compared with routine practices. This review is currently being updated.

The Ames 2017 review included qualitative studies exploring parents' and caregivers' views and experiences of communication about childhood vaccinations, and the influence of communication on their decision making. Ames 2017 used thematic analysis to synthesise data from 38 studies, primarily from high-income countries. The authors had high confidence in the evidence for the following findings: parents wanted more information than they receive; parents wanted balanced information about benefits and harms of vaccination; parents viewed healthcare workers as important sources of information; and parents found it difficult to know what information sources to trust, or how to find unbiased information. The authors compared their qualitative findings with the results of the trials included in the originally published version of this review (Kaufman 2013), and in Saeterdal 2014. They determined that most of the interventions evaluated in the trials addressed at least one aspect of communication that was important to parents (e.g. tailoring information to parent needs).

\section{O B J E C T IVES}

To assess the effects of face-to-face interventions for informing or educating parents about early childhood vaccination on vaccination status and parental knowledge, attitudes, and intention to vaccinate.

\section{METHODS}

\section{Criteria for considering studies for this review Types of studies}

Randomised controlled trials (RCTs) and cluster-RCTs. We excluded all studies rated at a high risk of bias on the random sequence generation criteria of the 'Risk of bias' tool, because we considered these studies to be quasi-RCTs.

\section{Types of participants}

Communication interventions about childhood vaccination are often complex because multiple participant groups are involved in the delivery and receipt of the intervention. The intervention is delivered to one group (parents) to promote vaccination, which is administered to another group (children). The planning and implementation of the intervention or the vaccination programme itself is addressed by a third group (program organisers). The three participant groups were:

- Children: infants (less than 1 year) or preschool-aged children (1 to 5 or 6 years). We only included RCTs with school-aged children if the main focus of the intervention was vaccines whose primary series began in infancy or preschool-aged children.

- Parents: parents, guardians, or others fulfilling the parental role, alone or in groups, targeted to receive face-to-face information or education, and who had at least one child due or overdue for childhood vaccinations. We also included participants who were expectant parents, individuals or couples currently pregnant, considering adoption, or otherwise expecting to 
become guardians of a child. The intervention could have been directed to parents individually or in groups.

- Vaccine program organisers: anyone involved in the planning or implementation of vaccination programmes or interventions

\section{Types of interventions}

Face-to-face communication interventions directed to parents to inform or educate them about routine childhood vaccinations. Such interventions describe or impart information about some feature of routine childhood vaccination with the purpose of changing parent knowledge, beliefs, attitudes, behaviour, or selfefficacy. The type of content that may be covered includes information about: vaccine-preventable diseases (e.g. symptoms, prevalence, transmission, severity); vaccines (e.g. delivery method, dose, ingredients, schedule, risks or side effects, benefits); or vaccine service delivery (e.g. where to go to receive vaccinations, costs, clinic opening hours, services to assist with access). Despite potential heterogeneity of intervention content or intensity across studies, we agreed that interventions with the purpose of informing or educating parents about vaccination were sufficiently similar to conceptually group for analysis in this review.

We included interventions delivered by anyone, including physicians, nurses, midwives, health visitors, or other healthcare professionals; trained volunteers; lay health workers; members of the community; or peers.

The term 'routine vaccinations' means all routine childhood vaccines outlined by the WHO (WHO 2018). Human papillomavirus vaccine (HPV) was excluded, because it is delivered to adolescents. This review focused only on interventions about early childhood vaccines because interventions related to vaccines for older children may be significantly different in nature (e.g. they may target children directly, or have a reduced focus on the parent's role in decision making).

We included face-to-face interventions conducted in cluster-RCTs in the context of a mass vaccination campaign if it was possible to isolate and report the effects of the face-to-face communication interventions delivered to parents for the vaccination of young children or infants from the larger campaign. Similarly, we included multi-component interventions with a face-to-face element if the outcomes of the face-to-face intervention alone could be determined from the reported data. For example, trials of multicomponent interventions involving face-to-face education plus reminders or health service access assistance measured both vaccination status and knowledge (Quinlivan 2003; Wood 1998). We could not isolate the effect of the face-to-face intervention on the vaccination rate, but we could attribute any changes in knowledge to the face-to-face educational intervention alone. We may also have been able to determine the effect of a face-toface intervention if a trial measured outcomes at multiple or staged time points (or both), including assessment of the effects of one intervention component or type before the addition of other intervention types. We did not consider Interventions to be multicomponent if a secondary form of information or education (e.g. a pamphlet) was provided along with the face-to-face intervention that was specifically described as supplementary or supporting.

In this updated review, we tightened our inclusion criteria with regard to complex, multi-topic, early parenting education and information interventions (e.g. well-child appointments or home visits). Such interventions generally cover a broad range of issues, which may be tailored to the individual participant. It is often unclear whether and what kind of vaccination information is discussed, or whether every participant receives the same information or education related to vaccination. These trials may measure vaccination uptake or status, but this may be used as a general health access indicator, and does not necessarily confirm that vaccination was a topic of discussion (or indeed a focus of the intervention). This review focused on face-to-face information or education that was specifically about vaccination, so our updated process for determining inclusion or exclusion of such studies was as follows:

1. If the trial specifically described the vaccination content in the intervention, and it met other inclusion criteria, we included it.

2. If the trial briefly mentioned that vaccination was a topic covered by the intervention, but did not describe the content in any detail, we included it only if it also measured a vaccinationspecific knowledge, attitude, or intention outcome (indicating that vaccination was covered to some degree within the content of the intervention).

3. We excluded trials that only mentioned vaccination briefly or not at all, and measured only vaccination status, on the grounds that the intervention was not primarily an information or educational intervention about vaccination.

We welcome contact from any authors who believe their studies may have been erroneously excluded based on our interpretation of the trial report.

This updated review addressed two comparisons:

1. Face-to-face interventions directed to parents versus control (usual care or passive intervention, i.e. non-face-to-face information or education, or no intervention),

2. Face-to-face intervention A versus face-to-face intervention B.

We reduced the comparisons from the original review, which considered the effects of the intervention when directed to individual parents or to groups of parents. There was no clear evidence to suggest that education delivered in a group setting was likely to work differently from education delivered to individuals, and so we felt that this comparison was less informative for end users of the review.

We included face-to-face interventions designed to inform or educate, which may have included oral sessions, lectures, oneon-one or group classes or seminars, information sessions, home visits, or outreach sessions.

We did not include community-directed interventions, as these were considered in the Saeterdal 2014 review.

\section{Types of outcome measures}

\section{Primary outcomes}

1. Children: vaccination status of child (i.e. vaccination status upto-date, or receipt of one or more vaccines, as defined by study authors); outcome domain: vaccination status and behaviours

2. Parents: knowledge or understanding of vaccination; outcome domain: knowledge or understanding 
3. Parents: attitudes or beliefs about vaccination; outcome domain: attitudes or beliefs

4. Parents: intention to vaccinate child; outcome domain: attitudes or beliefs

5. All categories: adverse effects; outcome domain: any

\section{Secondary outcomes}

1. Parents: parent experience of intervention (e.g. satisfaction, assessment of communication); outcome domain: communication delivery and design

2. Vaccine programme managers: cost of implementing intervention; outcome domain: cost

\section{Justification of outcome measures}

Our recent research to define and prioritise core outcome domains for the evaluation of vaccination communication interventions informed the selection of outcomes for this review (Kaufman 2017; Kaufman 2017a). First, we developed a taxonomy of potential vaccination communication outcomes that were derived from trials, non-vaccination health communication studies, and focus groups with stakeholders (parents, healthcare providers, researchers, and policymakers; Kaufman 2017). This taxonomy organised outcomes into eight domains: 1) knowledge or understanding, 2) attitudes or beliefs, 3) vaccination status and behaviours, 4) communication delivery and design, 5) community participation, 6) decision making, 7) health status and well-being, and 8) cost.

Using a Delphi survey, we asked representatives from each stakeholder group to rate the relative importance of each of these outcome domains when evaluating a communication intervention to inform or educate about vaccination (Kaufman 2017a). The top four domains for this type of intervention, according to stakeholders, were 'knowledge or understanding', 'attitudes or beliefs', 'vaccination status and behaviours', and 'communication delivery and design'. Therefore, we ensured that outcomes from each of these domains were captured by this review.

While changes in knowledge are not always directly linked to changes in health behaviours, we included knowledge as a primary outcome because improving knowledge was the stated purpose of many programmes and interventions (Ryan 2014). Particularly with complex communication interventions, it was important to measure intermediate outcomes that reflected the intervention's purpose, in addition to endpoint outcomes, such as vaccination status (Craig 2008; Moore 2015; Petticrew 2011; WHO SAGE Working Group on Vaccine Hesitancy 2014). Doing so could help to unpack how and whether an intervention worked or where it broke down.

In our taxonomy of outcomes, intention to vaccinate fell under the domain of 'attitudes or beliefs'. However, we decided to include two separate outcomes associated with this domain; one broadly defined as 'attitudes or beliefs', and the more specific outcome of 'intention to vaccinate'. Intention and attitudes are separate determinants of behaviour in most behaviour change theories (see How the intervention might work), with intention more directly preceding behaviour change. Changes in intention, but not behaviour, may indicate the presence of external barriers to vaccination (daCosta 2005). In comparison, changes in attitudes may be particularly relevant for identifying subtle shifts in vaccine acceptance or hesitancy that are not reflected by changes to either intentions or behaviours.

We included the outcome 'parent experience of the intervention', because the way in which communication is delivered and received can substantially impact its overall effectiveness. For instance, parents cited poor communication experiences with healthcare providers made them less likely to consider or undertake vaccination (Leask 2012; Leask 2015).

While it was not prioritised in the Delphi survey, we also included cost as an outcome in this review. The cost of implementing an intervention is particularly important to record, if it is measured, to improve equity in healthcare delivery and to increase the global applicability of research evidence. Cost is an important factor for decision and policy makers, so we included it, where reported. We included adverse events to capture any potential negative effects of the interventions - for example, anxiety or distress - and because it is Cochrane policy for systematic reviews to consider adverse effects (Loke 2011).

We did not include or exclude studies on the basis of whether the chosen outcomes were measured or reported.

\section{Search methods for identification of studies}

\section{Electronic searches}

We searched the following sources:

- Cochrane Central Register of Controlled Trials (CENTRAL; 2017, Issue 7) in the Cochrane Library (searched 3 July 2017);

- MEDLINE Ovid (2012 to July 32017 );

- Embase Ovid (2012 to July 32017 );

- CINAHL EBSCO (Cumulative Index to Nursing and Allied Health Literature; 2012 to July 32017 );

- PsycINFO Ovid (2012 to July 32017 ).

We tailored strategies to each database and reported them in the appendices section of the review (Appendices 4 to 9). We had no language or date restrictions.

In this update, we did not search two databases previously searched for the original review: Global Health (CAB) and Global Health Library (WHO). For a full list of the searches run in the original review, see Appendix 3. These databases had a very low yield of relevant RCTs, and we determined that any studies indexed in these databases would also be found via other databases and resources.

\section{Searching other resources}

- We searched all ongoing trials in ClinicalTrials.gov (searched July 2017) and the WHO International Clinical Trials Registry Platform (ICTRP) for any ongoing trials registered since 2012 (searched July 2017). We contacted authors to obtain further information or eligible data, if available.

- We searched for grey literature in OpenGrey (http:// www.opengrey.eu/; searched July 2017). The Grey Literature Report, a database searched in the original review, has been discontinued, so we did not search it for this update.

- We searched the reference lists of all included papers, and any key papers in the field. We also searched the ISI Web of Science (both the Social Science Citation Index and the Science Citation Index; searched July 2017), and Google Scholar (searched 
August 2017) for papers that cited the studies included in the review. We contacted authors of included studies and vaccination experts and asked for additional references.

\section{Data collection and analysis}

\section{Selection of studies}

We combined all electronic database search results in Endnote and removed duplicate records. Two review authors (JK and LW) independently screened all titles and abstracts to assess which studies met the selection criteria. These authors also independently screened all ongoing trials, grey literature, and studies identified through reference list or reverse citation searching. We excluded studies that clearly did not relate to the selection criteria. We retrieved the full text of all studies determined to be potentially relevant. Two review authors (JK and LW) independently screened these studies for inclusion. They resolved disagreements through discussion with another review author (RR). We reported studies excluded at this stage in the screening process in the 'Characteristics of excluded studies' table. We provided citation details and any available information about ongoing studies, and collated and reported details of duplicate publications, so that each study (rather than each report) was the unit of interest in the review. We reported the screening and selection process in an adapted PRISMA flow chart (Stovold 2014).

\section{Data extraction and management}

Two review authors (JK and LW) independently extracted the data from included studies and discussed any disagreements with a third author (RR) until consensus was reached. We used a revised version of the data extraction form used for the original review, which combined features of the template developed by the Cochrane Consumers and Communication Review Group (CCC 2016), the Cochrane equity checklist (Ueffing 2012), and the COMMVAC extraction template. The data extraction form included the following components: details of study, participant characteristics, country and health system features, setting, intervention, intervention quality, co-interventions, risk of bias, outcomes, and study conclusions. We reported this information for each included study in the 'Characteristics of included studies' table. One review author (JK) entered all data into Review Manager 5 (RevMan 5; RevMan 2014); a second review author (LW or RR) independently checked for accuracy against the data extraction sheets.

\section{Assessment of risk of bias in included studies}

We assessed and reported on the methodological risk of bias of included studies in accordance with the Cochrane Handbook for Systematic Reviews of Interventions (Higgins 2011a), and the guidelines of the Cochrane Consumers and Communication Review Group (Ryan 2013), which recommend the explicit reporting of the following individual elements for RCTs: random sequence generation, allocation sequence concealment, blinding (participants, personnel), blinding (outcome assessment), completeness of outcome data, selective outcome reporting, other sources of bias, such as contamination. We considered blinding separately for different outcomes where appropriate (e.g. blinding may affect subjective outcomes differently from objective ones), but made an overall judgment of the risk of bias for this element. For each criteria, we described the relevant information provided by the authors and judged each criteria as being at high, low, or unclear risk of bias, as set out in the judging criteria provided in Higgins 2011. We deemed studies to be at the highest risk of bias if they scored high or unclear on either sequence generation or allocation concealment (based on growing empirical evidence that these factors are particularly important in influencing risk of bias; Higgins 2011).

For cluster-RCTs, we assessed the risk of bias associated with an additional factor: selective recruitment of cluster participants (Ryan 2013).

In all cases, two authors (JK, LW or RR) independently assessed the risk of bias of included studies, and resolved any disagreements by discussion, to reach consensus. We contacted study authors for additional information about the included studies, and for clarification of the study methods, as required. We incorporated the results of the 'Risk of bias' assessment into the text of the review, through systematic description and commentary about each of the elements, and in standard tables, leading to an overall assessment of the risk of bias of included studies, and a judgment about the internal validity of the review's results.

\section{Measures of treatment effect}

For dichotomous outcomes (e.g. vaccination status), we analysed data based on the number of events and the number of people assessed in the intervention and comparison groups. We used these to calculate the risk ratio (RR) and 95\% confidence intervals $(\mathrm{CI})$.

For continuous measures (e.g. knowledge or understanding, attitudes, or beliefs), we analysed data based on the mean, standard deviation (SD), and number of people assessed, for both the intervention and comparison groups, to calculate the mean difference (MD) and $95 \% \mathrm{Cl}$. If the MD was reported without individual group data, we had intended to use this to report the study results. If more than one study measured the same outcome using different scales, we calculated the standardised mean difference $(\mathrm{SMD})$ and $95 \% \mathrm{Cl}$ using the inverse variance method in RevMan 5.

Vaccination status was defined slightly differently across studies (e.g. receipt of single or multiple vaccines; 'up to date' status for complete schedule). We accepted the definition of vaccination status used by study authors. We recorded these in the 'Characteristics of included studies' tables.

Where studies used two separate methods to measure the same outcome (e.g. two measures of parental knowledge), or measured two different outcomes that could be considered part of the same outcome category (e.g. receipt of one vaccine and completion of all vaccines, which both fall under 'vaccination status'), we adopted the approach outlined by Brennan and colleagues (Brennan 2009).

1. We selected the primary outcome identified by the study authors that correlated to our stated outcomes of interest.

2. If no primary outcome was specified, we selected the one specified in the sample size calculation.

3. If there was no sample size calculation, we ranked the reported effect estimates and selected the outcome with the median effect estimate. When there was an even number of outcomes, we included the outcome whose effect estimate was ranked $n / 2$, where $\mathrm{n}$ was the number of outcomes. 
Several studies measured multiple aspects of parent attitudes or beliefs (e.g. perceived severity of diseases, perceived benefit of vaccines, necessity of vaccines, self-efficacy). We compared the descriptions of these outcomes across studies, and selected the outcome from each that was most similar, in terms of what was measured and the direction of the scale used. We described all measures of attitudes or beliefs reported in each study in Table 2.

Where studies recorded outcome data at multiple time points, we reported the data from the final follow-up, because this time point may capture people who were delayed in obtaining vaccination directly following the intervention. We extracted outcome data recorded at other time points and reported these in Additional tables 8 to 12 .

\section{Unit of analysis issues}

The two cluster-RCTs used intraclass correlation coefficient (ICC) to adjust their sample sizes to account for clustering, and conducted appropriate analysis, but did not report their effective sample sizes. Therefore, we recalculated effective sample sizes based on information reported in each study, and divided the reported sample size by the design effect (Higgins 2011). In Jackson 2011, the authors used longitudinal analysis because they felt that the participant and cluster numbers were too small to use multilevel modelling. Saitoh 2017 used a hierarchical linear mixedeffects model to account for repeated measures, by adjusting for interactions between groups, time, and groups $x$ time (as fixedeffect) and participants (as random-effects).

We calculated the design effect (DE), using the ICC reported in each study (0.05) and the number of clusters in each study. For each reported outcome, we divided the original sample size by the DE to establish the effective sample size (Higgins 2011; McKenzie 2016). For the dichotomous outcome of vaccination status, we also divided the number of events occurring in each group by the DE. We reported the adjusted sample sizes in all meta-analyses, and reduced the weightings given to these studies.

Saitoh 2017 reported a DE of 1.95, based on an average cluster size of 20. There were 100 participants in the intervention group and 88 in the control group, which we adjusted to 51 (intervention) and 45 (control) for all outcomes.

Jackson 2011 reported a DE of 1.5, based on an average cluster size of 11 . There were 68 in the intervention group and 67 in the control group, which we adjusted to 45 (intervention) and 45 (control) for all outcomes.

\section{Dealing with missing data}

Where necessary, we contacted study authors for missing outcome data, missing study-level participant characteristics, or missing summary data. We had intended to impute missing summary data where possible, and report any assumptions in the results tables. We investigated the effect of our choice of any imputed data, including ICCS, on the pooled effect estimate through sensitivity analyses.

\section{Assessment of heterogeneity}

We assessed statistical heterogeneity through visual inspection of forest plots, and the $\mathrm{Chi}^{2}$ test for heterogeneity. We quantified the heterogeneity using the $\mathrm{I}^{2}$ statistic; however, we did not set a threshold for acceptable heterogeneity. As Pigott and Shepperd explain, complex interventions are much more likely to appear heterogeneous, but this does not necessarily mean they are not comparable (Pigott 2013). The decision to meta-analyse or not should ultimately be made by the reviewers. In this review, the interventions were very tightly defined, even though there could be variability in design or delivery. The target population was parents in all instances, regardless of setting. Therefore, while we anticipated some variability, we expected that the intervention would be working in largely the same way across included populations. We discuss the potential sources and implications of heterogeneity in our analysis, and assessment of the certainty of the evidence, using GRADE methodology.

\section{Assessment of reporting biases}

We assessed reporting bias qualitatively, based on the characteristics of the included studies (e.g. if only small studies were identified that indicated positive findings in favour of faceto-face information or educational interventions, or if information that we obtained from contacting experts in the area and the authors of retrieved studies suggested that there were unpublished studies). We did not find sufficient RCTs (at least 10) to construct a funnel plot to formally investigate small study effects or publication bias (Higgins 2011).

\section{Data synthesis}

We presented summary statistics for each of our outcomes in table form (see Table 3; Table 4; Table 5; Table 6; Table 7). These tables include data for each study group and the timing of outcome assessments.

The decision to conduct a meta-analysis was based on an assessment of whether the participants, setting, interventions, and outcome measures in the included trials were similar enough to draw meaningful conclusions from a statistically pooled result. Our consideration also depended on the availability of data from two or more primary studies for pooling. Due to the variability in the populations and interventions of the primary studies, we used a random-effects model. One included cluster-RCT was not included in the meta-analysis because it did not report usable data (Bjornson 1997). Where possible, we pooled relative risks and calculated associated $95 \%$ confidence intervals to measure the effects of:

1. Face-to-face interventions directed to parents versus control (usual care or passive intervention, i.e. non-face-to-face information or education, or no intervention), or

2. Face-to-face intervention $A$ versus face-to-face intervention $B$.

We described the findings in the text of the review, with consideration of the potential impact of bias on the size or direction of the effect, the degree of heterogeneity and its possible sources, and their relevance to practice. Where we were unable to conduct a meta-analysis, we grouped the data based on the comparison and outcome domain. Within each category, we presented the data in table format, and narratively described the results, grouped by outcome.

\section{Subgroup analysis and investigation of heterogeneity}

We did not plan any subgroup analyses at the protocol or original review stages. However, in this update, we made a post hoc decision to conduct two formal subgroup analyses to investigate potential sources of statistical heterogeneity in studies reporting 
vaccination status. The subgroups were relevant to practice and implementation, and were related to the delivery of the intervention (length of intervention session), and the number of vaccines received. Length of intervention delivery has important time and cost implications for decision makers and providers. We considered a subgroup analysis for the number of vaccines received following advice from vaccination experts, based on the possibility that receiving one vaccine may be less demanding, as an outcome, than receiving several.

\section{Sensitivity analysis}

We did not find enough studies to undertake a sensitivity analysis based on 'Risk of bias' assessment as planned. If we had found more studies, we had planned to remove those at the greatest risk of bias from the analyses. We also had intended to conduct sensitivity analyses to check the effects of imputed data (including imputation of ICC values), and to compare fixed-effect and random-effects analyses, in the event that small study effects were identified by funnel plots.

\section{Assessing the certainty of the evidence}

Two authors (JK, RR) independently assessed the certainty of the evidence, using the GRADE criteria. We assessed and reported the certainty of the evidence for each outcome, assessed against concerns of risk of bias, inconsistency, imprecision, indirectness, and publication bias, based on the methods described in chapter 11 of the Cochrane Handbook for Systematic Reviews of Interventions (Schünemann 2011).

We prepared Summary of findings for the main comparison to present the results for each of the major primary outcomes, including potential harms, as outlined in the Types of outcome measures section. We converted results into absolute effects when possible, and provided a source and rationale for each assumed risk cited in the table.

\section{Consumer participation}

Those with a potential interest in this review include vaccine programme managers, policy makers, practitioners, and parent interest groups. In the peer review process for the protocol and the review, we sought external referees reflecting these interests (Kaufman 2012; Kaufman 2013). In addition, the outcomes selected in this review reflect the findings of a multi-stage body of work that sought the views and outcome preferences of parents, healthcare providers, policy makers, and researchers (Kaufman 2017; Kaufman 2017a).

\section{RES U L T S}

\section{Description of studies}

Results of the search

In total, we identified 8247 new records through electronic database searches and 1416 records from other sources (Figure 1). After removing duplicates, we screened the title and abstract of 7177 reports, excluding 7141 . We gathered 33 full-text articles that appeared to be relevant (31 from databases and 2 from citation searches), as well as 3 records of ongoing studies (see Ongoing studies). Of these, we excluded 29 articles and records (see 'Characteristics of excluded studies' table). 
Figure 1. Study flow diagram: 2018 review update

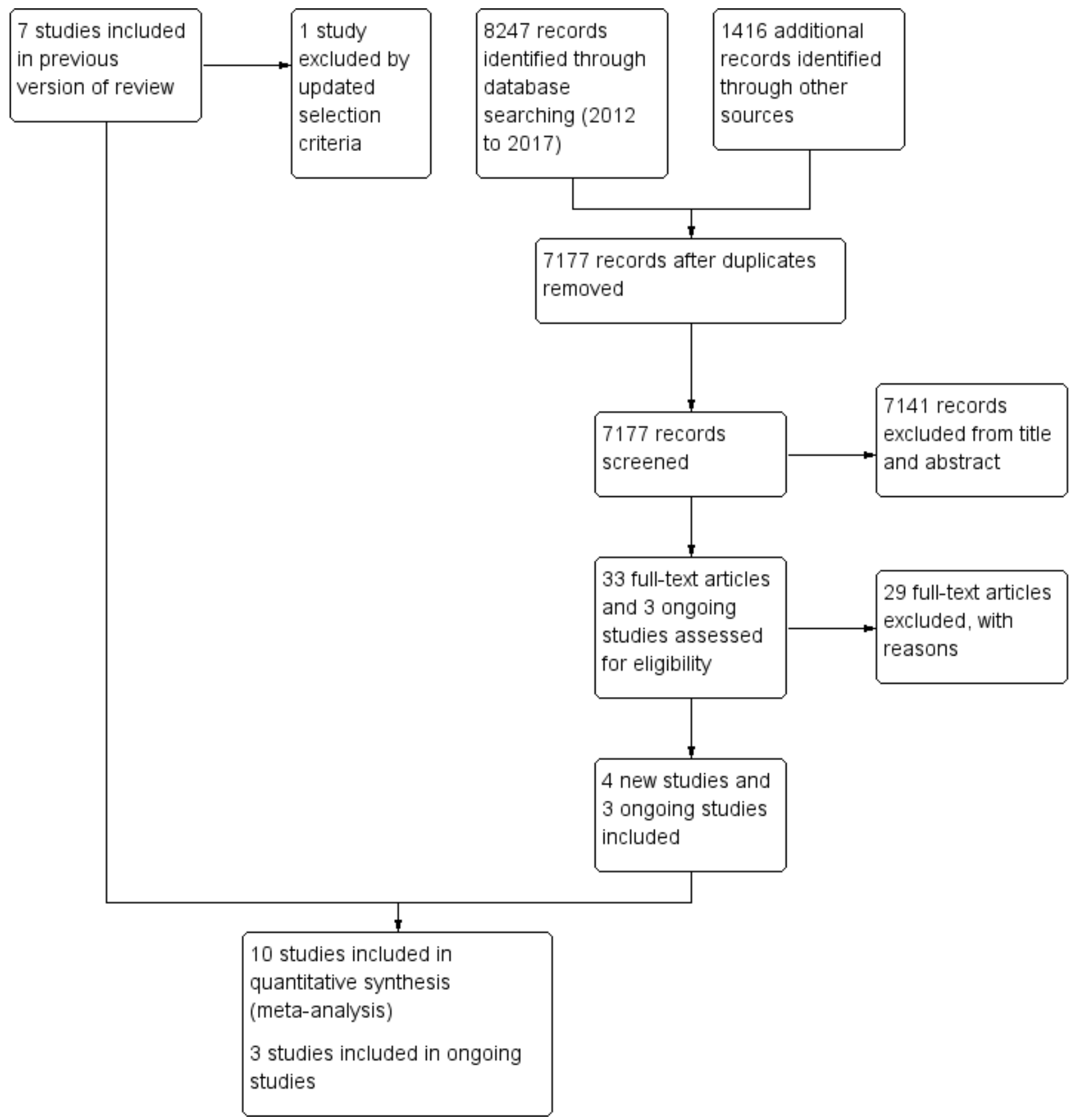

We excluded one previously included study, due to the decision to exclude multi-topic, early parenting interventions from this update (Bartu 2006). We also included one previously excluded study, based on our revised assessment of the informational and educational nature of the intervention (Jackson 2011).

\section{Included studies}

We included a total of 10 trials in this update. In addition to the six trials from the original review, we added four new trials described in seven papers (see 'Characteristics of included studies' table). We identified all the new trials through database searches. We found three ongoing studies by our searches of trial registries (JPRN-UMIN000012575; NCT02666872; NCT02984007). We contacted the authors of all included studies to clarify methods or to request additional data or intervention details. Some study authors responded with information on most, but not all queries, and one study author did not respond.

\section{Study design}

Three studies were cluster-randomised controlled trials (RCT; Bjornson 1997; Jackson 2011; Saitoh 2017). The remaining seven were RCTs. 


\section{Sample size}

Five studies involved between 100 and 250 participants, and five had more than 400 participants, including three studies with over 750 participants (Hu 2017; Usman 2009; Usman 2011). In two cluster trials, the effective sample sizes were calculated to be less than 100 (Jackson 2011; Saitoh 2017).

\section{Participants and setting}

The interventions were directed to mothers and parents, or expectant mothers or parents, and largely took place in clinics, hospitals, or other healthcare settings. Two studies targeted mothers for whom additional barriers to accessing vaccination exist (adolescent mothers, mothers of low socioeconomic status) (Quinlivan 2003; Wood 1998). Most studies took place in highincome countries: Australia, Canada, China, England, Japan (two studies), and the USA, with the exception of Nepal, and Pakistan (two studies). Study features and settings are outlined in Table A.

\section{Table A: Study features and settings}




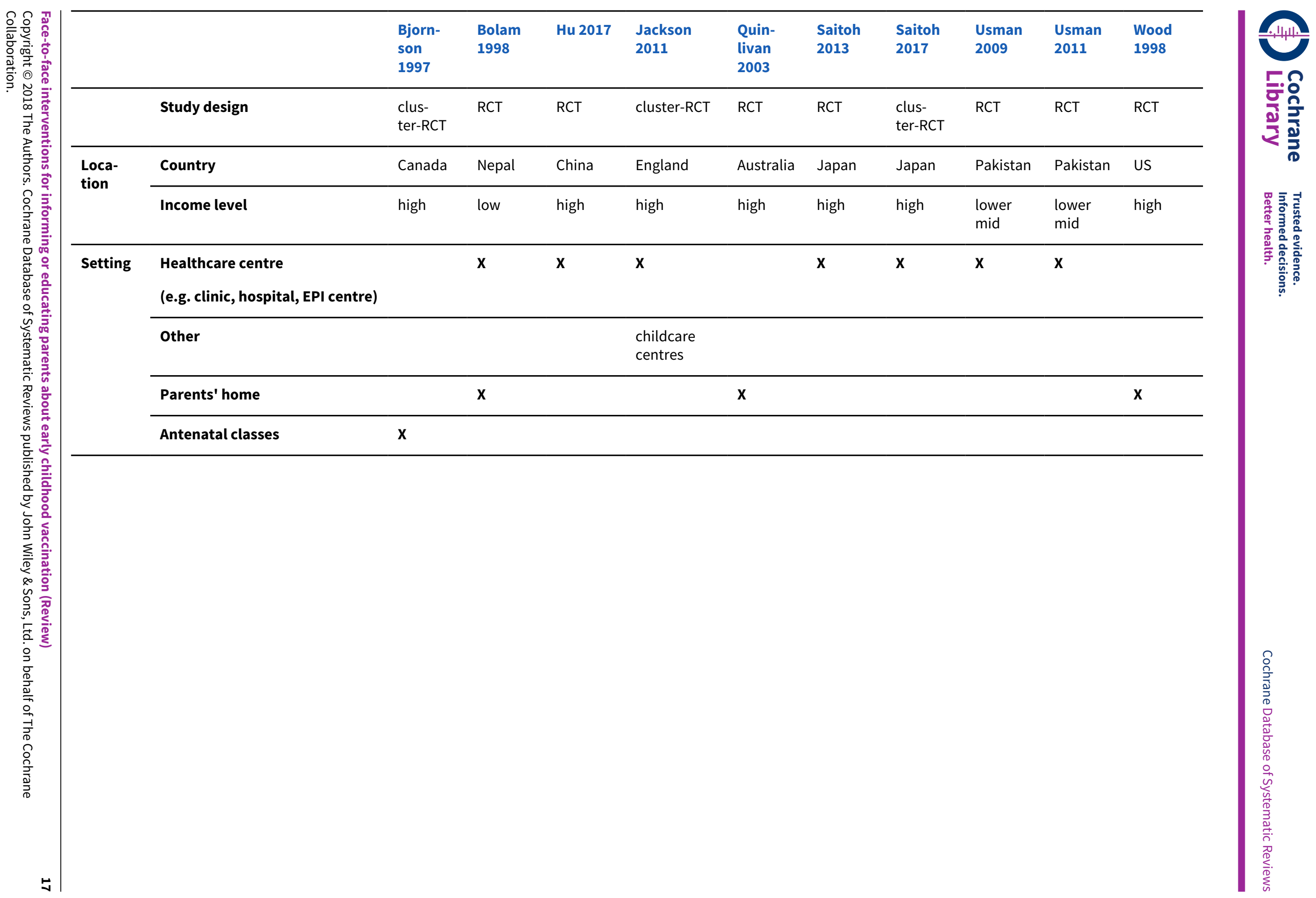




\section{Interventions}

Six studies had a single intervention arm and a single control arm (Bjornson 1997; Hu 2017; Jackson 2011; Quinlivan 2003; Saitoh 2017; Wood 1998; Table B). The face-to-face education in Bjornson 1997 was actually the control arm, which was compared to an educational video intervention. For the purposes of this review, that designation was reversed. Four studies had additional intervention arms. There were two intervention groups in Saitoh 2013 (Group 1: prenatal education; Group 2: postnatal education). We combined data from these into a single intervention group (receiving education either pre- or postnatally). There were three relevant intervention arms in Bolam 1998 (Group A: education at birth and three months after birth; Group B: education at birth only; Group C: education at three months after birth only). The outcome data we included in this review was that recorded at three months post-natally, when Groups A and B had both received education at birth (combined into a single intervention group) and Groups $C$ and D (control) had not. Usman 2009 and Usman 2011 measured identical interventions delivered to populations in different areas (urban and rural). Each featured one relevant intervention arm (centre-based education only), and two arms that were not relevant to this review (re-designed immunisation card with or without centre-based education).

\section{Table B: Intervention features}




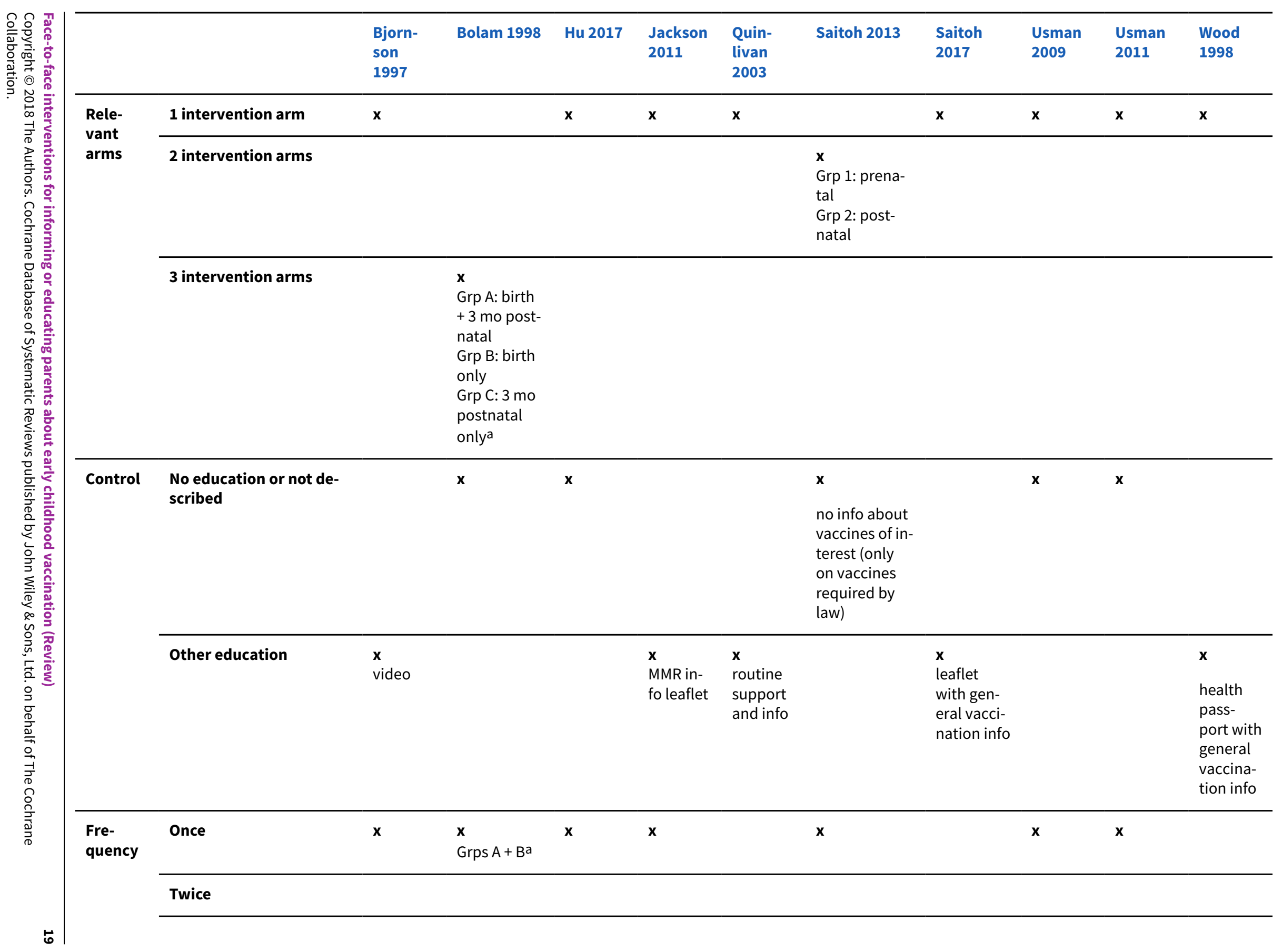




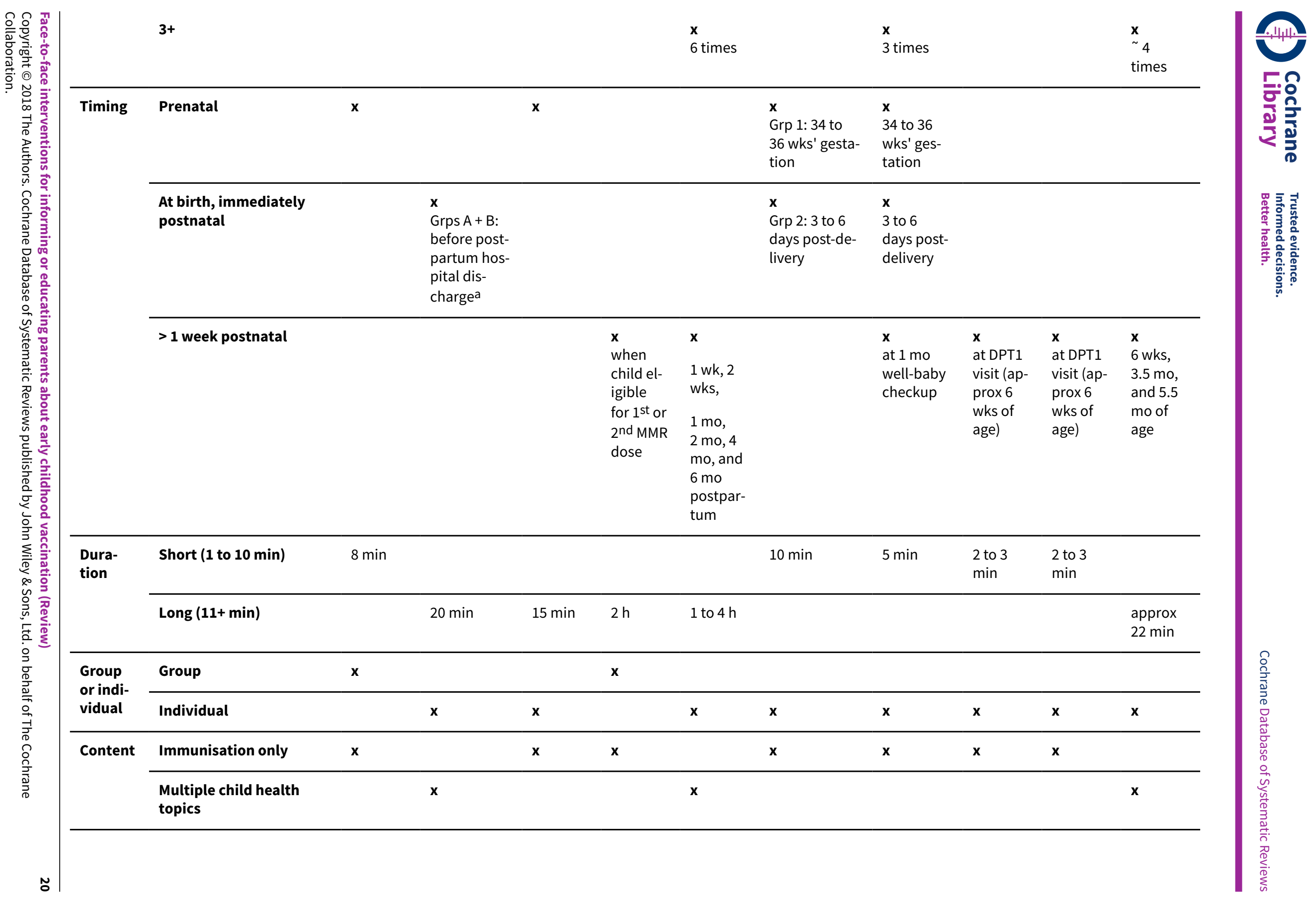


aThis review reports the 3-month time point, where Groups $A$ $+\mathrm{B}$ (intervention received once) were compared to Groups C + $D$ (no intervention). At the 6-month time point, reported in the study but not used in the meta-analysis, Group A had received the intervention twice (birth and 3 months postpartum), Group B received it once (birth only), and Group C received it once ( 3 months postpartum only). Complete details for all intervention arms are available in Additional Tables.

\section{Comparison 1: Face-to-face interventions directed to parents versus} control

All included studies assessed face-to-face interventions directed to parents, but there were variations in their intensity, content, length, and control group intervention.

Seven studies evaluated a single intervention session, and three evaluated multi-session interventions. Most interventions focused exclusively on delivering vaccination information, but interventions in three studies addressed a wider range of child health topics (e.g. breastfeeding, oral rehydration; Bolam 1998; Quinlivan 2003; Wood 1998).

There was considerable variation in the length of individual educational sessions evaluated across studies. Sessions were short (ten minutes or less) in five studies, and longer than 15 minutes in the remaining studies, including very long sessions - over an hour in two studies (Jackson 2011; Quinlivan 2003).

In four studies, it appeared there was no education provided to the control group (Bolam 1998; Hu 2017; Usman 2009; Usman 2011). In one study, control group participants received routine information, but only about those vaccines required by law (Saitoh 2013). Because the intervention focused on different vaccines that were not legally required (Hib, HBV, and PCV7), we categorised the control group for this study as not receiving any education. Control groups in three studies received printed educational materials describing MMR (Jackson 2011), or general routine vaccination information (Saitoh 2017; Wood 1998). In one study, control participants received some routine vaccination information, but the format in which it was provided was not described (Quinlivan 2003). The control group in Bjornson 1997 received an educational video covering the same topics as the face-to-face education.

\section{Comparison 2: Face-to-face intervention A versus face-to-face} intervention $B$

No studies compared different types of face-to-face interventions.

\section{Outcomes}

\section{Vaccination status}

Please see Appendix 4 for the glossary of vaccination acronyms.

Vaccination status was measured in nine of the ten included studies. However, in two studies that assessed multi-component interventions, the effect of the face-to-face intervention on changes to vaccination status could not be isolated from the effects of other components of the intervention. Therefore, we could not report on this outcome for these studies (Quinlivan 2003; Wood 1998).

Of the remaining seven studies, four measured appropriate or upto-date vaccination for multiple vaccines at a particular age, and three measured receipt of a single vaccine (MMR or DPT). Outcomes were assessed in different ways. The final (or only) measurement time point for most studies was approximately three months postintervention, but Saitoh 2017 measured this outcome at six months and $\mathrm{Hu} 2017$ at 12 months. Bolam 1998 measured vaccination status at both three and six months. We reported the three-month time point because this allowed for the comparison of the greatest number of participants (i.e. the combination of intervention Group A and Group B (education at birth) compared with intervention group $C$ and control group $D$ (no education)).

Table C: Vaccination status outcome features

Face-to-face interventions for informing or educating parents about early childhood vaccination (Review) 


\begin{tabular}{|c|c|c|c|c|c|c|c|c|c|c|}
\hline & & $\begin{array}{l}\text { Bolam } \\
1998\end{array}$ & Hu 2017 & $\begin{array}{l}\text { Jackson } \\
2011\end{array}$ & $\begin{array}{l}\text { Saitoh } \\
2013\end{array}$ & $\begin{array}{l}\text { Saitoh } \\
2017\end{array}$ & $\begin{array}{l}\text { Usman } \\
2009\end{array}$ & $\begin{array}{l}\text { Usman } \\
2011\end{array}$ & $\begin{array}{l}\text { Wood } \\
1998\end{array}$ & $\begin{array}{l}\text { Quinlivan } \\
2003\end{array}$ \\
\hline \multirow[t]{2}{*}{ Outcome } & Vaccination up-to-date & $\mathbf{x}$ & $\mathbf{x}$ & & $\mathbf{x}$ & $\mathbf{x}$ & & & $\begin{array}{l}\mathbf{x} \\
\text { (data un- } \\
\text { usable) }\end{array}$ & $\begin{array}{l}\mathbf{x} \\
\text { (data un- } \\
\text { usable) }\end{array}$ \\
\hline & Receipt of single vaccine & & $\mathbf{x}^{\mathrm{a}}$ & $\mathbf{x}$ & $\mathbf{x}^{\mathrm{a}}$ & $\mathbf{x}^{\mathrm{a}}$ & $\mathbf{x}$ & $\mathbf{x}$ & & \\
\hline \multirow[t]{4}{*}{$\begin{array}{l}\text { Outcome } \\
\text { timing }\end{array}$} & 3 months & $\mathbf{x}$ & & $\mathbf{x}$ & $\begin{array}{l}\mathbf{x} \\
\text { (100 days } \\
\text { post int) }\end{array}$ & & $\mathbf{x}$ & $\mathbf{x}$ & & \\
\hline & 6 months & $x^{b}$ & & & & $\mathbf{x}$ & & & & $\mathbf{x}$ \\
\hline & 12 months & & $\mathbf{x}$ & & & & & & & \\
\hline & 15 months & & & & & & & & $\mathbf{x}$ & \\
\hline \multirow{4}{*}{$\begin{array}{l}\text { Assess- } \\
\text { ment tool }\end{array}$} & Parent interview & $\mathbf{x}$ & & & & & & & & \\
\hline & Review of records & & $\mathbf{x}$ & & & & $\mathbf{x}$ & & $\mathbf{x}$ & \\
\hline & Questionnaire /test/ survey & & & $\mathbf{x}$ & $\mathbf{x}$ & $\mathbf{x}$ & & & $\mathbf{x}$ & $\mathbf{x}$ \\
\hline & Not described & & & & & & & $\mathbf{x}$ & & \\
\hline
\end{tabular}


aSecondary vaccination outcome reported by study but not used in meta-analysis

bAdditional time point reported by study but not used in metaanalysis

\section{Knowledge or understanding of vaccination}

Five studies contributed usable data for this outcome. The final assessment was at three or six months post-intervention. Wood 1998 measured knowledge at 15 months postpartum, but this was a multi-session intervention that included a variable number of home visits, and the time between final session and outcome assessment was not stated. All data were collected through pre- and post-tests (written or oral); higher scores corresponded to greater knowledge.

Jackson 2011 measured knowledge of MMR on a scale from 0 to 11. Quinlivan 2003 measured knowledge of the immunisation schedule using a scale ranging from 0 to 10 . Saitoh 2013 and Saitoh 2017 both measured knowledge in similar ways. The knowledge assessment in Saitoh 2017 comprised four questions about vaccine-preventable diseases, five basic immunisation knowledge questions, and a question asking participants to identify four recommended vaccines from a list of 12 (combined for a total score of 13). We received clarification from the study authors around the scales used in Saitoh 2013. Participants in this study were scored separately for correct identification of vaccine-preventable diseases ( 0 to 13 points) and basic immunisation knowledge ( 0 to 10). We combined the scores for these two tests in our analysis - this is explored further in the Effects of interventions section. Saitoh 2013 also included a self-reported knowledge test, which was not an objective measure of knowledge and was not included in this review. Wood 1998 used two tests to measure knowledge of the immunisation schedule and contraindications. Data from the immunisation schedule test were reported inconsistently, so for the purposes of this review, only scores relating to knowledge of contraindications for immunisation could be used. The test featured three questions with a scale of 0 to 3.

Two studies did not contribute usable data on knowledge or understanding to the review (Bjornson 1997; Hu 2017), and the data from Quinlivan 2003 were skewed, so were not included in the meta-analysis. Bjornson 1997 assessed knowledge of vaccines, infectious diseases, contraindications and the immunisation schedule using a 16-question test, administered immediately before and directly following the delivery of the intervention session. The authors reported the percentage of participants who got each of the 16 questions correct on each test, but did not provide the mean scores of the intervention and control clusters, so the data could not be used in this review. We contacted the study authors, but they were unable to provide additional data, due to the age of the study.

In $\mathrm{Hu} 2017$, the authors stated that they measured participant knowledge of the vaccine schedule and vaccine policy six months after the intervention was delivered. Participants were asked to correctly select 10 vaccines for a total of five points, and correct vaccine policy answers were worth up to six points. The aggregated knowledge score ranged from 0 to 11 and was dichotomised as seven points or higher, or less than seven points. However, the supplemental material provided with the published trial suggested that the knowledge test was not an objective measure of knowledge. The list of vaccines included only ten, and the answer options were 'Yes, I know' or 'I do not know'. These were also the answer options for the vaccine policy questions, e.g. 'Do you know the location for immunisation registry?' (Yes I know / I do not know). We contacted the authors to clarify the intent of these scales and to confirm that there had been no errors of translation, but we were unable to reach them. We determined that this measurement scale could not objectively assess knowledge, so we did not include these data in the review.

Table D: Knowledge or understanding outcome features 


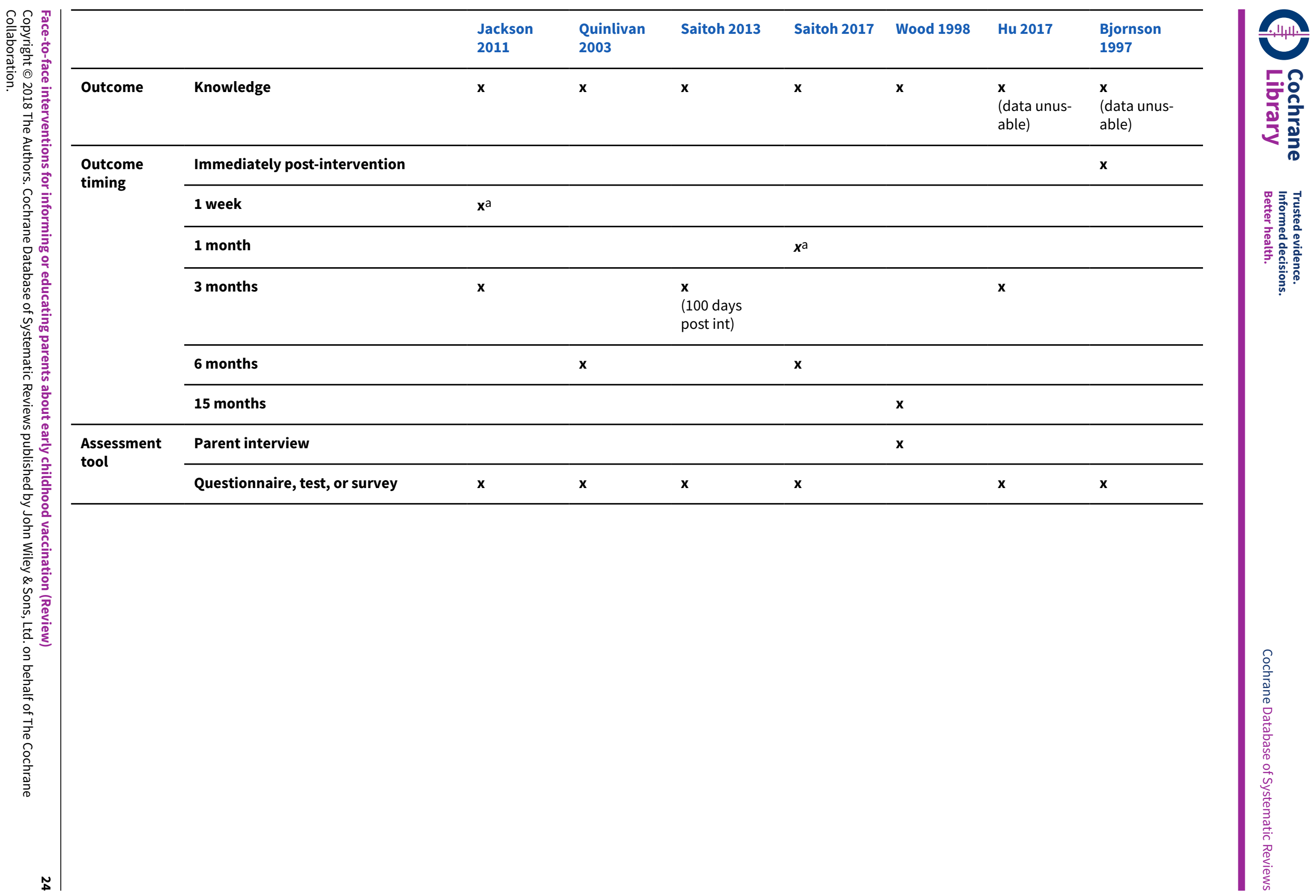


aAdditional time point reported by study but not used in metaanalysis

\section{Attitudes or beliefs}

Three studies measured parent attitudes or beliefs towards vaccines in general (Saitoh 2013; Saitoh 2017), or towards MMR in particular (Jackson 2011). The attitude assessment tools for Saitoh 2013 and Saitoh 2017 were very similar, and were both based on aspects of the Health Belief Model and the Integrated Behavioral Model. The tool measured eight separate attitude outcomes, using 21 statements (Saitoh 2013), or 20 statements (Saitoh 2017). The eight outcome categories were: perceived severity, susceptibility, benefits, barriers, self-efficacy, behavioural control, and injunctive and descriptive social norms. Participants rated each statement on a five-point Likert scale from one (strongly disagree) to five (strongly agree). The tool was translated from English to Japanese. The translation was confirmed and the tool piloted prior to use, but was not described as validated.

Jackson 2011 measured three attitude outcomes: attitude towards MMR, necessity of MMR beliefs, and concern about MMR beliefs. The tool assessed attitude towards MMR with one question, scored on a seven-point scale ('For me to give my child the combined MMR vaccine at the recommended ages would be ...' 1 extremely bad to 7 extremely good). This item had demonstrated reliability and validity. The authors adapted an existing questionnaire (Beliefs about Flu Vaccination Questionnaire) to assess beliefs, though this tool was not validated for MMR (Bekker 2003). Parents recorded their necessity beliefs using four items (e.g. 'Without the combined MMR vaccine, my child could get very ill from measles, mumps or rubella'). Concern beliefs were assessed with another four items (e.g. 'Giving my child the combined MMR vaccine worries me'). These items were scored on five-point scales. Scores were summed for each type of belief, for a total score of 4 to 20 for necessity and for concern (higher scores indicated stronger beliefs about the necessity for, or concern about, MMR).

Although three studies measured attitudes or beliefs related to vaccination, these were measured in a variety of ways both within each study and across studies (Table 2). We reviewed the descriptions of the outcome measures to identify the most similar attitude outcome across studies: perceived severity (Saitoh 2013; Saitoh 2017) and necessity beliefs (Jackson 2011).

Table E: Attitudes or beliefs outcome features

\begin{tabular}{|c|c|c|c|c|}
\hline & & Jackson 2011 & Saitoh 2013 & Saitoh 2017 \\
\hline Outcome & Attitudes & $\mathbf{x}$ & $\mathbf{x}$ & $\mathbf{x}$ \\
\hline \multirow[t]{4}{*}{ Outcome timing } & 1 week & $\mathbf{x}^{a}$ & & \\
\hline & 1 month & & & $\mathbf{x}^{a}$ \\
\hline & 3 months & $\mathbf{x}$ & $\begin{array}{l}\mathbf{x} \\
\text { (100 days post int) }\end{array}$ & \\
\hline & 6 months & & & $\mathbf{x}$ \\
\hline Assessment tool & Questionnaire, test, or survey & $\mathbf{x}$ & $\mathbf{x}$ & $\mathbf{x}$ \\
\hline
\end{tabular}

aAdditional time point reported by study but not used in metaanalysis

\section{Intention to vaccinate}

Two studies measured parents' intention to vaccinate at three months post-intervention (Jackson 2011; Saitoh 2013). Both studies used pre- and post-intervention questionnaires or surveys to record the data. In Jackson 2011, parents reported their intended choice about vaccinating their child with the first or second dose of MMR. They rated three items on a seven-point scale, and the scores were averaged to produce a score from 0 to 7 (from 'do not intend to vaccinate', to 'do intend to vaccinate'). These items had demonstrated reliability and validity, according to the authors. In Saitoh 2013, parents answered one question about their intention to vaccinate using a four-point scale $(1=$ no, $2=$ undecided, $3=$ yes, for a specific vaccine, and $4=$ yes).

Table F: Intention to vaccinate outcome features

\begin{tabular}{llll}
\hline & & Jackson 2011 & Saitoh 2013 \\
\hline Outcome & Intention to vaccinate & $\mathbf{x}$ & $\mathbf{x}$ \\
\hline Outcome timing & 1 week & $\mathbf{x}^{\mathrm{a}}$ & $\mathbf{x}$ \\
\cline { 2 - 4 } & 3 months & $\mathbf{x}$ (100 days post int) \\
\hline \hline
\end{tabular}

Face-to-face interventions for informing or educating parents about early childhood vaccination (Review) 
aAditional time point reported by study but not used in metaanalysis

\section{Adverse effects}

Anxiety associated with the intervention was the only adverse event measured in any studies. Anxiety was measured by Jackson 2011 at one week post-intervention and three months postintervention (final follow-up). The scale included six items (e.g. '। feel calm' or 'I am tense'), each scored on a four-point scale, from 'not at all', to 'very much'. Positive items were reversed, and the scores for all six items were combined and then multiplied by $20 / 6$ for a total score of 20 (very low anxiety) to 80 (very high anxiety). The authors report that a normal score was 34 to 36 .

\section{Secondary outcomes}

No studies measured parent experience of the intervention.

The cost of implementing the intervention was measured by Wood 1998. See Effects of interventions for further details about the costeffectiveness calculations used.

\section{Excluded studies}

We excluded 29 studies at the full-text stage (see 'Characteristics of excluded studies' table). The reasons for exclusion were:
1. the study was not an RCT or cluster-RCT $(N=10)$;

2. the intervention was a maternal outreach or support intervention, where the immunisation content was not specified or consistently delivered $(\mathrm{N}=5)$;

3. the study did not report on a face-to-face information or educational intervention $(\mathrm{N}=5)$;

4. the face-to-face intervention was part of a multi-component intervention or a mass media campaign, in which the effect of any face-to-face information or education could not be isolated $(\mathrm{N}=4)$;

5. the intervention was not targeted to parents $(\mathrm{N}=4)$; or

6. the intervention was not relevant to immunisation $(\mathrm{N}=1)$.

One study included in the original review was excluded from this update, as it was a maternal outreach or support intervention with unclear immunisation content (one of the five studies excluded for reason 2, above; Bartu 2006).

\section{Risk of bias in included studies}

The risk of bias for all included studies is summarised in Figure 2 and Figure 3. 
Figure 2. Risk of bias summary: review authors' judgements about each risk of bias item for each included study

\begin{tabular}{|c|c|c|c|c|c|c|c|c|}
\hline & 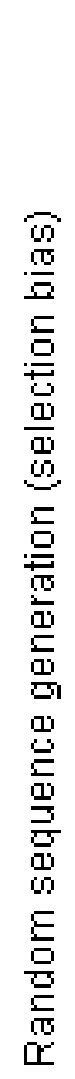 & 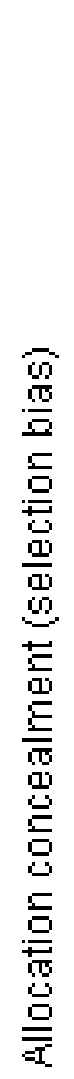 & 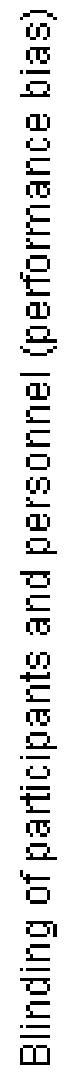 & 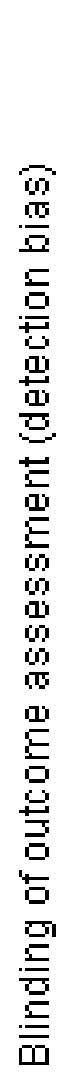 & 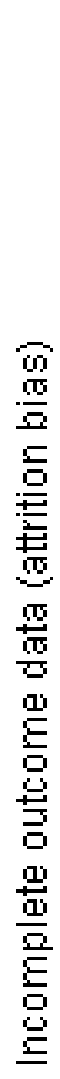 & 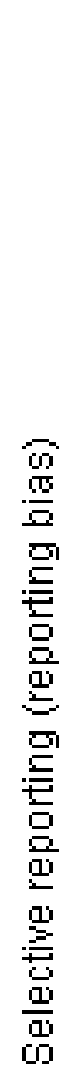 & 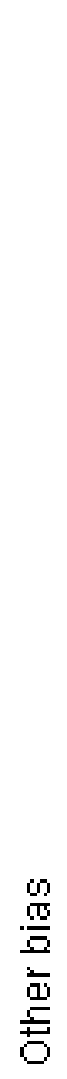 & 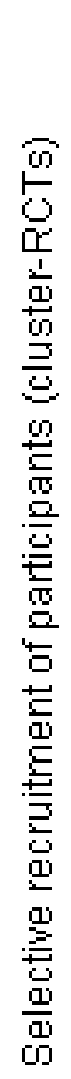 \\
\hline \multicolumn{9}{|l|}{ Bjornson 1997} \\
\hline Bolam 1998 & & & & 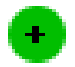 & & $?$ & + & \\
\hline Hu 2017 & & $?$ & & $?$ & & $?$ & + & \\
\hline Jackson 2011 & $?$ & + & & & $?$ & $?$ & $?$ & \\
\hline Quinlivan 2003 & & ( & & & $?$ & $?$ & $?$ & \\
\hline Saitoh 2013 & & & & & $?$ & + & + & \\
\hline Saitoh 2017 & & & & & + & $?$ & + & \\
\hline Usman 2009 & & & & & $?$ & $?$ & $?$ & \\
\hline Usman 2011 & & & & 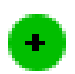 & $?$ & $?$ & $?$ & \\
\hline Wood 1998 & + & & & & $?$ & $?$ & $?$ & \\
\hline
\end{tabular}

Face-to-face interventions for informing or educating parents about early childhood vaccination (Review) 
Figure 3. Risk of bias graph: review authors' judgements about each risk of bias item presented as percentages across all included studies

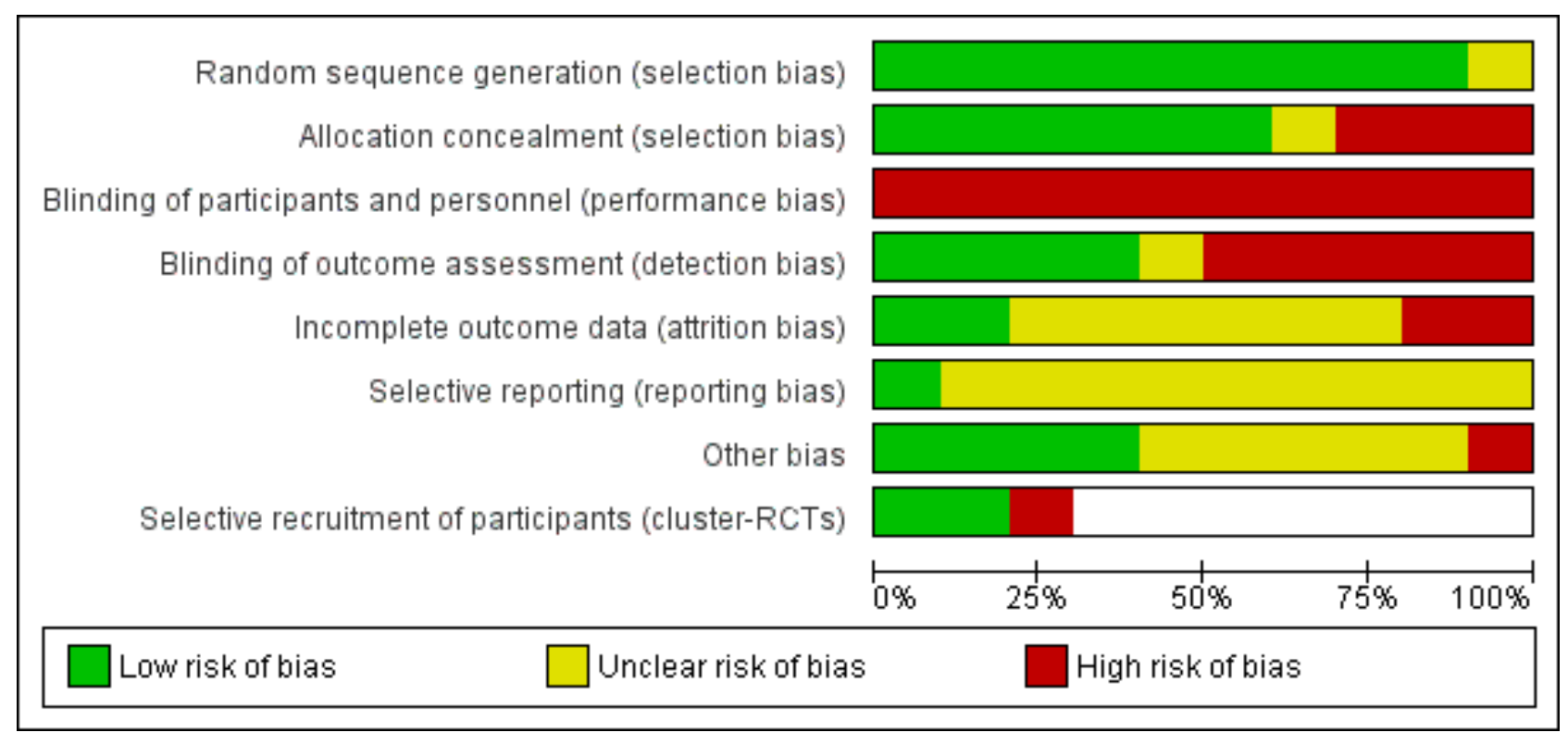

\section{Allocation}

We determined a priori that sequence generation and allocation concealment were the most significant and influential risk of bias attributes. We judged nine out of ten studies at low risk of bias for sequence generation, while Jackson 2011 was unclear. For allocation concealment, three were at high risk (Usman 2009; Usman 2011; Wood 1998) and we judged one as at unclear risk (Hu 2017). Through contact with study authors, we confirmed that appropriate allocation concealment had been performed in one study (Saitoh 2013).

\section{Blinding}

Due to the overt nature of face-to-face interventions, blinding participants and personnel was not possible in any of the included studies, and we assessed all as high risk of bias for these factors. Outcome assessors were adequately blinded in two studies (Bolam 1998; Quinlivan 2003). Assessors were not blinded in Usman 2009 or Usman 2011, but we judged the risk of bias to be low, because the only outcome assessed was receipt of vaccine, which is not a subjective outcome. The remainder were at high or unclear risk of detection bias due to lack of blinding.

\section{Incomplete outcome data}

We only assessed two studies at low risk of bias for incomplete outcome data, either because the outcome was assessed immediately following intervention delivery (Bjornson 1997), or because attrition was relatively low and the authors used an intention-to-treat analysis (Saitoh 2017). Two studies had a high risk of attrition bias because those lost to follow-up were excluded from the analysis, and the dropout rates were relatively high (25\% (Bolam 1998), and 32\% (Hu 2017)).

We judged six studies as being at unclear risk of attrition bias: large numbers of participants failed to receive the intervention (Jackson 2011; Wood 1998); all non-respondents were classified as not receiving the vaccine (Usman 2009; Usman 2011); substantially more participants withdrew from one group than the other without explanation (Quinlivan 2003; Saitoh 2013).

\section{Selective reporting}

We rated only one study at low risk of bias for this domain, because the outcomes planned in the trial registration record were all reported in the published study (Saitoh 2013). We rated one study at unclear risk of bias because the trial registration record included the proposed outcome of cost, which was not reported in the published study (Saitoh 2017). All other studies were at unclear risk of bias for this domain because protocols or trial registration records were not available.

\section{Other potential sources of bias}

We judged four studies to be at low risk of other bias due to low risk of contamination and comparability of groups at baseline (Bolam 1998; Hu 2017; Saitoh 2013; Saitoh 2017).

The authors of one cluster-RCT did not account for the effects of clustering in the analysis, so we rated this study as high risk of bias for this attribute (Bjornson 1997). Two studies reported some significant baseline demographic differences between the intervention and control groups, for which we rated them as unclear risk of bias (Quinlivan 2003; Usman 2011). In Jackson 2011, baseline characteristics were similar and contamination across study arms was unlikely, but the authors note that the leaflet they provided to all arms may have been more thorough than the actual usual care in the region, meaning they may have been comparing two different decision-support interventions (educational session plus leaflet versus leaflet) rather than an intervention with a control. We judged the potential risk of bias arising from this as unclear. There was insufficient information to judge if other potential sources of bias were present in Usman 2009 and Wood 1998 so we also rated them at unclear risk of bias. 


\section{Selective recruitment or participants (cluster-RCTs)}

We determined two cluster-RCTs to be at low risk of bias for selective recruitment of participants (Bjornson 1997; Jackson 2011), while one was at high risk because participants were recruited after clusters were randomised (Saitoh 2017).

\section{Effects of interventions}

See: Summary of findings for the main comparison

We present an outline of the main findings for each outcome in Summary of findings for the main comparison.

We did not find sufficient RCTs to investigate reporting bias or small-study effects using funnel plots. However, our qualitative assessment indicated that there was low risk of reporting bias for all outcomes, as the smaller studies showed no strong evidence of an effect.

\section{Comparison 1: Face-to-face interventions directed to parents versus control}

\section{Primary outcomes}

\section{Vaccination status}

Seven studies compared face-to-face information or educational interventions with control, with the vaccination status measured either three, six, or twelve months after the intervention (Bolam 1998; Hu 2017; Jackson 2011; Saitoh 2013; Saitoh 2017; Usman 2009; Usman 2011). Face-to-face communication to inform or educate parents may improve vaccination status (risk ratio (RR) $1.20,95 \%$ confidence interval $(\mathrm{Cl}) 1.04$ to 1.37 ; 3004 participants; low-certainty evidence).

Communication interventions are frequently complex, and it can be difficult to determine whether interventions are sufficiently similar to compare. While the level of statistical heterogeneity was high $\left(\mathrm{Chi}^{2}=40.68, \mathrm{df}=6(\mathrm{P}<0.00001) ; \mathrm{I}^{2}=85 \%\right)$, we decided to pool the data for these studies, acknowledging that the length of the educational sessions and the number of vaccines delivered were potentially important differences between them. We conducted post hoc formal subgroup analyses to investigate these two potential sources of heterogeneity (Analysis 1.1 and Analysis 1.2).

For analysis stratified by session length, we categorised sessions that lasted 10 minutes or less as 'short' (Analysis 1.1; Saitoh 2013; Saitoh 2017; Usman 2009; Usman 2011), and those lasting longer than 10 minutes as 'long' (Bolam 1998; Hu 2017; Jackson 2011). In Australia, the average clinical consultation time is 15 minutes, and healthcare providers need time to both deliver the intervention and the vaccine (Britt 2016). Therefore, we determined that 10 minutes was the maximum time an intervention could take without encountering potential scheduling and reimbursement implications. The test for subgroup differences was not significant $(P=0.15)$. Heterogeneity of the stratified studies remained relatively high, so we were unable to conclusively state whether session length was a major contributing factor to the heterogeneity in study effects.

The second analysis grouped studies that measured receipt of a single vaccine (Analysis 1.2; Jackson 2011; Usman 2009; Usman 2011) and those that measured receipt of multiple vaccines (Bolam 1998; Hu 2017; Saitoh 2013; Saitoh 2017). This decision was based on advice from vaccination experts, and reflects the fact that receiving one vaccine is less demanding, as an outcome, than receiving several. The test for subgroup differences was significant $(P=0.04)$. There was no appreciable difference in heterogeneity.

\section{Knowledge or understanding of vaccination}

Moderate-certainty evidence from four studies (657 participants) suggested that face-to-face information or education probably improved parent knowledge slightly, compared with control (standardised mean difference (SMD) $0.19,95 \% \mathrm{Cl} 0.00$ to 0.38 ; Analysis 1.3; Jackson 2011; Saitoh 2013; Saitoh 2017; Wood 1998). Knowledge was measured by two separate scales in Saitoh 2013 (knowledge of vaccine-preventable diseases and basic immunisation knowledge), which we combined into a single score by summing the mean scores from each scale and calculating revised standard deviation (SD) by squaring the SD for each scale, summing them and taking the square root. Statistical heterogeneity between these studies was low $\left(\mathrm{Chi}^{2}=3.86, \mathrm{df}=3(\mathrm{P}=0.28) ; \mathrm{I}^{2}=\right.$ $22 \%)$.

We were unable to include the outcome data from Quinlivan 2003 in our meta-analysis because they were given as medians rather than means. Contact with the authors confirmed that this was because the data were skewed. In the published article, the authors reported that there were no significant differences between knowledge scores of the intervention and control groups at the antenatal or postnatal assessments (mean difference (MD) $0.85,95 \% \mathrm{Cl}:-0.06$ to 1.76).

\section{Attitudes or beliefs}

Three studies (292 participants) reported data on several measures of attitudes or beliefs. For the purpose of this review, we selected the most comparable measures of attitudes across the studies - two on perceived severity of vaccine-preventable diseases (Saitoh 2013, Saitoh 2017), and one on beliefs about the necessity of the MMR vaccine (Jackson 2011). Face-to-face information or educational interventions may lead to little or no change in parent attitudes or beliefs about disease severity or vaccine necessity (SMD 0.03, 95\% $\mathrm{Cl}-0.20$ to 0.27 ; Analysis 1.4; low-certainty evidence). Heterogeneity was not detected $\left(\mathrm{Chi}^{2}=0.08, \mathrm{df}=2(\mathrm{P}=0.96) ; \mathrm{I}^{2}=0 \%\right)$, but all were small studies with a small combined total number of participants.

\section{Intention to vaccinate}

Low-certainty evidence from two studies (179 participants) suggests that face-to-face information or education delivered to parents may slightly increase parents' intention to vaccinate (SMD 0.55, 95\% Cl 0.24 to 0.85; Analysis 1.5; Jackson 2011; Saitoh 2013). Heterogeneity was not detected $\left(\mathrm{Chi}^{2}=0.81, \mathrm{df}=1(\mathrm{P}=0.37) ; \mathrm{I}^{2}=\right.$ $0 \%)$.

\section{Adverse effects (anxiety)}

Only one study (90 participants) measured this outcome (Jackson 2011). Face-to-face information or educational interventions may lead to little or no change in parents' anxiety (MD - 1.93, 95\% Cl -7.27 to 3.41 ; low-certainty evidence; Analysis 1.6).

\section{Secondary outcome}

Cost

Only one included study reported data on costs of implementing an intervention (Wood 1998). The certainty of this evidence was 
judged to be very low, and consequently we are very uncertain of the effects of the intervention on cost outcomes. This study reported a full cost-effectiveness analysis of a case management intervention to promote childhood immunisation, compared with usual practice. Total costs were estimated, based on costs of personnel, supplies, travel, office space, and orientation costs of the intervention only. Costs calculated per individual took account of indirect case management costs (based on the frequency and time taken for case managers to complete client-related contact tasks) in the same proportion as direct costs incurred by the intervention.

The total cost of the intervention was calculated to be USD 293,662 (price year not stated). For the intervention group $(N=185)$, the mean cost per participant was calculated as USD 1587, and the additional cost of bringing one non-immunised child fully up-todate with immunisations by one year was estimated to be USD 12,022 . This study did not consider potential costs arising from nonimmunisation (e.g. costs of contracting a disease).

Analysis was also conducted on a high-risk subgroup of those receiving the intervention, defined by the authors as those children who had received only three or fewer well-child visits (of a total of five visits). In this subgroup ( $n=86)$, the mean cost per participant was estimated as USD 1273 , with the additional cost of bringing one non-immunised child fully up to date with immunisations by one year calculated as USD 4546.

The study authors reported resource use, but this was expressed in terms of monetary costs rather than physical resource quantities. They noted that the cost-effectiveness data may underestimate the true cost-effectiveness of the intervention, due to start-up and evaluation costs associated with the delivery of the intervention over a short time period. However, there are several factors that may limit the conclusions that can be drawn from this study: the cost-effectiveness analysis did not consider effects of the intervention on subsequent care, nor of changes to the costs of usual practice over time. Cost data were presumably reported in US dollars, with no information provided on the price year. Given that the study was published in 1998, the costs and cost-effectiveness of such a case management intervention may be substantially different in today's terms. All outcomes and costs associated with the study were measured at 12 months, with no longer-term data reported, which limits the conclusions that can be drawn. Finally, the intervention delivered by this study was much more complex, and therefore potentially resource-intensive, than many of the other interventions included in this review.

\section{Parent experience of the intervention}

No included studies reported this outcome.

\section{Comparison 2: Face-to-face intervention A versus face-to-face} intervention $B$

No included studies reported this comparison.

\section{DISCUSSION}

\section{Summary of main results}

This systematic review found some evidence, of low to moderate certainty, suggesting that face-to-face interventions to inform or educate parents about childhood vaccination may improve children's vaccination status, probably slightly improves parents' knowledge or understanding of vaccination, and may slightly increase intention to vaccinate. These interventions may lead to little or no difference in parent attitudes or anxiety related to the intervention. There was uncertain evidence related to the cost of implementing interventions, and no evidence available from the included studies regarding parent experience of the intervention.

\section{Overall completeness and applicability of evidence}

This review used a comprehensive search strategy, which followed Cochrane search methods, and was not restricted by language or publication status. We included only randomised controlled trials (RCT), though there tend to be fewer trials in this area than there are for clinical or biomedical topics, due to the challenges of conducting RCTs of complex public health interventions. This meant that relatively few studies met the inclusion criteria, but by definition, those that did should have been of relatively high quality compared to other study designs (Higgins 2011). Implementing communication interventions can be costly and time-consuming, so it is important for policy makers and programme managers to be able to base their decisions on rigorous, high-quality evidence, wherever possible. We excluded quasi-RCTs, but recognise that excluding studies for inadequate randomisation can be seen as a form of research waste. Future updates of this review may consider quasi-RCTs and additional study designs as eligible for inclusion.

The global applicability of the evidence included in this review is uncertain. Two studies were conducted in Japan, where some vaccines are required and funded by the government, but some are not (Saitoh 2013; Saitoh 2017). The coverage rate for those vaccines that are not required and funded is substantially lower, in part because this policy implies that these vaccines are optional, or less important. In this context, an intervention that increases awareness by providing information and education may show greater effect than in a country where awareness is high, but vaccine hesitancy is a problem (e.g. the UK, where Jackson 2011 took place). Three of the ten included studies were conducted in low and middle income countries (LMIC), which may also have implications for the applicability of the findings.

We did not include multi-component interventions where the effects of the face-to-face intervention could not be isolated, which resulted in the exclusion of many studies that included a face-toface element. It is possible that face-to-face interventions may be more or less effective, depending on the additional interventions with which they are combined. However, assessing the effects of a single intervention is important to allow decision makers to determine whether it is worthwhile, cost-effective, or both, to implement a particular intervention alone; or whether it may be beneficial to combine interventions, and if so, which components to combine (Ryan 2014).

All of the new studies included in this update measured a much broader range of outcomes than those in the original review, which is encouraging, as it suggests increased recognition of the importance of considering intermediate outcomes, like knowledge, attitudes, and intention to vaccinate. In the original review, only two studies measured knowledge, and none measured any other intermediate outcomes. Unpacking the effects of complex interventions requires the measurement of a range of outcomes that are able to detect potential impacts along the causal chain (Breuer 2015; Craig 2008; Moore 2015). Measuring outcomes, such as knowledge, attitudes, and intention to vaccinate - in addition 
to endpoint outcomes related to vaccination status - is necessary to determine which parts of complex communication interventions are effective, and to identify whether interventions are impacting vaccine hesitancy. While the breadth of outcomes was greater in the newer studies, there were still some issues. The tools and scales used to measure attitudes were highly variable, making it difficult to compare the data for this outcome across studies. Also, no studies assessed parents' experiences of the intervention, such as satisfaction with, or acceptability of the intervention. Qualitative research has highlighted that parents' perceptions about their communication encounters can impact their decisions around vaccination (Ames 2017; Brown 2010). Similarly, cost is a critical factor affecting implementation decisions made by policymakers and programme managers, but cost was only reported in one study (Wood 1998). As this study was from 1998, and was limited to a specific complex intervention (case management) in a lowincome population in a high-income country, it is unlikely to be generalisable to other settings.

\section{Quality of the evidence}

The certainty of the evidence was moderate to low for each outcome. All studies had limitations in design. We downgraded evidence where the contributing studies were at high or unclear risk of bias for sequence generation (Jackson 2011), or allocation concealment (Hu 2017; Usman 2009; Usman 2011; Wood 1998).

We also downgraded the certainty of the evidence for vaccination status, due to inconsistency, which was clear from the high level of statistical heterogeneity. The certainty of the evidence for intention to vaccinate and adverse effects was downgraded for imprecision, due to the wide confidence intervals for the included studies. We downgraded the certainty of the evidence for attitudes due to indirectness, because the specific measures for this outcome (perceived diseases severity and vaccine benefits) were only part of what could be measured, and what was relevant to parents and other decision makers. We did not downgrade any outcomes for issues of publication bias.

\section{Potential biases in the review process}

We pooled the results of studies reporting vaccination status, despite high levels of statistical heterogeneity. This may have introduced some bias because the actual effect size might be substantially larger or smaller than that of the pooled (mean) result. We conducted post hoc formal subgroup analyses to investigate two potential implementation-relevant sources of this heterogeneity (length of intervention session and number of vaccines received). However, heterogeneity remained largely unexplained in both cases. As more studies are added in future updates of this review, we will reconsider this analysis and investigate the effects of relevant explanatory factors identified from the existing research.

Another possible source of bias is our selection of comparable measures of attitudes or beliefs. The data used for the purposes of analysis were selected from more than one measurement of attitudes and beliefs available per included trial. We cannot rule out the possibility that other researchers might choose alternative measurements from the same studies, and so reach different conclusions about the effects of the intervention on this outcome. This is relatively likely, as there is an absence of agreement over the most appropriate ways of measuring attitudes and beliefs in the field of vaccination.

All other methods and literature searching for this update did not deviate from the processes outlined in the original review, and should be relatively free from bias.

\section{Agreements and disagreements with other studies or reviews}

The findings of this review are largely consistent with those of other recent reviews, which suggest that educational interventions, face-to-face communication, or a combination, may have some positive impact on vaccination status and parent knowledge or attitudes. The Cochrane Review of interventions for improving childhood vaccination coverage in LMICs assessed 14 studies, six of which evaluated the effects of health education. The review authors found moderate-certainty evidence that health education at village meetings or at home probably improved coverage (Oyo-Ita 2016). Another Cochrane Review looked at communityaimed interventions to inform or educate about early childhood vaccination. The authors included two studies, which found that community-aimed interventions probably increased vaccination uptake in some circumstances, and may have improved knowledge and attitudes towards vaccination (Saeterdal 2014).

Two non-Cochrane reviews considered a broader range of intervention types, but also highlighted the relevance of face-toface educational interventions. According to Jarrett 2015, who reviewed strategies for addressing vaccine hesitancy, dialoguebased interventions were the most commonly used. Harvey 2015 assessed parental reminder, recall, and educational interventions, finding that discussion-based education was more effective than written education.

One recent review aimed to identify the effectiveness of specific provider-parent communication techniques, but found insufficient high-quality evidence on which to draw a conclusion (Connors 2017). Our review was similarly limited by the shortage of trial evidence on this topic.

In future updates of this review, we may compare our findings with those of RCTs involving face-to-face interventions for recommended adult vaccinations, to provide relevant context and insight.

\section{AUTHORS' CONCLUSIONS}

\section{Implications for practice}

Face-to-face communication about childhood vaccination is very common, and usually addresses a lack of acceptance or awareness of vaccination. It takes place in many settings, and is delivered by a range of people around the world; sometimes it is planned and formalised, other times it is a casual or informal discussion. It is important to consider this intervention against outcomes beyond the behavioural (e.g. vaccination status). Explanation and understanding of healthcare procedures form the basis of informed consent, so discussions about vaccination should and will continue to take place, regardless of the findings of research evidence about their effectiveness. However, given the ubiquity of this communication method, healthcare providers and practitioners should be encouraged to know that face-to-face information or education about childhood vaccination may have positive effects. 
This review suggests that immunisation-focused educational messages may be sufficient to improve vaccination coverage and knowledge.

There may be some populations or healthcare contexts in which face-to-face interventions may be more successful than others. The included studies did not specifically describe the hesitancy of the targeted populations and did not thoroughly explore the intervention's mechanism of effect, so it was unclear how effective information or educational interventions may be when hesitancy is the primary barrier. It is possible that these interventions may be more effective where awareness or understanding of vaccination is identified as a barrier (e.g. where people are unaware of new or optional vaccines). There were several studies that showed significant improvements in vaccination status, but the evidence across more diverse settings and populations is unclear at this time. When implementing such interventions, it is vital to understand what specific barriers to vaccination exist in that population, so their content can sufficiently target that barrier.

\section{Implications for research}

Vaccine programme managers, policy makers, and other decision makers need high-quality randomised trial evidence on the effects of face-to-face information and educational interventions for parents. The current low- to moderate-certainty evidence was provided by a small number of trials, conducted in high- and lowincome settings.

No included studies evaluated the effects of different types or styles of messaging, such as presumptive versus participatory, and how they affected different groups or levels of hesitancy. There is considerable interest in identifying the most effective way for healthcare providers to communicate with parents, but trial evidence remains limited. To date, the effects of physician communication styles have only been tested in one RCT, which focused on HPV rather than childhood vaccines (Brewer 2017), and a cluster-RCT, which evaluated a physician communication-training intervention (Henrikson 2015). Further RCT evidence in this area is critical, as healthcare providers are already engaged in these often-challenging discussions with parents, and seek evidencebased communication strategies and guidance. The participation and support of providers in future research will be essential to develop and evaluate new interventions.

One important consideration for future research aiming to improve vaccine acceptance is the need to identify and distinguish between parents who are supportive of vaccination, and those who are hesitant or planning to delay or decline recommended childhood vaccines. Nearly all parents want and value face-to-face communication with their healthcare providers about vaccination, but most parents already comply with recommendations. Studies that fail to differentiate between accepting and hesitant populations may fail to find relationships between an intervention and outcomes, or may underestimate an intervention's effect size, particularly in settings with high baseline vaccination rates.

The intervention was only delivered by a peer or parent facilitator in one of the nine studies (Jackson 2011). Future studies could consider alternative settings and deliverers, particularly when targeting parents with high hesitancy or mistrust of the healthcare system.

Face-to-face interventions can vary significantly from short, focused educational sessions that can be easily added to an existing healthcare consultation, to longer programmes covering a range of topics, and potentially involving multiple sessions. More studies are needed to determine the relative effectiveness of each approach, and descriptions of interventions and their components must be clear and detailed. One possible method for improving intervention reporting is the Template for Intervention Description and Replication (TIDieR) checklist, which provides guidance on the information needed to sufficiently describe an intervention (Hoffman 2014).

Due to the difficulty of isolating the effects of multi-component interventions, it may be beneficial to consider testing single interventions, or to organise trials with stepped interventions, to assess the effects of each component. The control comparison or routine care also needs to be clearly described, particularly if it includes some degree of face-to-face interaction. Failure of an intervention to sufficiently differentiate from usual care is a key barrier to successful implementation (May 2009).

More recent studies appear to be measuring a broader range of intermediate outcomes, including knowledge, attitudes and beliefs, and intention to vaccinate. However, there is little agreement on the most appropriate measurement method or scale to apply for many of these outcomes, so it remains difficult to compare effects across studies. Preliminary work has been undertaken to develop a core set of outcome domains to measure when evaluating the effects of vaccination communication interventions (Kaufman 2017a). The critical next step is to develop and test reliable and validated scales - particularly for multi-faceted outcomes, such as attitudes or beliefs - and disseminate them widely, in order to improve consistency of outcome assessment and consensus on which outcomes most closely reflect the outcome of interest.

\section{ACKNOWLEDGEMENTS}

We would like to thank John Kis-Rigo for developing the search strategy for this updated review. 


\section{RE F E R E N C E S}

\section{References to studies included in this review}

\section{Bjornson 1997 \{published and unpublished data\}}

Bjornson GL, Scheifele DW, Gold R. Assessment of parent education methods for infant immunization. Canadian Journal of Public Health/Revue Canadienne de Santé Publique 1997;88(6):405-8.

\section{Bolam 1998 \{published and unpublished data\}}

Bolam A, Manandhar DS, Shrestha P, Ellis M, Costello AM. The effects of postnatal health education for mothers on infant care and family planning practices in Nepal: a randomised controlled trial. BMJ (Clinical research edition) 1998;316(7134):805-11.

\section{Hu 2017 \{published data only\}}

Hu Y, Chen Y, Wang Y, Song Q, Li Q. Prenatal vaccination education intervention improves both the mothers' knowledge and children's vaccination coverage: evidence from randomized controlled trial from eastern China. Human Vaccines \& Immunotherapeutics 2017;13(6):1477-84.

\section{Jackson 2011 \{published and unpublished data\}}

Jackson C, Cheater FM, Harrison W, Peacock R, Bekker H, West $\mathrm{R}$, et al. Randomised cluster trial to support informed parental decision-making for the MMR vaccine. BMC Public Health 2011;11:475. [DOI: 10.1186/1471-2458-11-475]

\section{Quinlivan 2003 \{published and unpublished data\}}

Quinlivan JA, Box H, Evans SF. Postnatal home visits in teenage mothers: a randomised controlled trial. Lancet 2003;361(9361):893-900.

\section{Saitoh 2013 \{published data only\}}

Saitoh A, Nagata S, Saitoh A, Tsukahara Y, Vaida F, Sonobe T, et al. Perinatal immunization education improves immunization rates and knowledge: a randomized controlled trial. Preventive Medicine 2013;56:398-405.

\section{Saitoh 2017 \{published data only\}}

Saito A, Saitoh A, Sato I, Shinozaki T, Kamiya H, Nagata S. Effectiveness of stepwise perinatal immunization education: a cluster randomized controlled trial. Open Forum Infectious Diseases 2016;3(suppl_1):731.

* Saitoh A, Saitoh A, Sato I, Shinozaki T, Kamiya H, Nagata S. Effect of stepwise perinatal immunization education: a clusterrandomized controlled trial. Vaccine 2017;35:1645-51.

Saitoh A, Saitoh A, Sato I, Shinozaki T, Kamiya H, Nagata S. Improved parental attitudes and beliefs through stepwise perinatal vaccination education. Human Vaccines \& Immunotherapeutics 2017;13(11):2639-45.

Usman 2009 \{published and unpublished data\}

Usman HR, Akhtar S, Habib F, Jehan I. Redesigned immunization card and center-based education to reduce childhood immunization dropouts in urban Pakistan: a randomized controlled trial. Vaccine 2009;27(3):467-72.
Usman 2011 \{published and unpublished data\}

Usman HR, Rahbar MH, Kristensen S, Vermund SH, Kirby RS, Habib F, et al. Randomized controlled trial to improve childhood immunization adherence in rural Pakistan: redesigned immunization card and maternal education. Tropical Medicine and International Health 2011;16(3):334-42.

Wood 1998 \{published and unpublished data\}

* Wood D, Halfon N, Donald-Sherbourne C, Mazel RM, Schuster M, Hamlin JS, et al. Increasing immunization rates among inner-city, African American children: a randomized trial of case management. Journal of the American Medical Association 1998;279(1):29-34.

Wood D, Schuster M, Donald-Sherbourne C, Duan N, Mazel R, Halfon N. Reducing missed opportunities to vaccinate during child health visits: how effective are parent education and case management?. Archives of Pediatrics and Adolescent Medicine 1998;152(3):238-43.

\section{References to studies excluded from this review}

Banwat 2015 \{published data only\}

Banwat ME, Lar LA, Abok IA, Yiltok ES. Effect of peer education on knowledge, attitude and completeness of childhood routine immunization in a rural community of Plateau State. Research Journal of Health Sciences 2015;3(4):264-74.

\section{Bedford 2014 \{published data only\}}

Bedford H. Pro-vaccine messages may be counterproductive among vaccine-hesitant parents. Evidence Based Medicine 2014;19(6):219. [1473-6810: (Electronic)]

Brown 2016 \{published data only\}

Brown VB, Oluwatosin OA, Akinyemi JO, Adeyemo AA. Effects of community health nurse-led intervention on childhood routine immunization completion in primary health care centers in Ibadan, Nigeria. Journal of Community Health 2016;41(2):265-73. [1573-3610: (Electronic)]

\section{Chamberlain 2016 \{published data only\}}

Chamberlain AT, Seib K, Ault KA, Rosenberg ES, Frew PM, Cortes $\mathrm{M}$, et al. Impact of a multi-component antenatal vaccine promotion package on improving knowledge, attitudes and beliefs about influenza and Tdap vaccination during pregnancy. Human Vaccines and Immunotherapeutics 2016;12(8):2017-24.

\section{Donahue 2016 \{published data only\}}

Donahue KL, Hendrix KS, Sturm LA, Zimet GD. The effect of provider communication about vaccination on mothers willingness to vaccinate their children against HPV and influenza: a randomized trial of illustrated health messaging vignettes. Journal of Adolescent Health 2016;58(2):S117.

Habib 2017 \{published data only\}

Habib MA, Soofi S, Cousens S, Anwar S, Haque NU, Ahmed I, et al. Community engagement and integrated health and polio immunisation campaigns in conflict-affected areas of Pakistan: 
a cluster randomised controlled trial. Lancet Global Health 2017;5(6):e593-603.

\section{Hall 2016 \{published data only\}}

Hall S. Parental intentions to immunize children against influenza: a randomized trial of EPPM-based immunization messaging [Doctoral Dissertation]. Phoenix: Arizona State University, 2016.

\section{Hendrix 2013 \{published data only\}}

Hendrix KS, Finnell ME, Zimet GD, Sturm LA, Downs SM. Can the importance of herd immunity influence parents' intentions to vaccinate their children?. Medical Decision Making 2014;34(2):E32.

\section{Henrikson 2015 \{published data only\}}

Henrikson NB, Opel DJ, Grothaus L, Nelson J, Scrol A, Dunn J, et al. Physician communication training and parental vaccine hesitancy: a randomized trial. Pediatrics 2015;136(1):70-9.

\section{Johri 2015 \{published data only\}}

Johri M, Chandra D, Kone GK, Dudeja S, Sylvestre MP, Sharma JK, et al. Interventions to increase immunisation coverage among children 12 to 23 months of age in India through participatory learning and community engagement: pilot study for a cluster randomised trial. BMJ Open 2015; Vol. 5 , issue 9:e007972.

\section{Jordan 2015 \{published data only\}}

Jordan ET, Bushar JA, Kendrick JS, Johnson P, Wang J. Encouraging influenza vaccination among Text4baby pregnant women and mothers. American Journal of Preventive Medicine 2015;49(4):563-72.

\section{Kenyon 2012 \{published data only\}}

Kenyon S, Jolly K, Hemming K, Ingram L, Gale N, Dann SA, et al. Evaluation of lay support in pregnant women with social risk (ELSIPS): a randomised controlled trial. BMC Pregnancy Childbirth 2012;12:11.

\section{Kenyon 2016 \{published data only\}}

Kenyon S, Jolly K, Hemming K, Hope L, Blissett J, Dann SA, et al. Lay support for pregnant women with social risk: a randomised controlled trial. BMJ Open 2016;6(3):e009203.

\section{Kumar 2014 \{published data only\}}

Kumar R. Effective messages in vaccine promotion: a randomised trial: public health viewpoint. Indian Pediatrics 2014; Vol. 51, issue 6:493.

\section{Kuppuswamy 2016 \{published data only\}}

Kuppuswamy V, Summer A, Logan S, Sridhar J, O'Brien E, Raganathan D, et al. Effect of a home-based intervention by trained community health nurses on immunization rates, exclusive breastfeeding, growth parameters, and hospitalizations for respiratory and diarrheal illness - a pilot randomized controlled trial. Annals of Global Health 2016;82(3):323.

\section{Mathew 2014 \{published data only\}}

Mathew JL. Effective messages in vaccine promotion: a randomised trial: evidence based medicine viewpoint. Indian Pediatrics 2014;51(6):491-2.

\section{Meghea 2013 \{published data only\}}

Meghea Cl, Li B, Zhu Q, Raffo JE, Lindsay JK, Moore JS, et al. Infant health effects of a nurse-community health worker home visitation programme: a randomized controlled trial. Child: Care, Health and Devevelopment 2013;39(1):27-35.

\section{Mohan 2014 \{published data only\}}

Mohan P. Effective messages in vaccine promotion: a randomised trial: public policy viewpoint. Indian Pediatrics 2014;51(6):492.

\section{More 2017 \{published data only\}}

More NS, Das S, Bapat U, Alcock G, Manjrekar S, Kamble V, et al. Community resource centres to improve the health of women and children in informal settlements in Mumbai: a cluster-randomised, controlled trial. Lancet Global Health 2017;5(3):e335-49.

\section{Nyhan 2014 \{published data only\}}

Nyhan B, Reifler J, Richey S, Freed GL. Effective messages in vaccine promotion: a randomized trial. Pediatrics 2014;133(4):E835-42.

\section{Pati 2015 \{published data only\}}

Pati S, Ladowski KL, Wong AT, Huang J, Yang J. An enriched medical home intervention using community health workers improves adherence to immunization schedules. Vaccine 2015;33(46):6257-63.

\section{Persson 2013 \{published data only\}}

Persson LA, Nga NT, Malqvist M, Thi Phuong Hoa D, Eriksson L, Wallin L, et al. Effect of facilitation of local maternal-and-newborn stakeholder groups on neonatal mortality: cluster-randomized controlled trial. PLoS Medicine 2013;10(5):e1001445.

\section{Sadler 2013 \{published data only\}}

Sadler LS, Slade A, Close N, Webb DL, Simpson T, Fennie K, et al. Minding the Baby: Enhancing reflectiveness to improve early health and relationship outcomes in an interdisciplinary home visiting program. Infant Mental Health Journal 2013;34(5):391-405.

\section{Sege 2015 \{published data only\}}

Sege R, Preer G, Morton SJ, Cabral H, Morakinyo O, Lee V, et al. Medical-legal strategies to improve infant health care: a randomized trial. Pediatrics 2015;136(1):97-106.

\section{Shah 2013 \{published data only\}}

Shah More N, Das S, Bapat U, Rajguru M, Alcock G, Joshi W, et al. Community resource centres to improve the health of women and children in Mumbai slums: study protocol for a cluster randomized controlled trial. Trials 2013;14:132. 
Shrestha 2016 \{published data only\}

Shrestha S, Adachi K, Petrini MA, Shrestha S, Rana Khagi B. Development and evaluation of a newborn care education programme in primiparous mothers in Nepal. Midwifery 2016;42:21-8.

\section{Williams 2013 \{published data only\}}

Williams SE, Rothman RL, Offit PA, Schaffner W, Sullivan M, Edwards KM. A randomized trial to increase acceptance of childhood vaccines by vaccine-hesitant parents: a pilot study. Academic Pediatrics 2013;13(5):475-80.

Witteman 2015 \{published data only\} Witteman HO, Chipenda Dansokho S, Exe N, Dupuis A, Provencher T, Zikmund-Fisher BJ. Risk communication, values clarification, and vaccination decisions. Risk Analysis 2015;35(10):1801-19.

\section{Zimmerman 2014 \{published data only\}}

Zimmerman RK, Nowalk MP, Lin CJ, Hannibal K, Moehling KK, Huang $\mathrm{HH}$, et al. Cluster randomized trial of a toolkit and early vaccine delivery to improve childhood influenza vaccination rates in primary care. Vaccine 2014;32(29):3656-63.

\section{References to ongoing studies}

JPRN-UMIN000012575 \{published data only (unpublished sought but not used)\}

A randomized control study to investigate the effectiveness of childhood immunisation education program for parents in the perinatal period. Ongoing study 18 December 2013.

\section{NCT02666872 \{published and unpublished data\}}

Evaluation of a new educational strategy promoting vaccination in maternity in Quebec based on motivational interviewing techniques: PROMOVAQ study. Ongoing study June 2013.

\section{NCT02984007 \{published and unpublished data\}}

Addressing vaccine hesitancy: Pan-Canadian validation of an effective strategy (PROMOtion of VAccination in Canada (PROMOVAQ Study)). Ongoing study March 25, 2017.

\section{Additional references}

\section{Ajzen 1985}

Ajzen I. From intentions to actions: a theory of planned behavior. In: Kuhl J, Beckmann J editor(s). Action Control: From Cognition to Behavior. Berlin: Springer-Verlag, 1985:11-39.

\section{Ajzen 1991}

Ajzen I. The theory of planned behavior. Organizational Behavior and Human Decision Processes 1991;50(2):179-211.

\section{Ames 2017}

Ames H, Glenton C, Lewin S. Parents' and informal caregivers' views and experiences of communication about routine childhood vaccination: a synthesis of qualitative evidence. Cochrane Database of Systematic Reviews 2017, Issue 2. [DOI: 10.1002/14651858.CD011787.pub2]

\section{Bandura 1986}

Bandura A. Social Foundations of Thought and Action: A Social Cognitive Theory. Englewood Cliffs, NJ: Prentice-Hall, 1986.

\section{Barrett 2016}

Barrett P, Chaintarli K, Ryan F, Cotter S, Cronin A, Carlton $L$, et al. An ongoing measles outbreak linked to a suspected imported case, Ireland, April to June 2016. Euro Surveillance 2016;21(27):30277. [DOI: 10.2807/1560-7917.ES.2016.21.27.30277]

\section{Bartu 2006}

Bartu A, Sharp J, Ludlow J, Doherty DA. Postnatal home visiting for illicit drug-using mothers and their infants: a randomised controlled trial. Australian and New Zealand Journal of Obstetrics and Gynaecology 2006; Vol. 46, issue 5:419-26.

\section{Bekker 2003}

Bekker HL, Gough D, Williams M. Attendance choices about the influenza immunization programme: evidence for targeting patients' beliefs. Psychology, Health \& Medicine 2003;8(3):279-87

\section{Brennan 2009}

Brennan S, McKenzie J, Whitty P, Buchan H, Green S. Continuous quality improvement: effects on professional practice and healthcare outcomes. Cochrane Database of Systematic Reviews 2009, Issue 4. [DOI: 10.1002/14651858.CD003319.pub2]

\section{Breuer 2015}

Breuer E, Lee L, De Silva M, Lund C. Using theory of change to design and evaluate public health interventions: a systematic review. Implementation Science 2016;11:63.

\section{Brewer 2017}

Brewer NT, Hall ME, Malo TL, Gilkey MB, Quinn B, Lathren C. Announcements versus conversations to improve HPV vaccination coverage: a randomized trial. Pediatrics 2017;139(1):e20161764.

\section{Bright 2017}

Bright T, Felix L, Kuper H, Polack S. A systematic review of strategies to increase access to health services among children in low and middle income countries. BMC Health Services Research 2017;17(1):252.

\section{Britt 2016}

Britt H, Miller GC, Bayram C, Henderson J, Valenti L, Harrison C, et al. A Decade of Australian General Practice Activity 2006-07 to 2015-16. General Practice Series Number 41. Sydney: Sydney University Press, 2016. [ Available at purl.library.usyd.edu.au/ sup/9781743325155]

\section{Brown 2010}

Brown KF, Kroll JS, Hudson MJ, Ramsay M, Green J, Long SJ, et al. Factors underlying parental decisions about combination childhood vaccinations including MMR: a systematic review. Vaccine 2010;28(26):4235-48. 


\section{Brown 2012}

Brown KF, Long SJ, Ramsay M, Hudson MJ, Green J, Vincent CA, et al. U.K. parents' decision-making about measles-mumpsrubella (MMR) vaccine 10 years after the MMR-autism controversy: a qualitative analysis. Vaccine 2012;30(10):1855-64.

\section{2016}

CCC (Cochrane Consumers, Communication). Data Extraction Template for Cochrane Reviews, Version 1.8. cccrg.cochrane.org/author-resources (accessed 30 November 2017).

\section{CDC 2012}

Centers for Disease Control and Prevention, National Center for Immunization and Respiratory Diseases. Immunization: The Basics. 2012. www.cdc.gov/vaccines/vac-gen/imzbasics.htm\#terms (accessed 14 February 2013).

\section{Champion 2008}

Champion VL, Skinner CS. The Health Belief Model. In: Glanz K, Rimer BK, Viswanath K editor(s). Health Behavior and Health Education: Theory, Research and Practice. 4th Edition. San Francisco (CA): John Wiley \& Sons, Inc., 2008:45-66.

\section{Clift 2001}

Clift E. Information, Education and Communication: Lessons From the Past; Perspectives for the Future. Geneva: World Health Organization, 2001.

\section{Cohen 1988}

Cohen J. Statistical Power Analysis in the Behavioral Sciences. 2nd Edition. Hillsdale (NJ): Lawrence Erlbaum Associates, Inc., 1988.

\section{Connors 2017}

Connors JT, Slotwinski KL, Hodges EA. Provider-parent communication when discussing vaccines: a systematic review. Journal of Pediatric Nursing 2017;33(March-April):10-5.

\section{Corace 2016}

Corace KM, Srigley JA, Hargadon DP, Yu D, MacDonald TK, Fabrigar LR, et al. Using behavior change frameworks to improve healthcare worker influenza vaccination rates: $\mathrm{A}$ systematic review. Vaccine 2016;34(28):3235-42.

\section{Coulter 2007}

Coulter A, Ellins J. Effectiveness of strategies for informing, educating, and involving patients. BMJ 2007;335:24-7.

\section{Craig 2008}

Craig P, Dieppe P, Macintyre S, Michie S, Nazareth I, Petticrew M. Developing and evaluating complex interventions: the new Medical Research Council guidance. BMJ 2008;337:a1655.

\section{daCosta 2005}

daCosta M, DiBonaventura MD, Chapman GB. Moderators of the intention-behavior relationship in influenza vaccinations: Intention stability and unforeseen barriers. Psychology \& Health 2005;20(6):761-74.

\section{Dubé 2014}

Dubé È, Gagnon D, Nickels E, Jeram S, Schuster M. Mapping vaccine hesitancy - country-specific characteristics of a global phenomenon. Vaccine 2014;32(49):6649-54.

\section{Dubé 2015}

Dubé È, Vivion M, MacDonald NE. Vaccine hesitancy, vaccine refusal and the anti-vaccine movement: influence, impact and implications. Expert Review of Vaccines 2015;14(1):99-117.

\section{Dubé 2016}

Dubé È, Gagnon D, Ouakki M, Bettinger JA, Guay M, Halperin S, et al. Understanding vaccine hesitancy in Canada: results of a consultation study by the Canadian Immunization Research Network. PLOS ONE 2016;11:1-16.

\section{Dwamena 2012}

Dwamena F, Holmes-Rovner M, Gaulden CM, Jorgenson S, Sadigh G, Sikorskii A, et al. Interventions for providers to promote a patient-centred approach in clinical consultations. Cochrane Database of Systematic Reviews 2012, Issue 12. [DOI: 10.1002/14651858.CD003267.pub2]

\section{Esposito 2014}

Esposito S, Principi N, Cornaglia G. Barriers to the vaccination of children and adolescents and possible solutions. Clinical Microbiology and Infection 2014;20(Suppl. 5):25-31.

\section{Filia 2017}

Filia A, Bella A, Del Manso M, Baggieri M, Magurano F, Rota MC. Ongoing outbreak with well over 4000 measles cases in Italy from January to end August 2017 - what is making elimination so difficult?. Euro Surveillance 2017;22(37):30614.

\section{Foster 2007}

Foster G, Taylor SJC, Eldridge S, Ramsay J, Griffiths CJ. Selfmanagement education programmes by lay leaders for people with chronic conditions. Cochrane Database of Systematic Reviews 2007, Issue 4. [DOI: 10.1002/14651858.CD005108.pub2]

\section{Freed 2011}

Freed GL, Clark SJ, Butchart AT, Singer DC, Davis MM. Sources and perceived credibility of vaccine-safety information for parents. Pediatrics 2011;127(Suppl 1):S107-12.

\section{Goldstein 2015}

Goldstein S, MacDonald NE, Guirguis S, Sage Working Group on Vaccine Hesitancy. Health communication and vaccine hesitancy. Vaccine 2015;33(34):4212-4.

\section{Grammens 2017}

Grammens T, Schirvel C, Leenen S, Shodu N, Hutse V, Mendes da Costa $\mathrm{E}$, et al. Ongoing measles outbreak in Wallonia, Belgium, December 2016 to March 2017: characteristics and challenges. Euro Surveillance 2017;22(17):30524.

\section{Green 1990}

Green LW, Kreuter MW. Health promotion as a public health strategy for the 1990s. Annual Review of Public Health 1990;11:319-34. 


\section{Harvey 2015}

Harvey H, Reissland N, Mason J. Parental reminder, recall and educational interventions to improve early childhood immunisation uptake: a systematic review and meta-analysis. Vaccine 2015;33(25):2862-80.

\section{Health Canada 2012}

Health Canada. Awareness Campaign Ideas. 2012. immunize.ca/ uploads/niaw2012/awareness_campaign_ideas_e.pdf (accessed 30 April 2012).

\section{Higgins 2011}

Higgins JPT, Deeks JJ, Altman DG. Chapter 16: Special topics in statistics. In: Higgins JP, Green S, editor(s). Cochrane Handbook for Systematic Reviews of Interventions Version 5.1.0 (updated March 2011). The Cochrane Collaboration, 2011. Available from handbook.cochrane.org.

\section{Higgins 2011a}

Higgins JPT, Green S, editor(s). Cochrane Handbook for Systematic Reviews of Interventions Version 5.1.0 (updated March 2011). The Cochrane Collaboration, 2011. Available from handbook.cochrane.org.

\section{Hill 2011}

Hill S, Draper M. A new conceptual framework for advancing evidence-informed communication and participation. In: Hill S editor(s). The Knowledgeable Patient: Communication And Participation in Health. UK: Wiley Blackwell, 2011:12-26.

\section{Hoffman 2014}

Hoffmann TC, Glasziou PP, Boutron I, Milne R, Perera Rafael, Moher D, et al. Better reporting of interventions: template for intervention description and replication (TIDieR) checklist and guide. BMJ 2014;348:g1687.

\section{Hoving 2010}

Hoving C, Visser A, Mullen PD, van den Borne B. A history of patient education by health professionals in Europe and North America: from authority to shared decision making education. Patient Education and Counseling 2010;78:275-81.

\section{IUHPE 2009}

IUHPE (International Union for Health Promotion and Education). Making a difference to global health. 2009. www.iuhpe.org/index.html?page=5\&lang=en (accessed 30 April 2012).

\section{Janz 1984}

Janz NK, Becker MH. The Health Belief Model: a decade later. Health Education Quarterly 1984;11(1):1-47.

\section{Jarrett 2015}

Jarrett C, Wilson R, O'Leary M, Eckersberger E, Larson HJ, Eskola J, et al. Strategies for addressing vaccine hesitancy - a systematic review. Vaccine 2015;33:4180-90.

\section{Johnson 2003 \\ Johnson A, Sandford J, Tyndall J. Written and verbal information versus verbal information only for patients being discharged from acute hospital settings to home.}

Cochrane Database of Systematic Reviews 2003, Issue 4. [DOI: 10.1002/14651858.CD003716]

\section{Jones 2012}

Jones AM, Omer SB, Bednarczyk RA, Halsey NA, Moulton LH, Salmon DA. Parents' source of vaccine information and impact on vaccine attitudes, beliefs, and nonmedical exemptions. Advances in Preventive Medicine 2012;2012:932741.

\section{Jones 2014}

Jones CJ, Smith H, Llewellyn C. Evaluating the effectiveness of health belief model interventions in improving adherence: a systematic review. Health Psychology Review 2014;8(3):253-69.

\section{Kaufman 2016}

Kaufman J, Ryan R, Bosch-Capblanch X, Cartier Y, Cliff J, Glenton C, et al. Outcomes mapping study for childhood vaccination communication: too few concepts were measured in too many ways. Journal of Clinical Epidemiology 2016;72:33-44.

\section{Kaufman 2017}

Kaufman J, Ryan R, Glenton C, Lewin S, Bosch-Capblanch X, Cartier Y, et al. Childhood vaccination communication outcomes unpacked and organized in a taxonomy to facilitate core outcome establishment. Journal of Clinical Epidemiology 2017;84(April):173-84.

\section{Kaufman 2017a}

Kaufman J, Ryan R, Lewin S, Bosch-Capblanch X, Glenton C, Cliff J, et al. Identification of preliminary core outcome domains for communication about childhood vaccination: an online Delphi survey. Vaccine 20 August 2017 [epub ahead of print]:S0264-410X(17)31094-0. [DOI: 10.1016/ j.vaccine.2017.08.027]

\section{Kaufman 2017b}

Kaufman J, Ryan R, Ames H, Bosch-Capblanch X, Cartier Y, Cliff J, et al. The comprehensive 'Communicate to Vaccinate' taxonomy of communication interventions for childhood vaccination in routine and campaign contexts. BMC Public Health 2017;17:423.

\section{Kaufmann 2009}

Kaufmann JR, Feldbaum H. Diplomacy and the polio immunization boycott in Northern Nigeria. Health Affairs 2009;28(4):1091-101.

\section{Leask 2011}

Leask J. Target the fence-sitters. Nature 2011;473(7348):443-5.

\section{Leask 2012}

Leask J, Kinnersley P, Jackson C, Cheater F, Bedford H, Rowles G. Communicating with parents about vaccination: a framework for health professionals. BMC Pediatrics 2012;12:154.

\section{Leask 2014}

Leask J, Willaby HW, Kaufman J. The big picture in addressing vaccine hesitancy. Human Vaccines and Immunotherapeutics 2014;10(9):2600-2. 


\section{Leask 2015}

Leask J, Kinnersley P. Physician communication with vaccinehesitant parents: the start, not the end, of the story. Pediatrics 2015;136(1):180-2.

\section{Lewin 2011}

Lewin S, Hill S, Abdullahi LH, de Castro Freire SB, Bosch-Capblanch X, Glenton C, et al. 'Communicate to vaccinate' (COMMVAC). building evidence for improving communication about childhood vaccinations in low- and middle-income countries: protocol for a programme of research. Implementation Science 2011;6:125.

\section{Ling 2012}

Ling CC, Lui LY, So WK. Do educational interventions improve cancer patients' quality of life and reduce pain intensity? Quantitative systematic review. Journal of Advanced Nursing 2012;68:511-20.

\section{Loke 2011}

Loke Y, Price D, Herxheimer A. Chapter 14: Adverse effects. In: Higgins JP, Green S, editor(s). Cochrane Handbook for Systematic Reviews of Interventions Version 5.1.0 (updated March 2011). The Cochrane Collaboration, 2011. Available from handbook.cochrane.org.

\section{Luyten 2016}

Luyten J, Beutels P. The social value of vaccination programs: beyond cost-effectiveness. Health Affairs 2016;35:212-8.

\section{May 2009}

May C, Finch T. Implementing, embedding, and integrating practices: an outline of Normalization Process Theory. Sociology 2009;43(3):535-54.

\section{McKenzie 2016}

McKenzie J, Ryan R, Di Tanna G. Cochrane Consumers and Communication Review Group: cluster randomised controlled trials. December 2016. cccrg.cochrane.org/author-resources (accessed 12 November 2017).

\section{Montaño 2008}

Montaño DE, Kasprzyk D. Theory of reasoned action, theory of planned behavior, and the integrated behavioral model. In: Glanz K, Rimer BK, Viswanath K editor(s). Health Behavior and Health Education: Theory, Research and Practice. 4th Edition. San Francisco (CA): John Wiley \& Sons, Inc., 2008:67-96.

\section{Moore 2015}

Moore GF, Audrey S, Barker M, Bond L, Bonell C, Hardeman W, et al. Process evaluation of complex interventions: Medical Research Council guidance. BMJ 2015;350:h1258.

\section{Murakami 2014}

Murakami H, Kobayashi M, Hachiya M, Khan ZS, Hassan SQ, Sakurada S. Refusal of oral polio vaccine in northwestern Pakistan: a qualitative and quantitative study. Vaccine 2014;32:1382-7.

\section{Nandy 2016}

Nandy R. Immunization under fire, UNICEF Connect. 2016. blogs.unicef.org/blog/immunization-under-fire/ (accessed 13 April 2017).

\section{NICE 2009}

National Institute for Health and Clinical Excellence (NICE). Reducing differences in the uptake of immunisations. 2009. publications.nice.org.uk/reducing-differences-in-the-uptakeof-immunisations-ph21/recommendations. National Health Service, (accessed 30 April 2012).

\section{Nutbeam 1998}

Nutbeam D. Health promotion glossary. Health Promotion International 1998;13:349-64.

\section{Nutbeam 2000}

Nutbeam D. Health literacy as a public health goal: a challenge for contemporary health education and communication strategies in the 21st century. Health Promotion International 2000;15:259-67.

\section{Nyhan 2015}

Nyhan B, Reifler J. Does correcting myths about the flu vaccine work? An experimental evaluation of the effects of corrective information. Vaccine 2015;33(3):459-64.

\section{Odone 2015}

Odone A, Ferrari A, Spagnoli F, Visciarelli S, Shefer A, Pasquarella $C$, et al. Effectiveness of interventions that apply new media to improve vaccine uptake and vaccine coverage. Human Vaccines \& Immunotherapeutics 2015;11(1):72-82.

\section{Opel 2013}

Opel DJ, Heritage J, Taylor JA, Mangione-Smith R, Salas HS, Devere $\mathrm{V}$, et al. The architecture of provider-parent vaccine discussions at health supervision visits. Pediatrics 2013;132(6):1037-46.

\section{Opel 2015}

Opel DJ, Mangione-Smith R, Robinson JD, Heritage J, DeVere V, Salas HS, et al. The influence of provider communication behaviors on parental vaccine acceptance and visit experience. American Journal of Public Health 2015;105(10):1998-2004.

\section{Oyo-Ita 2016}

Oyo-Ita A, Wiysonge CS, Oringanje C, Nwachukwu CE, Oduwole O, Meremikwu MM. Interventions for improving coverage of childhood immunisation in low- and middleincome countries. Cochrane Database of Systematic Reviews 2016, Issue 7. [DOI: 10.1002/14651858.CD008145.pub3]

\section{Ozawa 2012}

Ozawa S, Mirelman A, Stack ML, Walker DG, Levine OS. Costeffectiveness and economic benefits of vaccines in lowand middle-income countries: a systematic review. Vaccine 2012;31:96-108. 


\section{Petticrew 2011}

Petticrew M. When are complex interventions 'complex'? When are simple interventions 'simple'?. European Journal of Public Health 2011;21:397-8.

\section{Pigott 2013}

Pigott T, Shepperd S. Identifying, documenting, and examining heterogeneity in systematic reviews of complex interventions. Journal of Clinical Epidemiology 2013;66(11):1244-50.

\section{Prochaska 1994}

Prochaska JO, Redding CA, Harlow LL, Rossi JS, Velicer WF. The transtheoretical model of change and HIV prevention: a review. Health Education Quarterly 1994;21(4):471-86.

\section{Pálsdóttir 2008}

Pálsdóttir Á. Information behaviour, health self-efficacy beliefs and health behaviour in Icelanders' everyday life. Information Research 2008;13:paper 334.

\section{RevMan 2014 [Computer program]}

Nordic Cochrane Centre, The Cochrane Collaboration. Review Manager 5 (RevMan 5). Version 5.3. Copenhagen: Nordic Cochrane Centre, The Cochrane Collaboration, 2014.

\section{Rodriguez-Osorio 2008}

Rodriguez-Osorio CA, Dominguez-Cherit G. Medical decision making: paternalism versus patient-centered (autonomous) care. Current Opinion in Critical Care 2008;14:708-13.

\section{Ryan 2013}

Ryan R, Hill S, Prictor M, McKenzie J. Cochrane Consumers and Communication Review Group Study Quality Guide - May 2013. cccrg.cochrane.org/authorresources (accessed 30 November 2017).

\section{Ryan 2014}

Ryan R, Santesso N, Lowe D, Hill S, Grimshaw J, Prictor M, et al. Interventions to improve safe and effective medicines use by consumers: an overview of systematic reviews. Cochrane Database of Systematic Reviews 2014, Issue 4. [DOI: 10.1002/14651858.CD007768.pub3]

\section{Sadaf 2013}

Sadaf A, Richards JL, Glanz J, Salmon DA, Omer SB. A systematic review of interventions for reducing parental vaccine refusal and vaccine hesitancy. Vaccine 2013;31(40):4293-304.

\section{Saeterdal 2014}

Saeterdal I, Lewin S, Austvoll-Dahlgren A, Glenton C, MunabiBabigumira S. Interventions aimed at communities to inform and/or educate about early childhood vaccination. Cochrane Database of Systematic Reviews 2014, Issue 11. [DOI: 10.1002/14651858.CD010232.pub2]

\section{Salmon 2015}

Salmon DA, Dudley MZ, Glanz JM, Omer SB. Vaccine hesitancy: causes, consequences, and a call to action. Vaccine 2015;33:D66-71.

\section{Sawmynaden 2012}

Sawmynaden P, Atherton H, Majeed A, Car J. Email for the provision of information on disease prevention and health promotion. Cochrane Database of Systematic Reviews 2012, Issue 11. [DOI: 10.1002/14651858.CD007982.pub2]

\section{Schünemann 2011}

Schünemann H, Oxman A, Higgins J, Vist G, Glasziou P, Guyatt G. Chapter 11: Presenting results and 'Summary of findings' tables. In: Higgins JP, Green S, editor(s). Cochrane Handbook for Systematic Reviews of Interventions Version 5.1.0 (updated March 2011). The Cochrane Collaboration, 2011. Available from handbook.cochrane.org.

\section{Shahrabani 2009}

Shahrabani S, Benzion U, Yom Din G. Factors affecting nurses' decision to get the flu vaccine. The European Journal of Health Economics 2009;10(2):227-31.

\section{Sheedy 2011}

Sheedy K. Communicating about Infant Immunizations: Translating Research into Practice. www.health.state.mn.us/ divs/idepc/immunize/conference/ksheedy.pdf. Minnesota, (accessed 12 April 2012).

\section{Smith 2008}

Smith MJ, Ellenberg SS, Bell LM, Rubin DM. Media coverage of the measles-mumps-rubella vaccine and autism controversy and its relationship to MMR immunization rates in the United States. Pediatrics 2008;121(4):e836-43.

\section{Smith 2015}

Smith MJ. Promoting vaccine confidence. Infectious Disease Clinics of North America 2015;29(4):759-69.

\section{Stacey 2017}

Stacey D, Légaré F, Lewis K, Barry MJ, Bennett CL, Eden KB, et al. Decision aids for people facing health treatment or screening decisions. Cochrane Database of Systematic Reviews 2017, Issue 4. [DOI: 10.1002/14651858.CD001431.pub5]

\section{Stovold 2014}

Stovold E, Beecher D, Foxlee R, Noel-Storr A. Study flow diagrams in Cochrane systematic review updates: an adapted PRISMA flow diagram. Systematic Reviews 2014;3:54.

\section{Sutter 2006}

Sutter RW, Maher C. Mass vaccination campaigns for polio eradication: an essential strategy for success. Current Topics in Microbiology and Immunology 2006;304:195-220.

\section{Söderlund 2011}

Söderlund A. The role of educational and learning approaches in rehabilitation of whiplash-associated disorders in lessening the transition to chronicity. Spine 2011;36:S280-5.

\section{Thomson 2016}

Thomson A, Robinson K, Vallee-Tourangeau G. The 5As: A practical taxonomy for the determinants of vaccine uptake. Vaccine 2016;34(8):1018-24 


\section{Townsville-Mackay 2013}

Townsville-Mackay Medicare Local. Status of measles cases in Australia up to 7 November 2013. www.tmml.com.au/assets/ files/health-alerts/Epi_Msles_in\%20Austr2013.pdf (accessed 11 February 2014).

\section{Ueffing 2012}

Ueffing E, Tugwell P, Welch V, Petticrew M, Kristjansson E. Equity Checklist for Systematic Review Authors Version 2012-10-02. Campbell and Cochrane Equity Methods Group. http://equity.cochrane.org/sites/equity.cochrane.org/files/ uploads/EquityChecklist2012.pdf (accessed 27 April 2018).

\section{UN Millennium Project 2006}

UN Millennium Project. MDGs: What they are. 2006. www.unmillenniumproject.org/goals/index.htm (accessed 31 March 2017)

\section{UNICEF 2005}

UNICEF. Building trust and responding to adverse events following immunisation in South Asia: using strategic communication. 2005. www.unicef.org/immunization/files/ Immunisation_report_17May_05\%28final_editing_text\%29.pdf (accessed 24 April 2012).

\section{UNICEF 2014}

UNICEF, World Health Organization. Immunization Summary: A statistical reference containing data through 2013. www.who.int/immunization/monitoring_surveillance/ Immunization_Summary_2013.pdf (accessed 13 April 2017).

\section{United Nations 2008}

United Nations, World Health Organization. Fact sheet no. 31: The right to health. 2008. www.who.int/hhr/activities/ Right_to_Health_factsheet31.pdf (accessed 2 December 2013).

\section{WFPHA 2017}

WFPHA (World Federation of Public Health Associations). A table of definitions for public health education and training. www.wfpha.org/images/WFPHA_Defining_Education.pdf (accessed 5 December 2017).

\section{WHO 2007}

World Health Organization. People at the centre of health care: harmonizing mind and body, people and systems. 2007. www.wpro.who.int/publications/PUB_139789290613169/en/ index.html. Geneva: World Health Organization, (accessed 2 December 2013).

\section{WHO 2009}

World Health Organization. Global Immunization Vision and Strategy Goals. 2009. www.who.int/immunization/givs/goals/ en/ (accessed 31 March 2017).

\section{WHO 2012}

World Health Organization. Global Vaccine Action Plan 2011-2020. www.who.int/immunization/ global_vaccine_action_plan/en/2012:1-147.

\section{WHO 2016}

World Health Organization. Immunization coverage fact sheet. 2016. www.who.int/mediacentre/factsheets/fs378/en/ (accessed 11 October 2016).

\section{WHO 2018}

World Health Organization. Table 2: Summary of WHO position papers - recommended routine immunizations for children. (updated April 2018). www.who.int/immunization/policy/ Immunization_routine_table2.pdf (accessed 27 April 2018):1-11.

\section{WHO SAGE Working Group on Vaccine Hesitancy 2014}

WHO SAGE Working Group on Vaccine Hesitancy. Report of the SAGE Working Group on Vaccine Hesitancy. 2014. www.who.int/ immunization/sage/meetings/2014/october/SAGE_working group_revised_report_vaccine_hesitancy.pdf (accessed 12 September 2016).

\section{WHO SAGE Working Group on Vaccine Hesitancy 2014a}

WHO SAGE Working Group on Vaccine Hesitancy. Strategies for addressing vaccine hesitancy - a systematic review. 2014. www.who.int/immunization/sage/meetings/2014/october/3_ SAGE_WG_Strategies_addressing_vaccine_hesitancy_ 2014.pdf. World Health Organization, (accessed 9 February 2016).

\section{Williams 2002}

Williams A, Forrest J. Immunisation: communication and perception of risk. Summary of a workshop held in Melbourne, Australia. 2002. www.ncirs.edu.au/publications/2003/riskperception-wshop.pdf (accessed 6 May 2012).

\section{Williams 2014}

Williams SE. What are the factors that contribute to parental vaccine-hesitancy and what can we do about it?. Human Vaccines \& Immunotherapeutics 2014;10(9):2584-96.

\section{Willis 2013}

Willis N, Hill S, Kaufman J, Lewin S, Kis-Rigo J, De Castro Freire SB, et al. "Communicate to vaccinate": the development of a taxonomy of communication interventions to improve routine childhood vaccination. BMC International Health and Human Rights 2013;13(1):23.

\section{Zipprich 2015}

Zipprich J, Winter K, Hacker J, Xia D, Watt J, Harriman K, et al. Measles outbreak - California, December 2014 to February 2015. MMWR Morbidity \& Mortality Weekly Report 2015;64(6):153-4.

\section{Zyngier 2011}

Zyngier S, D'Souza C, Robinson P, Schlotterlein M. Knowledge transfer: examining a public vaccination initiative in a digital age. 44th Hawaii International Conference on System Sciences (HICSS); 2011 Jan 4-7; Kauai (HI). IEEE, 2011. [DOI: 10.1109/ HICSS.2011.277] 


\section{References to other published versions of this review}

\section{Kaufman 2012}

Kaufman J, Synnot A, Hill S, Willis N, Horey D, Lin V, et al. Face to face interventions for informing or educating parents about early childhood vaccination. Cochrane Database of Systematic Reviews 2012, Issue 8. [DOI: 10.1002/14651858.CD010038]

\section{CHARACTERISTICS OF STUDIES}

Characteristics of included studies [ordered by study ID]

\section{Kaufman 2013}

Kaufman J, Synnot A, Ryan R, Hill S, Horey D, Willis N, et al. Face to face interventions for informing or educating parents about early childhood vaccination. Cochrane Database of Systematic Reviews 2013, Issue 5. [DOI: 10.1002/14651858.CD010038.pub2]

* Indicates the major publication for the study

Bjornson 1997

Methods Study design: cluster randomised controlled trial

Study duration: not described

Study arms: intervention - oral presentation; Control - video education (see Notes)

Participants

Setting:

Region, country and income level: Richmond and Vancouver, British Columbia, Canada (high income)

Vaccine programme delivery description (routine or mass campaign): routine

Degree of regional development: urban

Participants:

Parents

Inclusion and exclusion criteria for participation in study: no explicit inclusion or exclusion criteria stated. However, men and women attending prenatal classes were invited to take part, and non-English speakers were excluded from the analysis.

Categorisation (mothers, fathers, parents, expectant parents, guardians): expectant parents

Number randomised to intervention: $\mathrm{N}=99$ (number of clusters unknown)

Number randomised to control: $\mathrm{N}=128$ (number of clusters unknown)

Total number randomised: 16 clusters containing 227 participants

Number lost to follow-up, withdrawn from intervention: nil

Number lost to follow-up, withdrawn from control: nil

Age range: not described

Gender: male (44.9\%); female (54.6\%); unknown (0.4\%)

Ethnicity: not described

Religion: not described

Language(s) spoken: English

Household or family size: other children in household (4.8\%)

Level of education or literacy: not described

Socioeconomic status: not formally reported but authors stated that the classes encompassed a wide range of socioeconomic groups. 
Bjornson 1997 (Continued)

Employment status: not described

Children

Age range and categorisation (infant, preschool-aged children, school aged children): study included expectant parents, therefore no children were included.

Gender: not applicable

Interventions

Intervention purpose: to inform parents about childhood immunisation

Deliverer: nurse

Format or delivery mode: 8-minute group oral presentation with no visual props

Content of communication: discussion of five vaccine-preventable diseases (diphtheria, tetanus, pertussis, polio, and haemophilus influenzae type b); risks, benefits, and side effects of immunisation; and use of acetaminophen (analgesic). The script was written at a grade 6 English comprehension level. The presenters tried hard to make each presentation identical in content.

Vaccine or vaccines delivered or described: diphtheria, tetanus, pertussis, polio, and haemophilus influenzae type $b$

Direction of communication: nurse presented to parents

Group or individual: group

Where the intervention took place: antenatal classes

Frequency or timing of communication: intervention delivered once

Training required for intervention: the presenters were experienced nurses, chosen for their skills with individual counselling, but they were not experienced as group presenters or tutors. The presentation was scripted by the investigators, with input from the presenters to ensure that the wording felt natural.

Theoretical basis for intervention: not described

Cost of intervention: authors describe video production as 'inexpensive' as it was produced using the hospital's photography services rather than a professional videographer.

Intervention quality: the content of the oral presentations was standardised between the three nursing staff. The accuracy of the presentation was confirmed by four experts in childhood immunisation. The authors reported that there was a high degree of 'completeness and consistency' in the oral presentations, as they were intended to represent the 'gold standard' rather than standard practice.

Fidelity or integrity: not described

Details of control, usual, or routine care: 14-minute educational video, which followed the content of the oral presentations and featured the same presenter. The video separately described each disease, the vaccines, and risks of immunisation. It was produced with professional assistance and designed to mimic a counselling visit between a healthcare professional and a parent. Visual images were used to enhance the description of the infections (i.e. pictures of affected children). It also featured a 'commonly asked questions' segment, which was not matched in the oral presentations.

Details of co-interventions in all groups: none described

Definition of immunisation status used by authors: not applicable

Description of outcome assessment tool: 20 -item questionnaire including 4 demographic questions. The questions were modelled on a previous study conducted by the authors and were predominantly formatted as true or false. The questions related to the vaccine-preventable diseases, immunisation 
side effects, doses, use of acetaminophen, need for boosters, and whether the benefits of immunisation outweighed the risks.

Timing of outcome assessment: immediately pre- and post-intervention delivery

Secondary outcomes measured: none

Notes

In this study, the intervention was an educational video (passive intervention) while the control was an oral presentation. For the purposes of this review, we re-labelled the oral presentation as the intervention, and the video as the control.

Sample size: 80 participants per group were needed to detect a difference of $20 \%$ with $80 \%$ power.

Contact with author: yes, information clarifying randomisation method, allocation concealment, training required to deliver intervention, and cost of video intervention received.

\section{Risk of bias}

\begin{tabular}{|c|c|c|}
\hline Bias & Authors' judgement & Support for judgement \\
\hline $\begin{array}{l}\text { Random sequence genera- } \\
\text { tion (selection bias) }\end{array}$ & Low risk & $\begin{array}{l}\text { Authors stated that randomisation was achieved using a random numbers ta- } \\
\text { ble, in balanced blocks. }\end{array}$ \\
\hline $\begin{array}{l}\text { Allocation concealment } \\
\text { (selection bias) }\end{array}$ & Low risk & $\begin{array}{l}\text { Presentation assignments were placed in sealed envelopes for each class. The } \\
\text { nurse presenter opened the envelope upon arrival at the class. Through cor- } \\
\text { respondence, authors confirmed that envelopes were prepared by a separate } \\
\text { person (statistician), ensuring the blindness of the presenter. }\end{array}$ \\
\hline $\begin{array}{l}\text { Blinding of participants } \\
\text { and personnel (perfor- } \\
\text { mance bias) } \\
\text { All outcomes }\end{array}$ & High risk & Participants and personnel could not be blinded. \\
\hline $\begin{array}{l}\text { Blinding of outcome as- } \\
\text { sessment (detection bias) } \\
\text { All outcomes }\end{array}$ & High risk & $\begin{array}{l}\text { Outcome measure was self-reported, therefore outcome assessors could not } \\
\text { be blinded. }\end{array}$ \\
\hline $\begin{array}{l}\text { Incomplete outcome data } \\
\text { (attrition bias) } \\
\text { All outcomes }\end{array}$ & Low risk & No loss to follow-up \\
\hline $\begin{array}{l}\text { Selective reporting (re- } \\
\text { porting bias) }\end{array}$ & Unclear risk & $\begin{array}{l}\text { No published protocol was mentioned. The authors reported all outcomes and } \\
\text { analyses as identified, with the exception of the mean pre- and post-test total } \\
\text { scores between groups. }\end{array}$ \\
\hline Other bias & High risk & The authors did not account for the effects of clustering in the analysis. \\
\hline $\begin{array}{l}\text { Selective recruitment of } \\
\text { participants (cluster-RCTs) }\end{array}$ & Low risk & $\begin{array}{l}\text { Classes were unaware of their group assignment until the nurse arrived at the } \\
\text { class and opened the envelope. The authors did not describe when the partic- } \\
\text { ipants were asked to join the trial, but participants were asked to attend their } \\
\text { session } 30 \text { minutes early in order to take part. This implied that consent was } \\
\text { obtained prior to the group allocations being revealed. }\end{array}$ \\
\hline
\end{tabular}

Bolam 1998

Methods $\quad \begin{aligned} & \text { Study design: randomised controlled trial } \\ & \text { Study duration: } 19 \text { months }\end{aligned}$

Face-to-face interventions for informing or educating parents about early childhood vaccination (Review) 
Bolam 1998 (Continued)

Study arms: Group A - education at birth and 3 months post-partum; Group B - education at birth only; Group C - education at 3 months post-partum only; Group D - no education (control)

Setting:
Country and income level: Kathmandu, Nepal (low income)
Vaccine programme delivery description (routine or mass campaign): routine
Degree of regional development: one peri-urban and one urban area
Participants:
Parents

Inclusion and exclusion criteria for participation in study: all pregnant women residing in the target areas and admitted to the study hospital for delivery were eligible. No explicit exclusion criteria were stated.

Categorisation (mothers, fathers, parents, expectant parents, guardians): mothers

Number randomised to intervention: Group A ( $N=135)$; Group B ( $=135)$; Group C ( $N=135)$

Number randomised to control: $\mathrm{N}=135$

Total number randomised: $\mathrm{N}=540$

Number lost to follow-up or withdrawn from intervention: Group A: at 3 months $N=38(28 \%)$; at 6 months N $=41(30 \%)$. Group B: at 3 months N $=27(20 \%)$; at 6 months N $=30(22 \%)$. Group C: at 3 months $\mathrm{N}=37(24 \%)$; at 6 months $\mathrm{N}=39(29 \%)$.

Number lost to follow-up or withdrawn from control: at 3 months $N=35(26 \%)$; at 6 months $N=37$ (27\%).

Age range: mean overall age: 23.4 years (SD 4.0 years)

Gender: female

Ethnicity: not described

Religion: not described

Language(s) spoken: Nepali and Newari

Household or family size: not described

Level of education or literacy: literacy level - illiterate (28\%); primary level literate (24\%); secondary and above level literate $(49 \%)$

Socioeconomic status: husband's monthly income - low $<\$ 20(5 \%)$; medium $\$ 20$ to $\$ 100(81 \%)$; high > \$100 (15\%)

Employment status: housewife (83\%); other (15\%)

Children

Age range and categorisation (infants, preschool-aged children, school aged children): 0 to 6 months (infants)

Gender: male (49\%); female (51\%)

Deliverer: two midwives and one community health worker 
Format or delivery mode: 20-minute interactive educational session. Mothers were asked and responded to questions to facilitate interaction. Discussion followed, and at the end of each session, the educator repeated the key messages and asked if the mothers had further questions. Sessions were supplemented with illustrations on a cloth flip chart.

Content of communication: the health educator delivered key messages about breast feeding, family planning, diarrhoea and acute respiratory infection, the importance of immunisation, and where to go for injections.

Vaccine or vaccines delivered or described: BCG, DP, OPV

Direction of communication: interactive; mothers asked questions, followed by discussion led by educator

Group or individual: individual

Where the intervention took place: the first session took place in a quiet room at the hospital; the second session took place in the mother's home.

Frequency or timing of communication: Group A - education at birth and 3 months post-partum; Group $B$ - education at birth only; Group C - education at 3 months post-partum only

Training required for intervention: health educators were trained, but the nature of the training was not described

Theoretical basis for intervention: not described

Cost of intervention: not described

Intervention quality: intervention was developed with hospital staff and consultants experienced in health education and women's development, and piloted with 20 mothers prior to delivery

Fidelity and integrity: health educators were monitored by the study's principal investigators to check that the content and style of delivery were appropriate, especially the level of interaction. Constructive feedback was given.

Details of control, usual, or routine care: no health education

Details of co-interventions in all groups: none described

Outcomes Primary outcomes measured: immunisation status of child

Definition of immunisation status used by authors: appropriate uptake of immunisation: at 3 months, BCG plus at least two doses of DP and OPV; at 6 months, BCG plus three doses of DP and OPV

Description of outcome assessment tool: parent interview

Timing of outcome assessment: 3 months post-partum and 6 months post-partum

Secondary outcomes measured: none

Notes

Sample size: authors hypothesised that $40 \%$ of the control and $60 \%$ of the intervention infants would be fully immunised by 6 months of age. They calculated a sample size of 107 mothers in each group (95\% Cl, $80 \%$ power). Ultimately, immunisation coverage was higher in both groups than the authors had anticipated, and their sample size was enough to detect the increase at $5 \%$ significance and $78 \%$ power.

Contact with author: yes, information clarifying randomisation method received

\section{Risk of bias}


Bolam 1998 (Continued)

Random sequence genera- Low risk Random sequence was generated by random numbers table.

tion (selection bias)

Mothers were randomised using restricted randomisation in blocks of 20. Each block consisted of random ordering of the numbers 0 to 19. Numbers 0 to 4,5 to 9,10 to 14 , and 15 to 19 were assigned to groups $A$ to $D$ respectively.

$\begin{array}{ll}\begin{array}{l}\text { Allocation concealment } \\ \text { (selection bias) }\end{array} & \begin{array}{l}\text { Allocation details were provided in sealed envelopes. The opacity of the en- } \\ \text { velopes was not described. The member of the research team who identified } \\ \text { mothers for assignment was not involved in their allocation. }\end{array}\end{array}$

Blinding of participants High risk Participants and personnel could not be blinded.

and personnel (perfor-

mance bias)

All outcomes

\begin{tabular}{|c|c|c|}
\hline $\begin{array}{l}\text { Blinding of outcome as- } \\
\text { sessment (detection bias) } \\
\text { All outcomes }\end{array}$ & Low risk & $\begin{array}{l}\text { The outcome assessors were blind to the assignment of participants at all as- } \\
\text { sessment time points. Thus, the assessment of the relevant outcome - immu- } \\
\text { nisation status - was blind. However, knowledge of respiratory infection and } \\
\text { diarrhoea, and use of contraception were self-reported. Therefore, these out- } \\
\text { come assessors (as they were the participants themselves) were not blind }\end{array}$ \\
\hline
\end{tabular}

$\begin{array}{ll}\begin{array}{l}\text { Incomplete outcome data } \\ \text { (attrition bias) }\end{array} & \text { High risk } \\ \text { All outcomes } & \begin{array}{l}\text { 25\% loss to follow-up at } 3 \text { months and } 27 \% \text { loss to follow-up at } 6 \text { months. The } \\ \text { main reason given for loss to follow-up was mothers moving back to their } \\ \text { parental home as part of cultural tradition. } 12 \text { were withdrawn due to stillborn } \\ \text { infants or later infant death. The authors stated that they used an intention-to- } \\ \text { treat analysis, but they excluded those lost to follow-up in the analysis. }\end{array}\end{array}$

\begin{tabular}{lll}
\hline $\begin{array}{l}\text { Selective reporting (re- } \\
\text { porting bias) }\end{array}$ & Unclear risk & $\begin{array}{l}\text { No published protocol was mentioned. Authors mentioned that they would } \\
\text { measure infant nutritional status as a secondary outcome, but did not report } \\
\text { results. }\end{array}$
\end{tabular}

Other bias Low risk Authors stated that an average of seven mothers were enrolled in the trial
each week, from 250 to 300 admissions, and the mothers were seen individually for the educational session, indicating low risk of contamination.

No baseline imbalance between groups or other apparent sources of bias

\begin{tabular}{ll} 
Methods & Study design: randomised controlled trial \\
& Study duration: 3 months (recruitment period) \\
& Study arms: intervention - face-to-face session; control - no education \\
\hline Participants & Setting: \\
Country and income level: China (high; 6 districts categorized into 3 SES strata (high, middle, and low) \\
by GDP) \\
Degree of regional development: developed province \\
Participants: \\
Parents \\
Inclusion and exclusion criteria for participation in study: pregnant women with deliveries in the partic- \\
ipating hospitals during recruitment period
\end{tabular}


Hu 2017 (Continued)

Categorisation (mothers, fathers, parents, expectant parents, guardians): expectant mothers

Number randomised to intervention: $\mathrm{N}=626$

Number randomised to control: $\mathrm{N}=626$

Total number randomised: $\mathrm{N}=1252$

Number lost to follow-up, withdrawn from intervention: $\mathrm{N}=208$

Number lost to follow-up, withdrawn from control: $\mathrm{N}=193$

Age range: Intervention $<20 \mathrm{~N}=38 ; 20$ to $30 \mathrm{~N}=254 ; 31+\mathrm{N}=126$. Control $<20 \mathrm{~N}=39 ; 20$ to $30 \mathrm{~N}=268$;

$31+\mathrm{N}=126$

Gender: female

Ethnicity: "Migrant was defined as the person who lived in a district other than their hometown (even if from the same province) but had no local registration of the current living place." Intervention - migrant $\mathrm{N}=226$; resident $\mathrm{n}=192$. Control - migrant $\mathrm{N}=231$; resident $\mathrm{N}=202$

Level of education or literacy: Intervention - junior high school or less $\mathrm{N}=39$; senior high school or technical school $\mathrm{N}=125$; college or above $\mathrm{N}=254$. Control - junior high school or less $\mathrm{N}=41$; senior high school or technical school $\mathrm{N}=132$; college or above $\mathrm{N}=260$

Socioeconomic status: Intervention - high N = 138; middle N = 140; low N = 140. Control - high N = 139; middle $\mathrm{N}=149$; low $\mathrm{N}=145$

Children

Age range and categorisation (infants, preschool-aged children, school aged children): infant

Gender: not reported

Interventions
Intervention purpose: to improve mothers' knowledge of vaccination and coverage and the completeness and the timeliness of National Immunisation Program vaccination of their infants

Deliverer: physicians of selected hospitals who played the role of the educator

Format or delivery mode: 15 minutes of one-on-one interactive vaccination educational session

Content of communication: the educational session included issues on the importance of vaccination, the schedule of vaccination, immunisation policy in China, immunisation doses, adverse reactions, and contradictions.

Vaccine or vaccines delivered or described: all NIP vaccines

Direction of communication: interactive

Group or individual: individual

Where the intervention took place: obstetric hospitals and hospitals

Training required for intervention: not described

Theoretical basis for intervention: not described

Cost of intervention: not described

Intervention quality: the session was prepared by the researchers from Zhejiang provincial Centres for Disease Control and Prevention. The validity and understanding of the session were assessed by the vaccination staff, physicians, and pregnant women from each selected district, and modifications were made to adapt to the local situations.

Fidelity or integrity: not described 
Hu 2017 (Continued)

Details of control, usual, or routine care: the participants in the control group did not receive any educational instructions

Details of co-interventions in all groups: not described

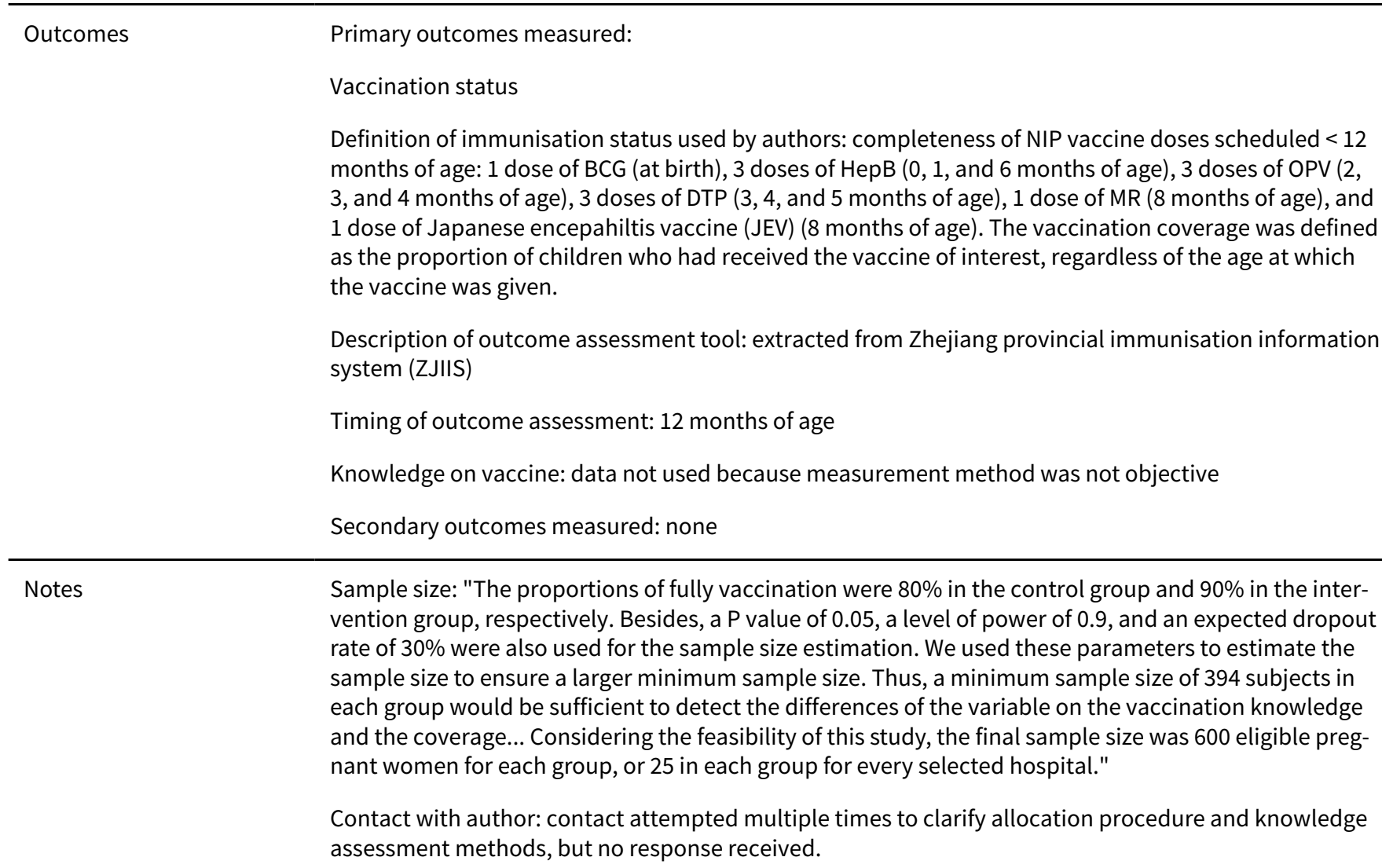

\section{Risk of bias}

\begin{tabular}{lll}
\hline Bias & Authors' judgement & Support for judgement \\
\hline $\begin{array}{l}\text { Random sequence genera- } \\
\text { tion (selection bias) }\end{array}$ & Low risk & Random sequence was generated by computer-generated randomisation list. \\
\hline $\begin{array}{l}\text { Allocation concealment } \\
\text { (selection bias) }\end{array}$ & Unclear risk & Authors contacted; unclear who performed allocation \\
\hline $\begin{array}{l}\text { Blinding of participants } \\
\text { and personnel (perfor- } \\
\text { mance bias) }\end{array}$ & High risk & Participants and personnel could not be blinded. \\
\hline $\begin{array}{l}\text { All outcomes } \\
\text { Blinding of outcome as- } \\
\text { sessment (detection bias) }\end{array}$ & Unclear risk & $\begin{array}{l}\text { The outcome assessors were not blinded. Immunisation status was objective- } \\
\text { ly assessed by reviewing the immunisation system records, so the risk of bias } \\
\text { for this outcome was low. Knowledge was assessed through a subjective self- } \\
\text { reported test, so the risk of bias for this outcome was high. }\end{array}$ \\
\hline $\begin{array}{l}\text { Incomplete outcome data } \\
\text { (attrition bias) } \\
\text { All outcomes }\end{array}$ & High risk & $\begin{array}{l}\text { Authors did not use an intention to treat analysis, and there was a relatively } \\
\text { high dropout rate (32\% dropout total). However, the dropout rate was similar } \\
\text { across groups (N = 208/626 from intervention; and } \mathrm{N}=193 / 626 \text { from control } \\
\text { groups) }\end{array}$ \\
\hline
\end{tabular}

Face-to-face interventions for informing or educating parents about early childhood vaccination (Review) 
Hu 2017 (Continued)

Selective reporting (re- $\quad$ Unclear risk $\quad$ No published protocol available
porting bias)

Other bias

Low risk

Baseline characteristics between the groups were similar. Risk of contamination was relatively low, though participants could have received information

from another source between the pre- and post-intervention surveys.

\section{Jackson 2011}

\section{Methods}

Study design: cluster randomised controlled trial

Study duration: recruitment occurred May to July 2006. The parent meeting was delivered eight times during July and August 2006. Follow-up was 3 months

Study arms: intervention - educational session plus leaflet; control - leaflet only

\section{Participants}

\section{Setting:}

Country and income level: England (high; 3 of 33 wards, selected to represent high-, medium-, and lowdeprived geographical areas)

Degree of regional development: not described

Participants:

Parents

Inclusion and exclusion criteria for participation in study: Clusters - primary healthcare centres with at least two medical practitioners selected by highest deprivation score. Childcare centres selected by largest size. Parents - English literate, with a child eligible for the first or second dose MMR vaccination (first dose was given at 13 months and the second dose between four and five and half years of age, so target age range was six months to five years.)

Categorisation (mothers, fathers, parents, expectant parents, guardians): parents

Number randomised to intervention: healthcare centres $N=3$; childcare centres $N=3$; parents $N=71$ ( $N$ $=68$ completed baseline survey)

Number randomised to control: healthcare centres $N=3$; childcare centres $N=3$; parents $N=71(N=67$ completed baseline survey)

Total number randomised: healthcare centres $N=6$; childcare centres $N=6$; parents $N=142$

Number lost to follow-up, withdrew from intervention: $\mathrm{N}=23$ did not receive intervention; $\mathrm{N}=13$ lost to follow-up for final time point

Number lost to follow-up, withdrew from control: $\mathrm{N}=7$ lost to follow-up for final time point

Age range: intervention 34.07 years \pm 5.43 ; control 34.06 years \pm 5.52

Gender: intervention female $N=67 ;$ male $N=4$. control female $N=67$; male $N=4$

Ethnicity: intervention - White British 68 (95.8\%); other 3 ( 4.2\%). control - White British 68 (95.8\%); other $3(4.2 \%)$

Level of education or literacy: intervention - left school at 16 years: 24 (33.8\%); left school at 18 years: 10 (14.1\%); achieved degree or higher: $37(52.1 \%)$. control - left school at 16 years 25: (35.2\%); left school at 18 years 10: (14.1\%); achieved degree or higher: $36(50.7 \%)$

Socioeconomic status: not described 
Jackson 2011 (Continued)

\section{Children}

Age range and categorisation (infants, preschool-aged children, school aged children): preschool-aged children

Mean age \pm SD of first (youngest) child eligible, months: intervention $25.73 \pm 14.66$. control $19.77 \pm 11.69$

Gender: not stated

Interventions

Intervention purpose: to provide parents with the opportunity to discuss MMR with other parents who are making an MMR decision; to provide information about MMR from a variety of perspectives; to introduce and practice one approach to supporting parents to ask questions about MMR of their healthcare practitioner

Deliverer: co-facilitated by a researcher and a parent facilitator. Parent facilitators were all female and recruited from local communities

Format or delivery mode: parent meeting including three components: provision of balanced information, a group discussion, and a coaching exercise. Mean of 6 participants per meeting

Content of communication: three parts. Group discussion provided opportunity to discuss any issues about MMR with other parents who were also making an MMR decision; Q\&A session provided opportunity to ask questions of the immunisation nurse specialist; Coaching exercise introduced and practiced one approach to supporting parents to ask questions about MMR in the primary care consultation (role playing exercise using question prompt sheet)

Vaccine or vaccines delivered or described: MMR

Direction of communication: interactive

Group or individual: group

Where the intervention took place: non-healthcare venues (e.g. community centres) close to participating healthcare centres and childcare organisations

Training required for intervention: parent facilitators received one half-day training

Theoretical basis for intervention: in line with fundamental tenets of health promotion, i.e. based on an 'engagement' model of communication where a key goal is empowerment

Cost of intervention: not described

Intervention quality: content and delivery of parent meeting informed by interviews with parents, systematic review of parents' decision-support needs, and two focus groups with parents

Fidelity and integrity: session was co-facilitated by a researcher at each meeting, which potentially kept the sessions consistent. 23/71 parents in intervention group did not attend an intervention meeting, so intervention was not delivered as intended to all those randomised to intervention group

Details of control, usual, or routine care: MMR leaflet only

Details of co-interventions in all groups: all participants received 'MMR - your questions answered' leaflet. Authors noted this leaflet was meant to be equivalent to usual care, but turned out to be more comprehensive than usual care (parents reported they were not normally given leaflets that were meant to be mandatory).

\section{Vaccination status}

Definition of immunisation status used by authors: receipt of MMR ('Since the study started, have you taken your child to have the combined MMR vaccine?')

Description of outcome assessment tool: postal questionnaire 
Timing of outcome assessment: three months post-intervention

Knowledge

Definition: knowledge about MMR

Description of outcome assessment tool: postal questionnaire, 11 questions (score 0 to 11 )

Timing of outcome assessment: one week and three months post-intervention

Attitudes or beliefs

Definition: attitude towards MMR, beliefs about vaccine necessity, concerns about MMR

Description of outcome assessment tool: one question about attitude (rate 1 to 7 ); four items assessing necessity beliefs (score 4 to 20); four items assessing concern beliefs (score 4 to 20)

Timing of outcome assessment: one week and three months post-intervention

Intention to vaccinate

Definition: intention to vaccinate child with MMR

Description of outcome assessment tool: postal questionnaire, 3 items on a 7-point scale, averaged over the three items

Timing of outcome assessment: one week and three months post-intervention

Adverse effects (anxiety)

Definition: anxiety from intervention

Description of outcome assessment: Short form State-Trait Anxiety Inventory (STAI) tool with 6 items scored 1 to 4 . Total score multiplied by $20 / 6$. A normal score is 34 to 36 .

Timing of outcome assessment: one week and three months post-intervention

Secondary outcomes measured: none

Sample size: "To achieve $80 \%$ power to detect a standardised effect size of 0.67 on the primary outcome of decisional conflict, using a two-sided t-test with significance level of 0.05 and an estimated intracluster correlation coefficient (ICC) of 0.05 (giving a design effect of 1.5 based on an average of 11 parents per cluster) required a sample size of 108 parents (54 in each group). Predicting $25 \%$ attrition, 73 parents were required in each group. Parent numbers were not balanced across the clusters. Based on our previous research, we estimated recruiting 12 parents per week over three months."

Contact with author: authors contacted to clarify sequence generation process and to identify any published protocol or trial record. No protocol available, and authors could not recall randomisation process but confirmed it was conducted by a statistician.

Other: authors conducted qualitative research alongside, determining that the intervention was feasible to deliver in non-healthcare, community venues, and it was acceptable to parents, with the majority expressing positive views

\section{Risk of bias}

\section{Bias}

Authors' judgement Support for judgement

Random sequence genera- Unclear risk tion (selection bias)
Authors describe using the 'sealed envelope' procedure but sequence generation was not described. Upon contact, authors noted that a statistician planned and performed randomisation, but could not confirm sequence generation method used. 
Quinlivan 2003 (Continued)

Participants:

Parents

Inclusion and exclusion criteria for participation in study: inclusion criteria - age younger than 18 years, ability to speak English, and intention to continue the pregnancy and keep the child. Exclusion criteria residence more than $150 \mathrm{~km}$ from hospital, or known fetal abnormality.

Categorisation (mothers, fathers, parents, expectant parents, guardians): mothers

Number randomised to intervention: $\mathrm{N}=65$

Number randomised to control: $\mathrm{N}=71$

Total number randomised: $\mathrm{N}=136$

Number lost to follow-up or withdrew from intervention: $\mathrm{N}=3$ ( 1 withdrew consent; 2 adverse neonatal outcomes)

Number lost to follow-up or withdrew from control: $\mathrm{N}=9$ (adverse neonatal outcomes)

Age range: mean (SD), years: intervention - 16.4 (0.96); control - 16.6 (0.90)

Gender: female

Ethnicity: Indigenous Australian: intervention - N = 21 (30\%); control - N = $12(18 \%)$

Religion: not described

Language(s) spoken: not described

Household or family size: not described

Level of education or literacy: not described

Socioeconomic status: socioeconomic status (\% low or destitute): intervention - N = 62 (88\%); control $\mathrm{N}=55(85 \%)$

Employment status: not described

Children

Age range and categorisation (infant, preschool-aged children, school aged children): 0 to 6 months (infants)

Gender: male: intervention: N = $41(57 \%)$ control: N = $29(45 \%)$

Deliverer: certified nurse-midwife

Format or delivery mode: series of structured home visits lasting 1 to 4 hours each (part of a multi-component intervention - see 'Details of co-interventions' below)

Content of communication: general parenting skills and maternal health topics were raised such as: breastfeeding, infant bonding, advice regarding contraceptive options, postnatal mood disorders, and alcohol and drug consumption. Vaccination advice and information were provided at the one-month visit. Parents were reminded about due vaccinations and were assisted in making appointments at the one-, two-, and four-month visits.

Vaccine or vaccines delivered or described: DTP, MMR, Hib, BCG, polio, and Hep B

Direction of communication: nurse to mother, with discussion

Group or individual: individual 
Quinlivan 2003 (Continued)

Where the intervention took place: at the mother's home

Frequency or timing of communication: visits at 1 week, 2 weeks, 1 month, 2 months, 4 months, and 6 months postpartum

Training required for intervention: not described

Theoretical basis for intervention: not described

Cost of intervention: not described

Intervention quality: not described

Fidelity or integrity: not described

Details of control, usual, or routine care: all participants received routine postnatal support, counselling, and information services from the hospital, including access to routine hospital and home visits. The control group also received a reminder for the follow-up visit at 6 months.

Details of co-interventions in all groups: reminders of when immunisations were due, assistance with making appointments, support

Outcomes

Primary outcomes measured: immunisation status. This outcome was measured in the trial but could not be reported in this review as the effects of the face-to-face education on immunisation status could not be isolated. The intervention was multi-component and included facilitating access and reminding parents of due immunisations.

Primary outcomes measured: knowledge or understanding of vaccination

Description of outcome assessment tool: a questionnaire delivered pre- and post-intervention designed to assess knowledge of contraception, vaccine schedule, and breastfeeding. The participant's answers were unprompted and were written down verbatim by a nurse, and were scored on a predefined scale by a researcher blinded to the girl's identity and allocation. Scores related to immunisation were out of ten. Three points for naming the triple antigen vaccines DTP and MMR, or one point for each condition named (diphtheria, tetanus, pertussis, measles, mumps, rubella). One point each for polio, Hib, Hep B, and BCG vaccines.

Timing of outcome assessment: pre-test conducted at enrolment, post-test conducted 6 months postpartum

Secondary outcomes measured: none

Notes

Sample size: 'We anticipated that baseline knowledge outcomes would be poor, with median scores of 2 in all categories. The sample size was calculated approximating parametric techniques, to be able to detect, with greater than $80 \%$ power, at a two-sided alpha error of 0.05 , an improvement in knowledge score from 2 to 3, assuming an SD of 2 . This power calculation indicated that 60 individuals needed to be enrolled to each group. Assuming a 10\% dropout rate, our target population was, therefore, 134 participants. Adverse neonatal outcomes of up to $18 \%$ have been reported, which is in line with our local experience. This sample size could detect a reduction in adverse outcomes to 5\%.'

Contact with author: yes, we received confirmation that data were presented in terms of median and IQR because they were skewed.

\section{Risk of bias}

\section{Bias \\ Authors' judgement Support for judgement}

Random sequence genera- Low risk

The randomisation sequence was generated by computer. tion (selection bias) 
Quinlivan 2003 (Continued)

Allocation concealment Low risk After delivery, a midwife who was not related to the study, visited each partici(selection bias) pant and randomised her to the intervention or control group. Allocation was concealed in numbered sealed opaque envelopes.

Blinding of participants High risk Participants and personnel could not be blinded.
and personnel (perfor-
mance bias)
All outcomes

Blinding of outcome as- Low risk sessment (detection bias) All outcomes

Incomplete outcome data Unclear risk (attrition bias)

All outcomes
Participant's answers were written down verbatim by the nurse, and were then scored on a pre-defined scale by a researcher, who was blinded to the participant's intervention

\begin{abstract}
Analysis was done on an intention-to-treat basis. All attrition was accounted for and was due to: withdrawn consent ( $\mathrm{N}=1$, intervention); neonatal death ( $N=1$ in intervention, $N=2$ in control); non-accidental injury ( $N=1$ in control); non-voluntary foster care of the neonate ( $N=1$ in intervention, $N=6$ in control). Total attrition from intervention was $\mathrm{N}=3$ (of $\mathrm{N}=65$ assigned) and $\mathrm{N}=9$ in control (of $\mathrm{N}=71$ assigned).

However, the rate of attrition due to non-voluntary foster care or non-accidental injury was higher in the control group than in the intervention group $(\mathrm{N}=1$ in the intervention (1.5\%); $\mathrm{N}=7$ in the control (9.8\%)). Missing data for these individuals may have had an effect on the overall control group scores, however, the effect of this was unclear.
\end{abstract}

\begin{tabular}{lll}
\hline $\begin{array}{l}\text { Selective reporting (re- } \\
\text { porting bias) }\end{array}$ & Unclear risk & No published protocol mentioned. \\
\hline Other bias & Unclear risk & $\begin{array}{l}\text { Baseline comparability: The number of Indigenous Australians in the interven- } \\
\text { tion group was } 30 \% \text { (21/71 participants) and } 18 \% \text { (12/65 participants) in the } \\
\text { control group. }\end{array}$ \\
\hline
\end{tabular}

\section{Saitoh 2013}

Study design: randomised controlled trial
Study duration: baseline surveys completed from June 2, 2011 to Aug 31,2011
Study arms: intervention arm 1 - prenatal education; Intervention arm 2 - postnatal education; control -
usual care (note: data from both intervention arms were combined for the purpose of this review)

Setting:
Country and income level: Japan (high); Tokyo
Degree of regional development: metropolitan
Participants:
Parents
Inclusion and exclusion criteria for participation in study: pregnant women $18+$ years, at gestational
week 32 to 33
Categorisation (mothers, fathers, parents, expectant parents, guardians): expectant mothers
Number randomised to intervention: $\mathrm{N}=74$ (intervention arm $1+2$ )


Number randomised to control: $\mathrm{N}=45$ ( $\mathrm{N}=42$ completed baseline survey)

Total number randomised: $\mathrm{N}=116$ ( $\mathrm{N}=3$ control did not complete baseline survey)

Number lost to follow-up or withdrew from intervention: $\mathrm{N}=4$

Number lost to follow-up or withdrew from control: $\mathrm{N}=6$

Age range; years: arm $1-35.5 \pm 5.2$; arm 2 - $35.9 \pm 4.6$; control $-34.7 \pm 3.8$

Gender: female

Ethnicity: not described

Level of education or literacy: middle or high school: arm 1 - 3 (8.8\%), arm - 6 (16.7\%), control - 4

(11.1\%); junior college: arm 1 - 12 (35.3\%), arm 2 - 8 (22.2\%), control - 13 (36.1\%); university: arm 1 - 19

(55.9\%), arm 1 - 22 (61.1\%), control - 19 (52.8\%)

Socioeconomic status: spread, but majority from all groups made over JPY 8,000,000 per year

Children

Age range and categorisation (infants, preschool-aged children, school aged children): infant

Gender: not described

Interventions

Intervention purpose: Increase coverage rates of non-mandatory vaccines and improve knowledge, attitudes, and intention to vaccinate

Deliverer: study investigator

Format or delivery mode: one-on-one 10-minute interactive educational information session

Content of communication: information on vaccine types, vaccine-preventable diseases (VPDs), the effectiveness and side effects of vaccines, and the procedure for scheduling infant immunisations. Arm 1 prenatal education delivered during weeks 34 to 36 of gestation, Arm 2 postnatal education delivered 3 to 6 days after delivery

Vaccine or vaccines delivered or described: focus on non-required vaccines (PCV7, Hib, HBV), but some information provided on all

Direction of communication: interactive

Group or individual: individual

Where the intervention took place: obstetrics hospitals (national hospital, private hospital, maternity home)

Training required for intervention: not described

Theoretical basis for intervention: health belief model (HBM) and integrated behavioral model (IBM) informed outcome assessment about attitudes

Cost of intervention: not described

Intervention quality: not described

Fidelity or integrity: not described

Details of control, usual, or routine care: no educational instructions, aside from routine check-up visits, which only provided instruction for vaccines under the law.

Details of co-interventions in all groups: educational materials provided to both groups - control group received them with the follow-up survey, but participants were instructed not to review them until after survey was completed. 
Saitoh 2013 (Continued)

Outcomes
Primary outcomes measured:

Vaccination status

Definition of immunisation status used by authors: up-to-date immunisation status for the Hib and HBV vaccines and PCV7, among infants at 3 months

Description of outcome assessment tool: postal survey (self-report)

Timing of outcome assessment: 100 days post-intervention

Knowledge

Definition: knowledge about vaccine-preventable diseases and basic vaccination knowledge

Description of outcome assessment tool: postal survey (self-report); knowledge of VPDs (score 1 to 13); basic knowledge multiple choice (score 0 to 10). Self-reported knowledge assessment not reported in this review because the measurement method was not objective.

Timing of outcome assessment: 100 days post-intervention

Attitudes

Definition: attitudes and beliefs about VPDs and vaccination

Description of outcome assessment tool: postal survey (self-report); attitude items based on the Health Belief Model and Integrated Behavior Model (perceived severity, perceived susceptibility, perceived benefits, perceived barriers, perceived self-efficacy, injunctive social norms, descriptive social norms, and perceived behavioral controls)

Timing of outcome assessment: 100 days post-intervention

Intention to vaccinate

Definition: intention to vaccinate

Description of outcome assessment tool: postal survey (self-report); four-point scale with scores of 1 (no), 2 (undecided), 3 (yes, for a specific vaccine), and 4 (yes)

Timing of outcome assessment: 100 days post-intervention

Secondary outcomes measured: none

Notes

Sample size: "Sample size was calculated assuming a completion rate of three vaccines of $10 \%$ in the control group; 37 subjects in each study group would be sufficient to detect a completion rate of $40 \%$ in the intervention groups, with an $80 \%$ power and an adjusted type 1 error of 5\%."

Contact with author: authors provided clarification around knowledge assessment tool or scale, and described allocation process.

Other: In Japan, some vaccines are under national immunisation law, and others are considered voluntary, and are paid for by parents. Voluntary vaccines include PCV7, Hib, and HBV. These were the focus of the intervention.

\section{Risk of bias}

\begin{tabular}{lll}
\hline Bias & Authors' judgement & Support for judgement \\
\hline $\begin{array}{l}\text { Random sequence genera- } \\
\text { tion (selection bias) }\end{array}$ & Low risk & The authors used a computer-generated random list for randomisation. \\
\hline $\begin{array}{l}\text { Allocation concealment } \\
\text { (selection bias) }\end{array}$ & Low risk & $\begin{array}{l}\text { A third-party researcher allocated participants to groups using the random } \\
\text { numbers list. }\end{array}$ \\
\hline
\end{tabular}


Saitoh 2013 (Continued)

Blinding of participants High risk Participants and personnel could not be blinded. and personnel (performance bias)

All outcomes

Blinding of outcome as- $\quad$ High risk
sessment (detection bias)

All outcomes

All outcomes were self-reported and participants were not blinded to their group assignment, so outcome assessment could not be blinded. However, the measures for knowledge were objectively scored.

Incomplete outcome data Unclear risk

(attrition bias)

There was relatively low attrition, though more parents withdrew from the

All outcomes control arm than the intervention arms. 3 parents from the prenatal intervention arm and 1 parent from the postnatal intervention arm did not complete the post-test (4/72 participants withdrew). From the control group, 3 did not complete the baseline survey and 6 did not complete the post-test $(9 / 45$ participants withdrew). Reasons for withdrawal were not stated and intention-totreat analysis was not performed.

\begin{tabular}{|c|c|c|}
\hline $\begin{array}{l}\text { Selective reporting (re- } \\
\text { porting bias) }\end{array}$ & Low risk & $\begin{array}{l}\text { The proposed outcomes listed in the clinical trial registration record for this } \\
\text { study were all measured and reported in the published study. }\end{array}$ \\
\hline \multirow[t]{2}{*}{ Other bias } & Low risk & $\begin{array}{l}\text { The authors stated that there were no significant differences between the } \\
\text { groups at baseline. }\end{array}$ \\
\hline & & $\begin{array}{l}\text { There was a potential risk of contamination, as the control group was also giv- } \\
\text { en educational materials, but participants were asked not to review them be- } \\
\text { fore completing the post-test. However, the control group could not have re- } \\
\text { ceived the face-to-face educational aspect of the intervention. }\end{array}$ \\
\hline
\end{tabular}

\section{Saitoh 2017}

Study design: cluster randomised controlled trial
Study duration: recruitment from 15 September 2014 to 31 January 2015. Study follow-up lasted for 6
months from birth
Study arms: intervention - vaccination education, control - control
Setting:
Country and income level: Japan (high)
Degree of regional development: not described
Participants:
Parents
Inclusion and exclusion criteria for participation in study: pregnant women aged 18 years and able to
communicate in Japanese eligible. Mothers with cognitive impairment and those for whom the study
would be an excessive physical or mental burden - as determined by medical professionals at each site
- were excluded
Categorisation (mothers, fathers, parents, expectant parents, guardians): mothers
Number randomised to intervention: clusters $\mathrm{N}=2$ hospitals, 2 clinics; mothers $\mathrm{N}=100$
Number randomised to control: clusters $\mathrm{N}=3$ hospitals, 2 clinics; mothers $\mathrm{N}=88$
Total number randomised: clusters $\mathrm{N}=5$ hospitals, 4 clinics; mothers $\mathrm{N}=188$


Saitoh 2017 (Continued)

Number lost to follow-up or withdrew from intervention: $\mathrm{N}=12$

Number lost to follow-up or withdrew from control: $\mathrm{N}=16$

Age range, years: intervention $31.9 \pm 4.4$; control $31.5 \pm 5.1$

Gender: female

Ethnicity: not described

Level of education or literacy: intervention - middle or high school: 27; junior college: 43; college or grad school: 30 . control - middle or high school: 20; junior college: 51; college or grad school: 17

Socioeconomic status: spread, but majority from both groups made between JPY $3,000,000$ to $6,999,000$

Children

Age range and categorisation (infants, preschool-aged children, school aged children): infants

Gender: not described vention on infant immunisation status and maternal knowledge"

Deliverer: clinical educators (also described as midwives)

Format or delivery mode: three interactive one on one 5-minute sessions

Content of communication: Prenatal period Meaning of immunisation, concept of VPDs, information on vaccine types, how to receive immunisation, how to reach immunisation information source; Postnatal period (3-6 days post delivery) Infant immunisation schedule, immunisation system in Japan, detailed information of VPDs, how to receive vaccination; Postnatal period (one month checkup) How to vaccinate, adverse events/reactions of immunisation

Vaccine or vaccines delivered or described: all

Direction of communication: interactive

Group or individual: individual

Where the intervention took place: prenatal session in an outpatient setting, postpartum session in an inpatient ward, and 1-month well baby checkup in an outpatient setting

Training required for intervention: educators at each participating site were provided with the study protocol and guidance on intervention delivery

Theoretical basis for intervention: the content of each session was established by combining parental needs with Health Belief Model concepts

Cost of intervention: described as "inexpensive"

Intervention quality: the educational content was then refined for each stage, and experts verified its validity

Fidelity/integrity: not described

Details of control/usual or routine care: the control group received an educational pamphlet which was more extensive than the intervention booklet but without an oral explanation. The pamphlet covered a wide range of subjects related to immunisation

Details of co-interventions in all groups: all educational sessions were implemented using a booklet containing all relevant information, as determined by Japanese immunisation specialists 
Saitoh 2017 (Continued)

\section{Vaccination status}

Definition of immunisation status used by authors: proportion of infants aged 2, 3, and 4 months who were up-to-date on their immunisations and who received Hib, PCV13, DTaP-IPV, HBV, and rotavirus immunisations according to the prescribed schedule

Description of outcome assessment tool: parent self-reports - all immunisation records were reported by study participants based on their maternal booklet

Timing of outcome assessment: 6 months postpartum

Knowledge

Definition: knowledge of infant immunisation practice

Description of outcome assessment tool: basic knowledge and knowledge of VPDs assessed through multiple choice and identification of VPDs from list (score 1-13)

Timing of outcome assessment: 1 and 6 months postpartum

Attitudes

Definition: attitudes and beliefs about VPDs and vaccination

Description of outcome assessment tool: postal survey (self-report); attitude items based on the Health Belief Model and Integrated Behavior Model (perceived severity, perceived susceptibility, perceived benefits, perceived barriers, perceived self-efficacy, injunctive social norms, descriptive social norms, and perceived behavioral controls)

Timing of outcome assessment: 1 and 6 months postpartum

Secondary outcomes measured: none

Notes

Sample size: "Sample size was determined using vaccination completion rate, i.e., proportion of infants vaccinated with Haemophilus influenzae type b (Hib), 13-valent Pneumococcal conjugate (PCV13), diphtheria, tetanus toxoid, acellular pertussis, and inactivated poliovirus (DTaP-IPV), hepatitis B virus (HBV), and rotavirus, as the primary outcome. A $10 \%$ completion rate was assumed for the control group (18). Therefore, 37 subjects in each treatment group was sufficient to detect a completion rate of $40 \%$ in the intervention group with a power of $80 \%$ at a significance level of $p=0.05$ using a two-sided ttest."

Contact with author: authors provided details of knowledge assessment tool, clarification that participants were recruited after site randomisation, and clinical trial registry entry.

\section{Risk of bias}

\section{Bias \\ Authors' judgement Support for judgement}

Random sequence genera- Low risk The authors used a computer-generated random list for randomisation.
tion (selection bias)

\begin{tabular}{lll}
\hline $\begin{array}{l}\text { Allocation concealment } \\
\text { (selection bias) }\end{array}$ & Low risk & $\begin{array}{l}\text { A third-party researcher used the random numbers list to allocate the medical } \\
\text { centres to intervention and control groups. }\end{array}$ \\
\hline $\begin{array}{l}\text { Blinding of participants } \\
\text { and personnel (perfor- } \\
\text { mance bias) }\end{array}$ & High risk & Participants and personnel unable to be blinded \\
All outcomes & \\
\hline
\end{tabular}

Blinding of outcome as- High risk sessment (detection bias)

All outcomes

\begin{abstract}
All outcomes were self-reported and participants were not blinded to their group assignment, so outcome assessment could not be blinded. However, the measures for knowledge were objectively scored.
\end{abstract}

Face-to-face interventions for informing or educating parents about early childhood vaccination (Review) 
Saitoh 2017 (Continued)

Incomplete outcome data Low risk (attrition bias)

All outcomes
Attrition was relatively low and the authors used an intention-to-treat analysis. The ITT population was defined as all participants who completed the baseline questionnaire.

Of 100 participants allocated to the intervention, number lost to follow-up/ withdrew: $\mathrm{N}=7$ after baseline but before intervention ( 3 transferred to different hospitals, 4 premature births); $\mathrm{N}=2$ no reply after intervention but before first follow up; $\mathrm{N}=3$ no reply after 1 month follow-up.

Of 88 allocated to control, number lost to follow-up/withdrew: $\mathrm{N}=5$ (transferred) after baseline; $\mathrm{N}=6$ no reply after intervention; $\mathrm{N}=5$ no reply after 1 month follow-up
Selective reporting (re- Unclear risk The clinical trial registration record for this study included the proposed outporting bias) come of cost, which was not reported in the published study.

$\begin{array}{ll}\text { Other bias } \quad \text { Low risk } & \begin{array}{l}\text { The authors state that there were no significant differences between the } \\ \text { groups at baseline. }\end{array}\end{array}$

Cluster randomisation was used to prevent contamination by participant and physician preferences.

Selective recruitment of High risk The individual participants were recruited after the randomisation.

participants (cluster-RCTs)

\begin{tabular}{|c|c|}
\hline Methods & $\begin{array}{l}\text { Study design: randomised controlled trial } \\
\text { Study duration: } 200 \text { days } \\
\text { Study arms: intervention - centre-based education; control - standard care. (Two additional study arms } \\
\text { were not relevant to this review: redesigned immunisation card only; redesigned immunisation card } \\
\text { plus centre-based education) }\end{array}$ \\
\hline \multirow[t]{12}{*}{ Participants } & Setting: \\
\hline & Region, country and income level: Karachi, Pakistan (lower middle income) \\
\hline & Vaccine programme delivery description (routine or mass campaign): routine \\
\hline & Degree of regional development: urban \\
\hline & Participants: \\
\hline & Parents \\
\hline & $\begin{array}{l}\text { Inclusion and exclusion criteria for participation in study: inclusion criteria - all children visiting select- } \\
\text { ed EPI centres for DPT1 immunisation and residing in the same area for the previous } 6 \text { months. Exclu- } \\
\text { sion criteria - none stated. }\end{array}$ \\
\hline & Categorisation (mothers, fathers, parents, expectant parents, guardians): mothers or caregivers \\
\hline & Number randomised to intervention: $\mathrm{N}=375$ \\
\hline & Number randomised to control: $\mathrm{N}=375$ \\
\hline & Total number randomised: $\mathrm{N}=1500$ \\
\hline & Number lost to follow-up or withdrew from intervention: nil \\
\hline
\end{tabular}


Number lost to follow-up or withdrew from control: nil

Age range: mother's age at enrolment: $\leq 19(6 \%) ; 20$ to $29(64 \%) ;>29(30 \%)$

Gender: female

Ethnicity: the major ethnic groups enrolled in the study were Mohajirs (50\%), Punjabi (16\%), and Pashto $(15 \%)$.

Religion: not described

Language spoken: Urdu

Household or family size: participants with $\leq 5$ household members (26\%)

Level of education or literacy: mother's years of formal schooling: $\geq 6(50 \%) ; 1$ to 5 (13\%); 0 (37\%)

Socioeconomic status: monthly household income (Pakistani Rupees): > 5000 (37\%); 0 to 5000 (63\%)

Employment status: percentage of mothers who were housewives (94\%)

Children

Age range and categorisation (infant, preschool-aged children, school-aged children): infants; child's age at enrolment: $\leq 60$ days $(65 \%) ;>60$ days $(32 \%)$; not available $(3 \%)$

Gender: male (50\%); female (50\%)

Deliverer: data collectors

Format or delivery mode: 2 to 3 minute face-to-face educational session delivered in simple local language in consideration of low literacy level of mothers.

Content of communication: educational session emphasised importance of immunisation schedule completion and described adverse effects of not completing schedule.

Vaccine or vaccines delivered or described: DPT

Direction of communication: data collectors to mothers; no information on interactivity of the session

Group or individual: not stated specifically, but delivered at DPT1 delivery appointment, so presumed to be individual

Where the intervention took place: EPI centres

Frequency or timing of communication: delivered once at DPT1 appointment

Training required for intervention: some training of data collectors mentioned but not described

Theoretical basis for intervention: not described

Cost of intervention: not described

Intervention quality: not described

Fidelity or integrity: not described

Details of control, usual, or routine care: standard care (no centre-based education or redesigned immunisation card)

Details of co-interventions in all groups: none described 
Definition of immunisation status used by authors: DPT3 completed: those who completed both DPT2 and DPT3; or DPT3 not completed: those who either did not complete both DPT2 and DPT3, or did not complete DPT3 only during the follow-up period

Description of outcome assessment tool: return immunisation visit dates for DPT2 and DPT3 recorded on follow-up cards

Timing of outcome assessment: 90 days after DPT1 visit (enrolment date)

Secondary outcomes measured: none measured

Notes

Sample size: 'Assuming DPT3 completion of $75 \%$ in the standard care group, we calculated that a sample size of 375 subjects in each study group would be sufficient to detect at least $10 \%$ higher DPT3 completion in the intervention groups with $90 \%$ power and an unadjusted type- 1 error of $5 \%$. We only controlled alpha of $5 \%$ for each pairwise comparison and not for the whole experiment. The sample size was calculated for the comparison of two proportions.'

Contact with author: yes, information confirming blinding and allocation concealment, and information about the content of the control intervention received

\title{
Risk of bias
}

\begin{tabular}{lll}
\hline Bias & Authors' judgement & Support for judgement \\
\hline $\begin{array}{l}\text { Random sequence genera- } \\
\text { tion (selection bias) }\end{array}$ & Low risk & $\begin{array}{l}\text { A computer-generated randomisation list was used to match study IDs (given } \\
\text { to each enrolled mother) to a study group. The list was provided to each enrol- } \\
\text { ment centre. }\end{array}$ \\
\hline
\end{tabular}

\begin{tabular}{|c|c|c|}
\hline $\begin{array}{l}\text { Allocation concealment } \\
\text { (selection bias) }\end{array}$ & High risk & $\begin{array}{l}\text { Authors stated that the data collectors enrolling the study participants were } \\
\text { not blinded to the type of intervention assigned. }\end{array}$ \\
\hline
\end{tabular}

Blinding of participants High risk Participants and personnel could not be blinded.
and personnel (performance bias)

All outcomes

Blinding of outcome as- $\quad$ Low risk
sessment (detection bias)

\begin{abstract}
Authors stated that the data collectors enrolling the study participants and recording study outcomes were not blinded to the type of intervention received by participants. However, the immunisation status outcome was assessed objectively by recording children attending the EPI centre.
\end{abstract}

Incomplete outcome data Unclear risk (attrition bias)

All outcomes

The authors recorded no loss to follow-up, adopting a conservative approach to analysis in which all non-respondents were classed as failing to meet the outcome (DPT3 not complete). The impact of this approach to analysis was unclear, as it was possible that some non-respondent participants may have received vaccination elsewhere.

\begin{tabular}{|c|c|c|}
\hline $\begin{array}{l}\text { Selective reporting (re- } \\
\text { porting bias) }\end{array}$ & Unclear risk & $\begin{array}{l}\text { No published protocol was mentioned. All outcomes identified for collection } \\
\text { were reported in the results of the paper. }\end{array}$ \\
\hline
\end{tabular}

\begin{tabular}{lll}
\hline Other bias & Unclear risk & No details reported \\
\hline
\end{tabular}

Usman 2011

Methods Study design: randomised controlled trial
Study duration: 9 months

Face-to-face interventions for informing or educating parents about early childhood vaccination (Review) 
Usman 2011 (Continued)

Study arms: intervention - centre-based education; control - standard care. (Two additional study arms were not relevant to this review: redesigned immunisation card only; redesigned immunisation card plus centre-based education)

Participants

Setting:

Region, country and income level: Karachi, Pakistan (lower middle income)

Vaccine programme delivery description (routine or mass campaign): routine

Degree of regional development: rural

Participants:

Parents

Inclusion and exclusion criteria for participation in study: inclusion criteria - children visiting participating EPI centres for DPT1 immunisation and living in the area for at least the previous 6 months. Exclusion criteria - children of mothers who had been living in the area for 6 months or less.

Categorisation (mothers, fathers, parents, expectant parents, guardians): mothers or caregivers

Number randomised to intervention: $\mathrm{N}=376$

Number randomised to control: $\mathrm{N}=378$

Total number randomised: $\mathrm{N}=1506$

Number lost to follow-up or withdrew from intervention: nil

Number lost to follow-up or withdrew from control: nil

Age range: mother's age at enrolment: $\leq 19(8 \%) ; 20$ to 29 (67\%); > 29 (25\%)

Gender: female

Ethnicity: the ethnic groups enrolled in the study were Pashto (32\%); Hindko (19\%); Mohajir (14\%); Punjabi (14\%); Sindhi (11\%), and others (10\%)

Religion: not described

Language spoken: Urdu

Household or family size: participants with $\leq 5$ household members (31\%)

Level of education or literacy: mother's years of formal schooling: $\geq 6(26 \%) ; 1$ to 5 (18\%); 0 (56\%)

Socioeconomic status: monthly household income (Pakistani Rupees): 0 to 5000 (60\%); > 5000 (40\%)

Employment status: percentage of mothers who were housewives (98\%)

Children

Age range and categorisation (infant, preschool-aged children, school-aged children): infants; child's age at enrolment (days): $\leq 60(59 \%) ;>60(38 \%)$; Missing (3\%)

Gender: male (51\%); female (49\%)

Interventions

Intervention purpose: to inform mothers about subsequent immunisation visits to reduce dropouts

Deliverer: trained study interviewer

Format or delivery mode: 2 to 3 minute conversation with mother, delivered using simple vocabulary in the local language of Urdu 
Content of communication: when to present for future immunisation visits, the importance of completing the immunisation schedule, and potential adverse effects of incomplete immunisation

Vaccine or vaccines delivered or described: DPT

Direction of communication: conversation

Group or individual: individual

Where the intervention took place: in a private space within a study EPI centre

Frequency or timing of communication: intervention delivered once at DPT1 visit

Training required for intervention: study interviewers were trained, but the nature of the training was not described.

Theoretical basis for intervention: not described

Cost of intervention: not described

Intervention quality: not described

Fidelity or integrity: not described

Details of control, usual, or routine care: routine EPI centre visit which did not include standardised sharing of information about immunisation

Details of co-interventions in all groups: not described

Outcomes

Primary outcomes measured: immunisation status of child

Definition of immunisation status used by authors: DPT3 completed: those who completed both DPT2 and DPT3; or DPT3 not completed: those who either did not complete both DPT2 and DPT3, or did not complete DPT3 only during the follow-up period

Description of outcome assessment tool: not described

Timing of outcome assessment: 90 days from child's DPT1 visit or intervention delivery

Secondary outcomes measured: none

Notes

Sample size: Sample size calculations were based on a comparison of two proportions. DPT3 completion was assumed to reach $75 \%$ with standard care. Therefore, sample size of 375 subjects in each intervention arm was calculated as sufficient to detect DPT3 completion of $10 \%$ or higher in any intervention group over standard care, with $90 \%$ power and $5 \%$ unadjusted type 1 error.

Contact with author: yes, confirmation about blinding and allocation concealment and information about the content of the control intervention received.

\section{Risk of bias}

Bias Authors' judgement Support for judgement

$\begin{array}{lll}\begin{array}{l}\text { Random sequence genera- } \\ \text { tion (selection bias) }\end{array} & \text { Low risk } & \begin{array}{l}\text { A computer-generated randomisation list was used to match IDs (given to each } \\ \text { enrolled mother) to a study group. The list was provided to each enrolment } \\ \text { centre. }\end{array}\end{array}$

\begin{tabular}{|c|c|c|}
\hline $\begin{array}{l}\text { Allocation concealment } \\
\text { (selection bias) }\end{array}$ & High risk & $\begin{array}{l}\text { Authors stated that the interviewers enrolling the study participants were not } \\
\text { blinded to the type of intervention assigned. }\end{array}$ \\
\hline
\end{tabular}

Blinding of participants High risk Participants and personnel could not be blinded.
and personnel (perfor-
mance bias)


Usman 2011 (Continued)

All outcomes

$\begin{array}{lll}\begin{array}{l}\text { Blinding of outcome as- } \\ \text { sessment (detection bias) }\end{array} & \text { Low risk } & \begin{array}{l}\text { Authors stated that the data collectors enrolling the study participants and } \\ \text { recording study outcomes were not blinded to the type of intervention re- } \\ \text { All outcomes }\end{array} \\ & \begin{array}{l}\text { ceived by participants. However, the immunisation status outcome was as- } \\ \text { sessed objectively by recording children attending the EPI centre. }\end{array}\end{array}$

Incomplete outcome data Unclear risk

The authors recorded no loss to follow-up, adopting a conservative approach

(attrition bias) to analysis in which all non-respondents were classed as failing to meet the

All outcomes outcome (DPT3 not complete). The impact of this approach to analysis was unclear, as it was possible that some non-respondent participants may have received vaccination elsewhere.

\begin{tabular}{lll}
\hline $\begin{array}{l}\text { Selective reporting (re- } \\
\text { porting bias) }\end{array}$ & Unclear risk & $\begin{array}{l}\text { No published protocol was mentioned. All outcomes identified for collection } \\
\text { were reported in the results of the paper. }\end{array}$ \\
\hline Other bias & Unclear risk & $\begin{array}{l}\text { Baseline comparability: The authors reported that baseline characteristics } \\
\text { across study groups were similar, except for a statistically significant differ- } \\
\text { ence in mothers' age. }\end{array}$
\end{tabular}

\section{Wood 1998}

\section{Methods}

Participants
Study design: randomised controlled trial

Study duration: approximately 15 months

Study arms: intervention - case management plus health passport; control - health passport only

\section{Setting:}

Region, country, and income level: Los Angeles, California, USA (high income)

Vaccine programme delivery description (routine or mass campaign): routine

Degree of regional development: urban

Participants:

Parents

Inclusion and exclusion criteria for participation in study: inclusion criteria - African American, living in one of 10 ZIP codes in the Los Angeles area. Exclusion criteria - not described

Categorisation (mothers, fathers, parents, expectant parents, guardians): mothers

Number randomised to intervention: $\mathrm{N}=209$

Number randomised to control: $\mathrm{N}=210$

Total number randomised: $\mathrm{N}=419$

Number lost to follow-up or withdrew from intervention: refused case management $(\mathrm{N}=32)$; lost to follow-up $(\mathrm{N}=25)$. However, of those who refused case management, 29 were included in the analysis.

Number lost to follow-up or withdrew from control: lost to follow-up ( $N=29)$

Age range: Mean (SD), years: intervention - 24.7 (6.2); control - 25.3 (6.2)

Gender: female

Ethnicity: African American 
Wood 1998 (Continued)

Religion: not described

Language(s) spoken: not described

Household or family size: first child for mother (25\%); second child for mother (31\%); third (or more) child for mother (44\%)

Level of education or literacy: highest grade level completed by the mother: Intervention - mean 11.9 (SD 1.6); Control - mean 12.0 (SD 1.5)

Socioeconomic status: authors describe population as low-income

Employment status: mother employed in past year (41\%)

Children

Age range and categorisation (infant, preschool-aged children, school-aged children): infants; mean age at enrolment - 17.8 days (range 0 to 42 days)

Gender: not described

Interventions
Intervention purpose: to improve immunisation receipt in the first year of life among inner-city African American infants

Deliverer: case managers

Format or delivery mode: face-to-face home visits (part of a multi-component intervention - see 'Details of co-interventions' below)

Content of communication: visits included assessing health needs, development of a service plan and goals, assistance with co-ordinating services, monitoring, follow-up, and help to resolve barriers to access. At visits, case managers made sure clients understood the immunisation schedule, knew which immunisations were upcoming, and confirmed that appointments were scheduled. Case managers reduced misconceptions about contraindications to vaccination, and encouraged mothers to ask their providers for immunisations.

Vaccine or vaccines delivered or described: DTP, OPV, Hib

Direction of communication: case manager to mother

Group or individual: individual

Where the intervention took place: at the mother's home

Frequency or timing of communication: first in-depth assessment conducted in the home before the child was 6 weeks of age, with subsequent visits scheduled 2 weeks prior to when immunisations were due. Optimal schedule was home visits when infant was approximately 3.5 and 5.5 months, with a fourth optional visit. Case managers followed up by phone or home visit to determine if appointments were kept. Families who were more compliant received fewer home visits, phone or mail contacts. Mean number of visits was 4.0 (SD 2; range 0 to 13) and mean phone contacts was 7.0 (SD 4.1; range 0 to 23).

Training required for intervention: not described

Theoretical basis for intervention: not described

Cost of intervention: cost data reported, described as a secondary outcome

Intervention quality: not described

Fidelity or integrity: not described

Details of control, usual, or routine care: health passport, produced by the state of California and containing information on the recommended visits for well-child care and CDC childhood immunisation schedule. 
Wood 1998 (Continued)

Details of co-interventions in all groups: telephone and mail reminders. Intervention group also received health passports.

Outcomes

Primary outcomes measured: immunisation status. This outcome was measured in the trial but could not be reported in this review as the effects of the face-to-face education on immunisation status could not be isolated. The intervention was multi-component and included facilitating access and reminding parents of due immunisations.

Primary outcomes measured: knowledge of immunisation schedule and knowledge of contraindications

Description of outcome assessment tool: knowledge of immunisation schedule - 2-item scale (scores 0 to 2), parental knowledge of the timing of immunisations in the first year. Knowledge of immunisation contraindications - 3-item scale (scores 0 to 3), parental knowledge of false and true contraindications.

Timing of outcome assessment: at initial interview and interview immediately following conclusion of intervention

Secondary outcomes measured: cost of implementing intervention (see Included studies for narrative description)

Notes Sample size: not described

Contact with author: yes, information describing the method of randomisation and allocation concealment received. Further information requested, but not received.

\section{Risk of bias}

Bias Authors' judgement Support for judgement

Random sequence genera- Low risk tion (selection bias)

Staff used a random number generator for group assignment. Participants were randomised in blocks of 4 prior to baseline interview, and assigned to interviewers in advance, so the group assignment was balanced by interviewer and timing.

\begin{tabular}{|c|c|c|}
\hline $\begin{array}{l}\text { Allocation concealment } \\
\text { (selection bias) }\end{array}$ & High risk & $\begin{array}{l}\text { The survey supervisor handled the randomisation and communicated the par- } \\
\text { ticipant assignment to the interviewer. }\end{array}$ \\
\hline
\end{tabular}

\begin{tabular}{|c|c|c|}
\hline $\begin{array}{l}\text { Blinding of participants } \\
\text { and personnel (perfor- } \\
\text { mance bias) } \\
\text { All outcomes }\end{array}$ & High risk & Participants and personnel could not be blinded. \\
\hline $\begin{array}{l}\text { Blinding of outcome as- } \\
\text { sessment (detection bias) } \\
\text { All outcomes }\end{array}$ & High risk & $\begin{array}{l}\text { Outcome measure was self-reported, therefore outcome assessors could not } \\
\text { be blinded. }\end{array}$ \\
\hline $\begin{array}{l}\text { Incomplete outcome data } \\
\text { (attrition bias) } \\
\text { All outcomes }\end{array}$ & Unclear risk & $\begin{array}{l}\text { After randomisation, } 32 \text { mothers assigned to receive the intervention refused } \\
\text { to participate. The authors used a conservative intention to treat analysis, in- } \\
\text { cluding outcome data for } 29 \text { of the } 32 \text { participants who refused to receive the } \\
\text { intervention. The impact of this approach on the outcome data was unclear, } \\
\text { as it may have diluted the effect of the intervention. } \\
\text { Additionally, there were some inconsistencies between the participant num- } \\
\text { bers reported in the text of the trial (Intervention: } \mathrm{N}=181 \text {; Control: } \mathrm{N}=181 \text { ) } \\
\text { and the numbers reported in the data tables (Intervention: } \mathrm{N}=185 ; \text { Control: } \mathrm{N} \\
=180 \text { ). For the purposes of this review, the numbers from the data tables were } \\
\text { used. }\end{array}$ \\
\hline
\end{tabular}


Wood 1998 (Continued)

\begin{tabular}{lll}
$\begin{array}{l}\text { Selective reporting (re- } \\
\text { porting bias) }\end{array}$ & Unclear risk & No published protocol was mentioned \\
\hline Other bias & Unclear risk & No details reported
\end{tabular}

See Appendix 4 for glossary of acronyms and abbreviations

Characteristics of excluded studies [ordered by study ID]

\begin{tabular}{|c|c|}
\hline Study & Reason for exclusion \\
\hline Banwat 2015 & Not an RCT \\
\hline Bedford 2014 & Not an RCT \\
\hline Brown 2016 & Intervention not directed to parents \\
\hline Chamberlain 2016 & Multicomponent intervention \\
\hline Donahue 2016 & Intervention not face-to-face communication \\
\hline Habib 2017 & Intervention not directed to parents \\
\hline Hall 2016 & Intervention not face-to-face communication \\
\hline Hendrix 2013 & Not an RCT \\
\hline Henrikson 2015 & Intervention not directed to parents \\
\hline Johri 2015 & Multicomponent intervention \\
\hline Jordan 2015 & Not an RCT \\
\hline Kenyon 2012 & Not an RCT \\
\hline Kenyon 2016 & Maternal outreach and support intervention \\
\hline Kumar 2014 & Not an RCT \\
\hline Kuppuswamy 2016 & Maternal outreach and support intervention \\
\hline Mathew 2014 & Not an RCT \\
\hline Meghea 2013 & Multicomponent intervention \\
\hline Mohan 2014 & Not an RCT \\
\hline More 2017 & Multicomponent intervention \\
\hline Nyhan 2014 & Intervention not face-to-face communication \\
\hline Pati 2015 & Maternal outreach and support intervention \\
\hline Persson 2013 & Intervention not focused on immunisation \\
\hline
\end{tabular}




\begin{tabular}{|c|c|}
\hline Study & Reason for exclusion \\
\hline Sadler 2013 & Maternal outreach and support intervention \\
\hline Sege 2015 & Maternal outreach and support intervention \\
\hline Shrestha 2016 & Not an RCT \\
\hline Williams 2013 & Intervention not face-to-face communication \\
\hline Witteman 2015 & Intervention not face-to-face communication \\
\hline Zimmerman 2014 & Intervention not directed to parents \\
\hline
\end{tabular}

Characteristics of ongoing studies [ordered by study ID]

\section{JPRN-UMIN000012575}

Trial name or title A randomized control study to investigate the effectiveness of childhood immunisation education program for parents in the perinatal period

\section{Study design: parallel randomized controlled trial}

Study duration: ongoing

Study arms: intervention: individual immunisation education for 10 min during late pregnancy and at one-month postpartum checkup, check whether women are prepared to receive immunisation; control: usual perinatal checkups and health education

Setting:

Country and income level: Japan

Degree of regional development: not stated

Participants:

Parents

Inclusion and exclusion criteria for participation in study: Included: Pregnant women at 29 to 33 weeks of gestation; 18 years or older; good command of written and spoken Japanese; can receive two interventions (late pregnancy and one month after the delivery). Excluded: It is predicted that birth weight is estimated at less than $2000 \mathrm{~g}$ due to intrauterine growth restriction (IUGR), or others; it is predicted that there is need for newborn hospitalisation for more than one month; those who are judged not capable of participating in the study by the obstetrician, or midwife and nurse

Categorisation (mothers, fathers, parents, expectant parents, guardians): expectant mothers

Number randomised to intervention: not stated

Number randomised to control: not stated

Total number randomised: target sample size $\mathrm{N}=175$

Number lost to follow-up or withdrew from intervention: not stated

Number lost to follow-up or withdrew from control: not stated

Age range: 18 and older 
Gender: female

Ethnicity: not stated

Level of education or literacy: not stated

Socioeconomic status: not stated

Children

Age range and categorisation (infants, preschool-aged children, school-aged children): infants

Gender: not stated

Interventions

Intervention purpose: To educate parents on childhood immunisation, specifically in Japan, where voluntary vaccines exist

Deliverer: not stated

Format or delivery mode: (1) During late pregnancy, pregnant women who visit prenatal checkup receive individual immunisation education for $10 \mathrm{~min}$. (2) At one-month postpartum checkup, postpartum women are supposed to check whether they are prepared to receive immunisation information for 3 to $5 \mathrm{~min}$. If possible, participant's husband (partner) or family would also be present at the sessions.

Content of communication: not stated

Vaccine or vaccines delivered or described: HBV, Rotavirus, Hib, PCV13

Direction of communication: not stated

Group or individual: Individual

Where the intervention took place: prenatal checkup and postpartum checkup

Frequency or timing of communication: first session during late pregnancy, second session at onemonth postpartum checkup

Training required for intervention: not stated

Theoretical basis for intervention: not stated

Cost of intervention: not stated

Intervention quality: not stated

Fidelity or integrity: not stated

Details of control, usual or routine care: The participants in the control group receive the usual perinatal checkups and health education.

Details of co-interventions in all groups: not stated

Vaccination status

Definition of immunisation status used by authors: An immunisation up-to-date status when the infant is at three months of age for HBV vaccine (also measured: receipt of Rotavirus vaccine, Hib vaccine, PCV13)

Description of outcome assessment tool: not stated

Timing of outcome assessment: 3 months

Knowledge and attitudes

Definition: knowldedge, attitudes and beliefs; health literacy

Description of outcome assessment tool: not stated

Face-to-face interventions for informing or educating parents about early childhood vaccination (Review) 
Timing of outcome assessment: pre- and post-intervention

Intention to vaccinate

Definition: Maternal intention to receive immunisation

Description of outcome assessment tool: not stated

Timing of outcome assessment: pre- and post-intervention

Secondary outcomes measured: none

\begin{tabular}{ll}
\hline Starting date & 18 December 2013 \\
\hline Contact information & Name: Hiroko Otsuka-Ono \\
& Address: 7-3-1 Hongo, Bunkyo-ku, Tokyo, 113-0033, Japan \\
Telephone: 03-5841-3399 & Email: hirokoo-tky@umin.ac.jp \\
& Affiliation: Graduate School of Medicine, The University of Tokyo Department of Family Nursing, Di- \\
& vision of Health Sciences \& Nursing \\
& Name: Kiyoko Kamibeppu \\
& Address: 7-3-1 Hongo, Bunkyo-ku, Tokyo, 113-0033, Japan \\
& Telephone: 03-5841-3556 \\
& Email: kkamibeppu-tky@umin.ac.jp \\
Affiliation: Graduate School of Medicine, The University of Tokyo Department of Family Nursing, Di- \\
vision of Health Sciences \& Nursing
\end{tabular}

Notes

We contacted the authors to enquire about the publication status of this trial. The authors responded that the trial is still underway and is not yet published.

Study funding: Pfizer Health Research Foundation

\section{Trial name or title}

Evaluation of a new educational strategy promoting vaccination in maternity in Quebec based on motivational interviewing techniques: PROMOVAQ study
Methods

Study design: randomised parallel study

Study duration: March 2014 to February 2015 (intervention delivered)

Study arms: intervention - motivational interviewing on vaccination; control - brochure about vaccines for infants

Participants Setting:

Country and income level: Québec, Canada (high income)

Degree of regional development: not stated

Participant:

Parents

Inclusion and exclusion criteria for participation in study: included: parents (18 years and older) of infants born in each participating maternity hospital. In Sherbrooke, inclusion limited to parents residing in the region of the Eastern Townships. In Québec, inclusion limited to parents residing in the National Capital region. Excluded: parents who do not speak English or French, parents under 18 , and any health condition of the child or the mother needing acute care (e.g. if the child must be hospitalised in neonatology, or if the mother has an condition incompatible with an interview.) 
NCT02666872 (Continued)
Categorisation (mothers,fathers, parents, expectant parents, guardians): parents

Number randomised to intervention: $\mathrm{N}=1223$

Number randomised to control: not stated

Total number randomised: reported total enrolment $\mathrm{N}=2719$

Number lost to follow-up or withdrew from intervention: not stated

Number lost to follow-up or withdrew from control: not stated

Age range: not stated

Gender: not stated

Ethnicity: not stated

Level of education or literacy: not stated

Socioeconomic status: not stated

Children

Age range and categorisation (infants, preschool-aged children, school-aged children): infants

Gender: not stated

Interventions
Intervention purpose: To enhance vaccination intention and reduce vaccine hesitancy among parents

\section{Deliverer: not stated}

Format or delivery mode: face-to-face motivational interviewing session, 15 minutes

Content of communication: educational information session on the topic of immunisation of infants at 2, 4, and 6 months. A five-point standardized information plan on vaccination was developed: 1) vaccine-preventable diseases, 2) vaccines, 3) importance of the 2-, 4-, 6-month schedule, 4) fear of vaccination, and 5) access to vaccination

Vaccine or vaccines delivered or described: 2-, 4-, and 6-month childhood vaccines

Direction of communication: interactive

Group or individual: individual

Where the intervention took place: in hospital maternity wards after delivery

Frequency or timing of communication: one session, delivered during postpartum hospitalisation Training required for intervention: Motivational Interviewing techniques

Theoretical basis for intervention: intervention informed by Motivational Interviewing techniques and the transtheoretical model. Evaluation questionnaire based on the Health Belief Model and the Opel tool to measure vaccine hesitancy

Cost of intervention: not stated

Intervention quality: not stated

Fidelity or integrity: not stated

Details of control, usual, or routine care: brochure about infant vaccines (provided to all parents)

Details of co-interventions in all groups: brochure given to all fathers and mothers giving birth 
NCT02666872 (Continued)

Outcomes

Primary outcomes measured:

Vaccination status

Definition of immunisation status used by authors: vaccination status of the child at 7 months of age (vaccination coverage is defined by the number of infants who received all recommended childhood vaccines at 7 months of age, by the total number of children)

Description of outcome assessment tool: data were collected at 10 months of age for all children from regional immunisation registries or self-reported by parents over the phone.

Timing of outcome assessment: assessed at 10 months

Intention to vaccinate

Definition: parent's intention to vaccine

Description of outcome assessment tool: assessed by a questionnaire based on the Health Belief Model

Timing of outcome assessment: within the 20 minutes right before the intervention, and within the first 20 minutes right after the intervention

Secondary outcomes measured: none

Additional outcomes measured: vaccination status of the child at 3 and 5 months of age; vaccination status of the child at 13,19 and 24 months of age; parent's hesitancy towards vaccination

\begin{tabular}{ll}
\hline Starting date & June 2013 \\
\hline Contact information & Arnaud Gagneur \\
& Université de Sherbrooke \\
& arnaud.gagneur@usherbrooke.ca \\
\hline Notes & $\begin{array}{l}\text { We contacted the author to enquire about the publication status of this trial. The author shared } \\
\text { a conference poster with some further information, but confirmed that the full results of the trial } \\
\text { have not yet been published. }\end{array}$ \\
\hline
\end{tabular}

\title{
NCT02984007
}

\section{Trial name or title}

Addressing vaccine hesitancy: Pan-Canadian validation of an effective strategy (PROMOtion of VAccination in Canada (PROMOVAQ Study))

\section{Methods}

Study design: multi-centre RCT (randomization will be stratified by centre and will be made in blocks of 4,6 , and 8 participants)

Study duration: ongoing

Study arms: Intervention - Motivational Interviewing on vaccination; Control - informational flyer about vaccines for infants

\section{Participants}

\author{
Setting: \\ Country and income level: 5 Canadian provinces (QC, BC, ON, NS, PEI) \\ Degree of regional development: not stated \\ Participants: \\ Parents
}


Inclusion and exclusion criteria for participation in study: included: all mothers (18 years and older) of infants born in 1 of the 6 participating maternity wards. excluded: mothers aged < 18 years; mothers who do not speak English or French; any health situation of the newborn or the mother requiring acute care (i.e. if the newborn needs to be hospitalised in the neonatology unit, or if the mother has an condition incompatible with an interview); mothers who have participated in one of the two studies evaluating the impact of the Motivational Interviewing intervention in the Eastern Townships in 2009 to 2010 and in the province of Quebec in 2014 to 2015.

Categorisation (mothers, fathers, parents, expectant parents, guardians): mothers

Number randomised to intervention: not stated

Number randomised to control: not stated

Total number randomised: anticipated enrolment $\mathrm{N}=1600$ mothers of infants

Number lost to follow-up or withdrew from intervention: not stated

Number lost to follow-up or withdrew from control: not stated

Age range: not stated

Gender: female

Ethnicity: not stated

Level of education or literacy: not stated

Socioeconomic status: not stated

Children

Age range and categorisation (infants, preschool-aged children, school-aged children): infants

Gender: not stated

Format or delivery mode: face-to-face educational Motivational Interviewing session, 15 to 20 minutes. The Motivational Interviewing intervention will be carried out in simple and understandable language in order to allow discussion and questions from parents rather than provide prescriptive and direct information.

Content of communication: Infact vaccination topics

Vaccine or vaccines delivered or described: infant vaccines

Direction of communication: interactive

Group or individual: individual

Where the intervention took place: 6 maternity wards in 4 health centres

Frequency or timing of communication: once, during postpartum hospitalisation

Training required for intervention: Motivational Interviewing intervention will be delivered by research assistants (RA) who will have first received a standardised training session on the content and techniques of Motivational Interviewing. Training will be conducted over 3 days, including supervision via audio recordings ( 2 days +1 day). RAs will practice their MI skills during a 4 to $6-$ week trial period in their respective maternity ward. During this time, RAs will send an online audio recording of their Motivational Interviewing intervention and the certified Motivational Interviewing trainer will assess their Motivational Interviewing skills and offer them support and feedback. After 6 weeks of trial, the study co-ordinator and the certified Motivational Interviewing trainer will 
visit each centre to give individual feedback and coaching to each RA. The Motivational Interviewing trainer will be available to answer questions and offer support to the RAs regarding their Motivational Interviewing techniques throughout the study.

Theoretical basis for intervention: intervention draws from Motivational Interviewing and Stages of Change theory. Descriptive analysis, according to a composite model inspired from the Health Belief Model, the Theory of Planned Behavior, and the vaccine hesitancy measures (based on a validated questionnaire)

Cost of intervention: not stated

Intervention quality: not stated

Fidelity or integrity: to ensure that the content of the information sessions will be standardised and similar for each centre or RA, a reference document on the primary vaccination (vaccines administered before the age of 1 year) will be made according to the provincial recommendations for each centre, and will be used for the training of RAs.

Details of control, usual, or routine care: the flyer that will be given to mothers of the control group will be the one that is usually given to parents at the maternity ward or at the first home visit after birth during the first week. Thus, flyers will be different according to the participating regions in this study.

Details of co-interventions in all groups: flyer only

\section{Outcomes}

Primary outcomes measured:

Vaccination status

Definition of immunisation status used by authors: vaccination status of the child at 3 months of age (a child is considered to have a complete vaccine status if he has received all vaccines and antigens recommended by his respective provincial immunisation schedule at 3 months of age.) Description of outcome assessment tool: online questionnaire sent to parents by email Timing of outcome assessment: assessed at 3 months of age

Knowledge and attitudes

Definition: knowledge, attitudes, and beliefs Description of outcome assessment tool: parents will complete a self-administered questionnaire to measure knowledge

Timing of outcome assessment: before and after the intervention

Intention to vaccinate

Definition: parents' intention to vaccinate their child at 2 months of age

Description of outcome assessment tool: questionnaire based on the Health Belief Model. Parents' intention to vaccinate their infant measured before the intervention will be dichotomised as 'certainly' vs. 'probably'; 'probably not' and 'certainly not' and compared to all covariates measured before the intervention

Timing of outcome assessment: during the 24-hour postpartum stay at the maternity ward - before and after the intervention

Secondary outcomes measured: satisfaction with the intervention received

Other outcomes measured: vaccine hesitancy assessed during the 24-hour postpartum stay at the maternity ward and 3 months later, at home, by a questionnaire based on the Parent Attitudes about Childhood Vaccines (PACV)

\begin{tabular}{ll}
\hline Starting date & March 25, 2017 \\
\hline Contact information & Arnaud Gagneur, MD, PhD
\end{tabular}


NCT02984007 (Continued)

\author{
819 346-1110 ext 74634 \\ arnaud.gagneur@usherbrooke.ca \\ Virginie Gosselin, MD, PhD \\ 819 346-1110 ext 16376 \\ vgosselin.agence05@ssss.gouv.qc.ca \\ Université de Sherbrooke
}

\title{
Notes
}

We contacted the author to enquire about the publication status of this trial. The author responded that the trial is still underway and is not yet published.

Sample size: "In order to identify a statistically significant amelioration of $8 \%$ in parents' intention to vaccinate, and taking account of a basic intention to vaccinate of $78 \%$, a risk of alpha error of 0.05 and a power of $80 \%$, a total of 400 parents by centre will be included. This sample size will also allow detection of a minimum of $5 \%$ reduction in $\mathrm{VH}$ scores in each centre. The total sample of 1600 families will allow detection of a significant amelioration of $6 \%$ in infants' VC."

aSee Appendix 4 for glossary of acronyms and abbreviations

\section{DATA AND ANALYSES}

\section{Comparison 1. Face-to-face education versus control or non-face-to-face education (all)}

\begin{tabular}{|c|c|c|c|c|}
\hline Outcome or subgroup title & No. of studies & $\begin{array}{l}\text { No. of partici- } \\
\text { pants }\end{array}$ & Statistical method & Effect size \\
\hline $\begin{array}{l}1 \text { Vaccination status (strati- } \\
\text { fied by length) }\end{array}$ & 7 & 3004 & Risk Ratio (M-H, Random, 95\% Cl) & $1.20[1.04,1.37]$ \\
\hline 1.1 Short ( 1 to $10 \mathrm{~min}$ ) & 4 & 1706 & Risk Ratio (M-H, Random, 95\% Cl) & $1.32[1.01,1.73]$ \\
\hline 1.2 Long $(11+\min )$ & 3 & 1298 & Risk Ratio (M-H, Random, 95\% Cl) & $1.07[1.00,1.16]$ \\
\hline $\begin{array}{l}2 \text { Vaccination status (strati- } \\
\text { fied by number of vaccines } \\
\text { delivered) }\end{array}$ & 7 & 3004 & Risk Ratio (M-H, Random, 95\% Cl) & $1.20[1.04,1.37]$ \\
\hline 2.1 Single vaccine & 3 & 1548 & Risk Ratio (M-H, Random, 95\% Cl) & $1.33[1.11,1.61]$ \\
\hline 2.2 Multiple vaccines & 4 & 1456 & Risk Ratio (M-H, Random, 95\% Cl) & $1.06[0.95,1.18]$ \\
\hline 3 Knowledge & 4 & 657 & $\begin{array}{l}\text { Std. Mean Difference (IV, Random, } \\
95 \% \mathrm{Cl} \text { ) }\end{array}$ & $0.19[0.00,0.38]$ \\
\hline 4 Attitudes - necessity & 3 & 292 & $\begin{array}{l}\text { Std. Mean Difference (IV, Random, } \\
95 \% \mathrm{CI} \text { ) }\end{array}$ & $0.03[-0.20,0.27]$ \\
\hline 5 Intention to vaccinate & 2 & 179 & $\begin{array}{l}\text { Std. Mean Difference (IV, Random, } \\
95 \% \mathrm{Cl} \text { ) }\end{array}$ & $0.55[0.24,0.85]$ \\
\hline 6 Adverse effects (anxiety) & 1 & 90 & $\begin{array}{l}\text { Mean Difference (IV, Random, 95\% } \\
\mathrm{Cl} \text { ) }\end{array}$ & $-1.93[-7.27,3.41]$ \\
\hline
\end{tabular}

Face-to-face interventions for informing or educating parents about early childhood vaccination (Review) 
Analysis 1.1. Comparison 1 Face-to-face education versus control or non-faceto-face education (all), Outcome 1 Vaccination status (stratified by length).

\begin{tabular}{|c|c|c|c|c|c|}
\hline Study or subgroup & $\begin{array}{c}\text { face-to-face } \\
n / N \\
\end{array}$ & $\begin{array}{c}\text { control (all) } \\
\mathrm{n} / \mathrm{N}\end{array}$ & $\begin{array}{c}\text { Risk Ratio } \\
\text { M-H, Random, } 95 \% \mathrm{Cl}\end{array}$ & Weight & $\begin{array}{c}\text { Risk Ratio } \\
\text { M-H, Random, } 95 \% \text { Cl }\end{array}$ \\
\hline \multicolumn{6}{|c|}{ 1.1.1 Short ( 1 to $10 \mathrm{~min}$ ) } \\
\hline Saitoh 2013 & $24 / 70$ & $3 / 36$ & & $1.41 \%$ & $4.11[1.33,12.75]$ \\
\hline Saitoh 2017 & $22 / 51$ & $21 / 45$ & $\rightarrow$ & $6.81 \%$ & $0.92[0.59,1.44]$ \\
\hline Usman 2009 & $242 / 375$ & $205 / 375$ & $\rightarrow$ & $19.21 \%$ & $1.18[1.05,1.33]$ \\
\hline Usman 2011 & $228 / 376$ & $149 / 378$ & $\rightarrow-$ & $17.77 \%$ & $1.54[1.33,1.79]$ \\
\hline \multicolumn{6}{|c|}{ Total events: 516 (face-to-face), 378 (control (all)) } \\
\hline \multicolumn{6}{|c|}{ Heterogeneity: $\mathrm{Tau}^{2}=0.05 ; \mathrm{Chi}^{2}=14.05, \mathrm{df}=3(\mathrm{P}=0) ; \mathrm{I}^{2}=78.64 \%$} \\
\hline \multicolumn{6}{|c|}{ Test for overall effect: $Z=2.03(P=0.04)$} \\
\hline \multicolumn{6}{|l|}{ 1.1.2 Long (11+ min) } \\
\hline Bolam 1998 & $179 / 205$ & $169 / 198$ & *- & $20.89 \%$ & $1.02[0.95,1.11]$ \\
\hline Jackson 2011 & $18 / 19$ & $18 / 25$ & & $12.26 \%$ & $1.32[1.01,1.72]$ \\
\hline Subtotal $(95 \% \mathrm{CI})$ & 642 & 656 & $V$ & $\mathbf{5 4 . 8} \%$ & $1.07[1,1.16]$ \\
\hline \multicolumn{6}{|c|}{ Total events: 573 (face-to-face), 546 (control (all)) } \\
\hline \multicolumn{6}{|c|}{ Heterogeneity: $\operatorname{Tau}^{2}=0 ; \mathrm{Chi}^{2}=3.85, \mathrm{df}=2(\mathrm{P}=0.15) ; \mathrm{I}^{2}=48.11 \%$} \\
\hline \multicolumn{6}{|c|}{ Test for overall effect: $Z=1.89(P=0.06)$} \\
\hline Total $(95 \% \mathrm{Cl})$ & 1514 & 1490 & & $100 \%$ & $1.2[1.04,1.37]$ \\
\hline \multicolumn{6}{|c|}{ Total events: 1089 (face-to-face), 924 (control (all)) } \\
\hline \multicolumn{6}{|c|}{ Heterogeneity: $\operatorname{Tau}^{2}=0.02 ; \mathrm{Chi}^{2}=41.31, \mathrm{df}=6(\mathrm{P}<0.0001) ; \mathrm{I}^{2}=85.48 \%$} \\
\hline \multicolumn{6}{|c|}{ Test for overall effect: $Z=2.53(P=0.01)$} \\
\hline Test for subgroup dif & $11, \mathrm{df}=1(\mathrm{P}=0.15)$ & $2.63 \%$ & & & \\
\hline
\end{tabular}

Analysis 1.2. Comparison 1 Face-to-face education versus control or non-face-to-face education (all), Outcome 2 Vaccination status (stratified by number of vaccines delivered).

\begin{tabular}{|c|c|c|c|c|c|}
\hline Study or subgroup & $\begin{array}{c}\text { face-to-face } \\
n / N\end{array}$ & $\begin{array}{c}\text { control (all) } \\
n / N\end{array}$ & $\begin{array}{c}\text { Risk Ratio } \\
\text { M-H, Random, 95\% Cl }\end{array}$ & Weight & $\begin{array}{c}\text { Risk Ratio } \\
\text { M-H, Random, } 95 \% \mathrm{Cl}\end{array}$ \\
\hline \multicolumn{6}{|l|}{ 1.2.1 Single vaccine } \\
\hline Jackson 2011 & $18 / 19$ & $18 / 25$ & $\longrightarrow$ & $12.26 \%$ & $1.32[1.01,1.72]$ \\
\hline Usman 2009 & $242 / 375$ & $205 / 375$ & - & $19.21 \%$ & $1.18[1.05,1.33]$ \\
\hline Usman 2011 & $228 / 376$ & $149 / 378$ & $\rightarrow-$ & $17.77 \%$ & $1.54[1.33,1.79]$ \\
\hline Subtotal $(95 \% \mathrm{Cl})$ & 770 & 778 & & $49.24 \%$ & $1.33[1.11,1.61]$ \\
\hline \multicolumn{6}{|c|}{ Heterogeneity: $\mathrm{Tau}^{2}=0.02 ; \mathrm{Chi}^{2}=7.53, \mathrm{df}=2(\mathrm{P}=0.02) ; \mathrm{I}^{2}=73.45 \%$} \\
\hline \multicolumn{6}{|c|}{ Test for overall effect: $Z=3.01(P=0)$} \\
\hline \multicolumn{6}{|c|}{ 1.2.2 Multiple vaccines } \\
\hline Bolam 1998 & $179 / 205$ & $169 / 198$ & + & $20.89 \%$ & $1.02[0.95,1.11]$ \\
\hline Hu 2017 & $376 / 418$ & $359 / 433$ & - & $21.64 \%$ & $1.08[1.03,1.14]$ \\
\hline Saitoh 2017 & $22 / 51$ & $21 / 45$ & $\longrightarrow$ & $6.81 \%$ & $0.92[0.59,1.44]$ \\
\hline
\end{tabular}

Face-to-face interventions for informing or educating parents about early childhood vaccination (Review) 


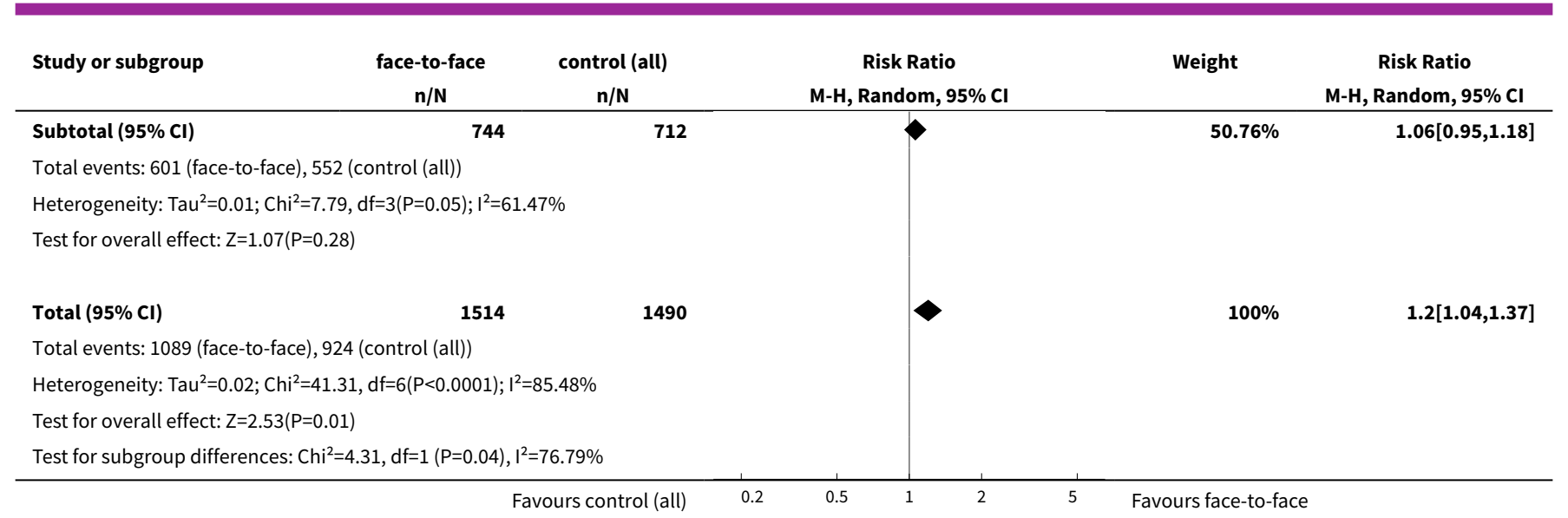

\section{Analysis 1.3. Comparison 1 Face-to-face education versus control or non-face-to-face education (all), Outcome 3 Knowledge.}

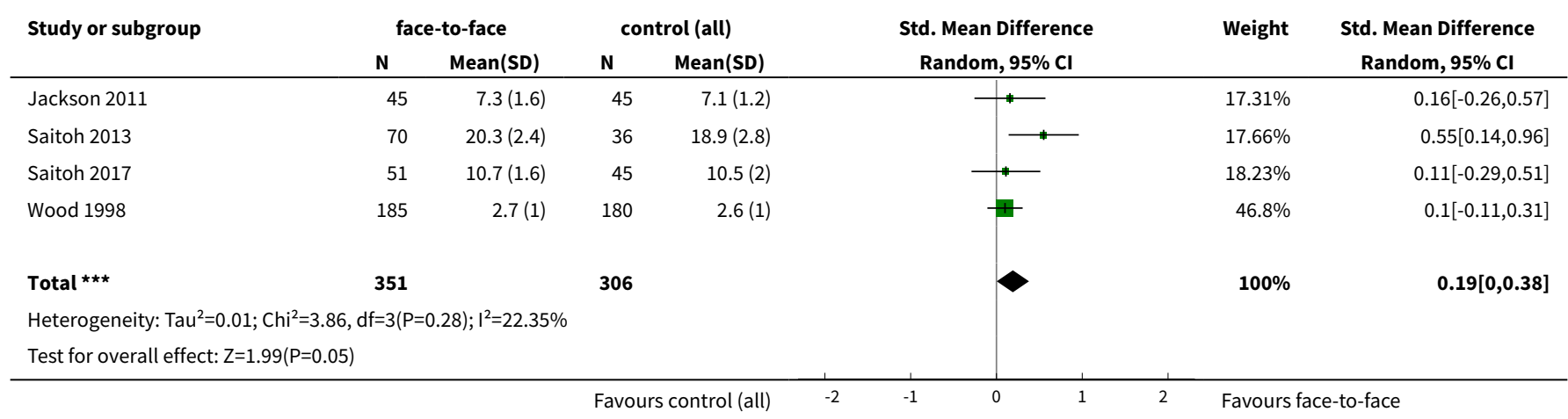

\section{Analysis 1.4. Comparison 1 Face-to-face education versus control} or non-face-to-face education (all), Outcome 4 Attitudes - necessity.

\begin{tabular}{|c|c|c|c|c|c|c|c|}
\hline \multirow[t]{2}{*}{ Study or subgroup } & \multicolumn{2}{|c|}{ face-to-face } & \multicolumn{2}{|c|}{ control (all) } & \multirow{2}{*}{$\begin{array}{c}\text { Std. Mean Difference } \\
\text { Random, } 95 \% \mathrm{Cl} \\
\end{array}$} & \multirow[t]{2}{*}{ Weight } & \multirow{2}{*}{$\begin{array}{c}\text { Std. Mean Difference } \\
\text { Random, } 95 \% \mathrm{Cl} \\
\end{array}$} \\
\hline & $\mathbf{N}$ & Mean(SD) & $\mathbf{N}$ & Mean(SD) & & & \\
\hline Jackson 2011 & 45 & $17.4(2.3)$ & 45 & $17.2(3.1)$ & $-1-$ & $32.04 \%$ & $0.08[-0.33,0.49]$ \\
\hline Saitoh 2013 & 70 & $8.2(1.7)$ & 36 & $8.2(1.5)$ & $\longrightarrow$ & $33.88 \%$ & $0.02[-0.38,0.43]$ \\
\hline Saitoh 2017 & 51 & $8.3(1.8)$ & 45 & $8.3(1.6)$ & 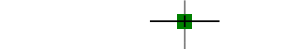 & $34.07 \%$ & $0[-0.4,0.4]$ \\
\hline 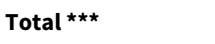 & 166 & & 126 & & & $100 \%$ & $0.03[-0.2,0.27]$ \\
\hline \multicolumn{8}{|c|}{ Test for overall effect: $\mathrm{Z}=0.28(\mathrm{P}=0.78)$} \\
\hline & & & Fave & trol (all) & -1 & Favours & face \\
\hline
\end{tabular}


Analysis 1.5. Comparison 1 Face-to-face education versus control or non-face-to-face education (all), Outcome 5 Intention to vaccinate.

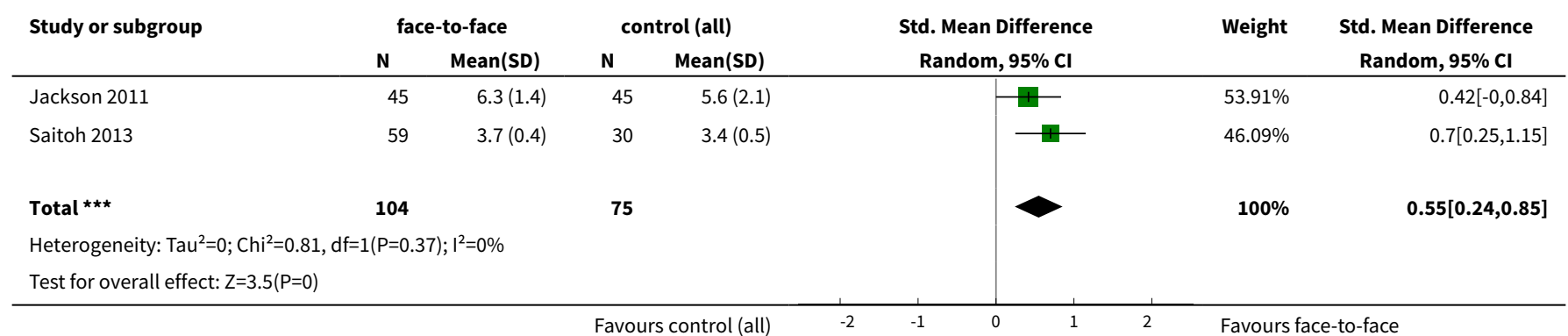

Analysis 1.6. Comparison 1 Face-to-face education versus control or non-face-to-face education (all), Outcome 6 Adverse effects (anxiety).

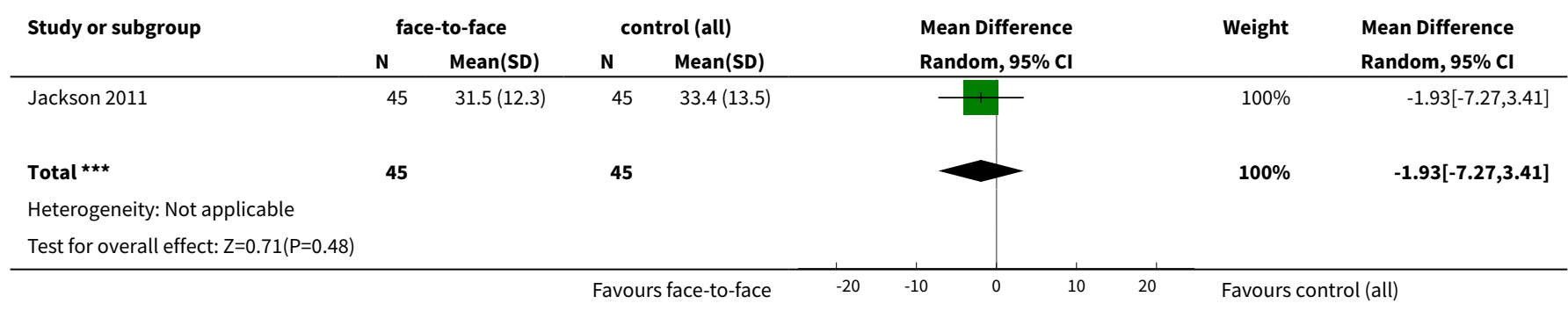

\section{ADDITIONAL TABLES}

Table 1. Summary of related non-Cochrane reviews

\begin{tabular}{llcl}
\hline Review & Title & Review focus and main findings & $\begin{array}{l}\text { Relationship / key } \\
\text { differences }\end{array}$
\end{tabular}

Bright $2017 \quad$ A systematic re- $\quad$ Focus: effectiveness of interventions aimed at increasing access view of strategies to increase access to health services among children in low and middle income countries to health services for children aged 5 years and below in LMICs. Supply side interventions included: delivery of services at or of services). Demand side interventions included: educational programmes, text messages, and financial or other incentives. closer to home and service level improvements (e.g. integration

Broad range of interventions addressing health topics beyond vaccination and limited to LMICs.

Included studies: 57 RCTs and non-randomised controlled trials

Findings: health promotion or educational programmes were the most commonly evaluated intervention in the review. Education delivered by healthcare workers generally showed a positive impact on healthcare utilisation or immunisation uptake, but mixed effectiveness when delivered by community health workers

\section{Connors $2017 \quad$ Provider-parent} communication when discussing vaccines: a systematic review
Focus: determining effective communication practices for providers and parents, and establishing whether collaborative and participatory communication between parents and providers impact parents' views on vaccination.
Included qualitative studies, found similar dearth of highquality evidence on effectiveness. The 
Table 1. Summary of related non-Cochrane reviews (Continued)

Included studies: 9 studies, mostly descriptive and qualitative, with 1 RCT

Findings: evidence was limited and low quality. Themes of trust and support suggested the value of participatory communication, though opposing evidence in favour of presumptive communication also existed.
$\mathrm{RCT}$ tested an intervention directed to physicians, so was not included in our review.

Harvey $2015 \quad$ Parental reminder,
recall and educa-
tional interventions
to improve early
childhood immu-
nisation uptake: a
systematic review
and meta-analysis

Focus: effectiveness of remind, recall, and educational interventions for childhood vaccination uptake

Included studies: 28 controlled studies, 13 focusing on reminders and 17 on parental education

Findings: postal and telephone reminders combined showed the greatest positive effect as a reminder intervention. Educational interventions may be more effective in LMICs. Discussion-based education was more effective than written education.
Several studies appearing in our review also appeared in the meta-analysis of educational interventions in this review, but there were additional non-face-to-face educational interventions included in this review.
Jarrett 2015
Strategies for addressing vaccine hesitancy - a systematic review
Focus: identify, describe, and assess potential effectiveness of strategies to reduce vaccine hesitancy

Included studies: 166 peer-reviewed and 15 grey literature records reporting an evaluation of an intervention. There was no restriction on study design

Findings: three intervention categories: dialogue-based, incentive-based, or reminder- and recall-based interventions. Most interventions were dialogue-based. The most effective strategies were multi-component and tailored to specific populations and specific problems.

\begin{tabular}{ll}
\hline Odone 2015 & Effectiveness of in- \\
terventions that ap- & ply new media to \\
improve vaccine \\
uptake and vaccine \\
coverage
\end{tabular}

Focus: effectiveness of interventions that apply new media to promote vaccination uptake and increase vaccination coverage

Included studies: 19 studies, most from the USA. 13 experimental and 6 observational.

Findings: interventions included Facebook, SMS, YouTube videos, apps, software, email, and targeted websites. Some evidence that SMS, some websites or web portals, and computerised reminders may increase vaccination rates.
Broad range of included interventions, beyond faceto-face communication. Many non-RCT study designs were included in this review.
Included vaccines for children, adolescents, and adults. No face-to-face communication interventions, only new media

\section{Sadaf 2013}

A systematic review of interventions for reducing parental vaccine refusal and vaccine hesitancy
Focus: effectiveness of interventions to decrease parental vaccine refusal and hesitancy toward recommended childhood and adolescent vaccines

Included studies: 30 studies, primarily before-and-after intervention design with some RCTs, non-RCTs and evaluation studies. Most from USA

Findings: three intervention categories: passage of state laws, implementation of school- and state-level laws, and parent-centred information or education. Education, particularly short pamphlets, most commonly studied, with heterogeneous formats and mixed effects. Overall, no convincing evidence on effective strategies. Authors noted few studies measured hesitancy-relevant outcomes, and most evidence was of low quality.
Broad range of included interventions, beyond faceto-face communication

Face-to-face interventions for informing or educating parents about early childhood vaccination (Review) 


\section{Table 1. Summary of related non-Cochrane reviews (Continued)}

\begin{tabular}{|c|c|c|c|}
\hline Williams 2014 & $\begin{array}{l}\text { What are the fac- } \\
\text { tors that contribute } \\
\text { to parental vac- } \\
\text { cine-hesitancy and } \\
\text { what can we do } \\
\text { about it? }\end{array}$ & $\begin{array}{l}\text { Focus: barriers to vaccination and strategies to address vaccine } \\
\text { hesitancy } \\
\text { Included studies: seven studies, largely RCTs or CRCTs. Not all } \\
\text { specifically recruited hesitant parents } \\
\text { Findings: current data did not support one method for commu- } \\
\text { nicating with hesitant parents over another. Wide range of in- } \\
\text { terventions used }\end{array}$ & $\begin{array}{l}\text { Included interven- } \\
\text { tions beyond face- } \\
\text { to-face, also in- } \\
\text { cluded adolescent } \\
\text { (HPV) as well as } \\
\text { childhood vaccine }\end{array}$ \\
\hline
\end{tabular}

Table 2. Additional measures of parent attitudes

\begin{tabular}{lll}
\hline Study & Outcome & Scale used \\
\hline Jackson 2011 & $\begin{array}{l}\text { Attitude towards MMR } \\
\text { One item: 'For me to give my child the combined } \\
\text { MMR vaccine at the recommended ages would be...' }\end{array}$ & $\begin{array}{l}1 \text { (extremely negative attitude) to 7 (extremely } \\
\text { positive attitude) }\end{array}$ \\
\cline { 2 - 3 } & $\begin{array}{l}\text { Necessity beliefs } \\
\text { Four items assessing the necessity of MMR: e.g. } \\
\text { 'Without the combined MMR vaccine, my child could } \\
\text { get very ill from measles, mumps, or rubella' }\end{array}$ & $\begin{array}{l}\text { Each item scored from 1 to 5 and summed, for to- } \\
\text { tal outcome scale of 4 (not at all necessary) to 20 } \\
\text { (very necessary) }\end{array}$ \\
$\begin{array}{ll}\text { Concern beliefs } & \text { We used this item in the meta-analysis. } \\
\text { Four items assessing concerns about MMR: e.g. 'Giv- } \\
\text { ing my child the combined MMR vaccine worries me' }\end{array}$ & $\begin{array}{l}\text { Each item scored from 1 to 5, and summed for to- } \\
\text { (very concerned) }\end{array}$ \\
\hline
\end{tabular}

Saitoh 2013 Perceived severity (HBM)

Two items: e.g. 'The vaccine-preventable diseases

Each item scored from 1 to 5 (strongly disagree to are serious diseases.' strongly agree), and summed for a total outcome scale of 2 to 10 .

We used this item in the meta-analysis.

Perceived susceptibility(HBM)

One item: 'My baby is not very likely to get vaccine preventable diseases.'

Perceived benefits (HBM)

Four items: e.g. 'The vaccines for babies will prevent my baby from getting sick with a vaccine-preventable disease.'
Each item scored from 1 to 5 (strongly disagree to strongly agree), and summed for a total outcome scale of 1 to 5 .

Each item scored from 1 to 5 (strongly disagree to strongly agree), and summed for a total outcome scale of 4 to 20
Perceived barriers (HBM)

Five items: e.g. 'The vaccines will make my baby sick, 'The vaccines do not prevent the vaccine-preventable diseases.'

Self-efficacy (HBM)

Two items: e.g. 'I feel comfortable getting the vaccines for my baby.'
Each item scored from 1 to 5 (strongly disagree to strongly agree), and summed for a total outcome scale of 5 to 25

Each item scored from 1 to 5 (strongly disagree to strongly agree), and summed for a total outcome scale of 2 to 10 


\section{Table 2. Additional measures of parent attitudes (Continued)}

Perceived behavioral control (IBM)

One item: 'I have control over whether or not my baby gets the vaccines.'

Social norm (injunctive)

Four items: e.g. 'Most people important to me think I should get my baby the vaccines.'
Each item scored from 1 to 5 (strongly disagree to strongly agree), and summed for a total outcome scale of 1 to 5

Each item scored from 1 to 5 (strongly disagree to strongly agree), and summed for a total outcome scale of 4 to 20

Each item scored from 1 to 5 (strongly disagree to strongly agree), and summed for a total outcome scale of 2 to 10

Two items: e.g. 'I know other people my age who got their baby the vaccines.'

\section{Saitoh 2017}

Perceived severity (HBM)

Two items: e.g. 'Vaccine preventable diseases are serious diseases.'

Each item scored from 1 to 5 (strongly disagree to strongly agree), and summed for a total outcome scale of 2 to 10

We used this item in the meta-analysis.

Perceived susceptibility(HBM)

Each item scored from 1 to 5 (strongly disagree to strongly agree), and summed for a total outcome

One item: 'My baby is not very likely to get vaccine preventable diseases.' scale of 1 to 5

Perceived benefits (HBM)

Five items: e.g. 'The vaccines for babies will prevent my baby from getting sick with vaccine-preventable diseases.' 'If my baby receives his or her vaccines, it will help protect my friends and family from getting vaccine-preventable diseases.'

Perceived barriers (HBM)

Six items: e.g. 'I feel uncomfortable because vaccines are painful or uncomfortable for my baby,' 'Vaccines are too expensive.'

Perceived behavioral control (IBM)

One item: 'I have control over whether or not my baby gets the vaccines.'

Each item scored from 1 to 5 (strongly disagree to strongly agree), and summed for a total outcome scale of 5 to 25

Each item scored from 1 to 5 (strongly disagree to strongly agree), and summed for a total outcome scale of 6 to 30

Each item scored from 1 to 5 (strongly disagree to strongly agree), and summed for a total outcome scale of 1 to 5

Social norm (injunctive)

Each item scored from 1 to 5 (strongly disagree to strongly agree), and summed for a total outcome scale of 3 to 15 I should have my baby vaccinated.'

Social norm (descriptive)

Two items: e.g. 'I know other people my age who had their babies vaccinated.'
Each item scored from 1 to 5 (strongly disagree to strongly agree), and summed for a total outcome scale of 2 to 10 
Table 3. Vaccination status outcome data

\begin{tabular}{|c|c|c|c|c|c|c|c|c|}
\hline \multirow{2}{*}{$\begin{array}{l}\text { Session } \\
\text { length }\end{array}$} & \multirow[t]{2}{*}{ Outcome } & \multirow[t]{2}{*}{ Study } & \multirow{2}{*}{$\begin{array}{l}\text { Timing of } \\
\text { outcome } \\
\text { assess- } \\
\text { ment (days/ } \\
\text { months) }\end{array}$} & \multicolumn{2}{|c|}{ Intervention group } & \multicolumn{2}{|c|}{ Control group } & \multirow[t]{2}{*}{ Notes } \\
\hline & & & & $\begin{array}{l}\text { Observed } \\
\text { (n) }\end{array}$ & Total (N) & $\begin{array}{l}\text { Observed } \\
\text { (n) }\end{array}$ & Total (N) & \\
\hline \multirow[t]{4}{*}{$\begin{array}{l}\text { Shorter } \\
\text { sessions (1 } \\
\text { to } 10 \mathrm{~min})\end{array}$} & $\begin{array}{l}\text { Up-to-date immunisation } \\
\text { status at } 3 \text { months of age for } \\
\text { Hib, HBV, and PCV7 vaccines }\end{array}$ & Saitoh 2013 & $\begin{array}{l}3 \text { months } \\
\text { post-interven- } \\
\text { tion }\end{array}$ & 24 & 70 & 3 & 36 & $\begin{array}{l}\text { One 10-minute session } \\
\text { Intervention participants } \\
=\text { combined prenatal inter- } \\
\text { vention arm and postnatal } \\
\text { intervention arm }\end{array}$ \\
\hline & $\begin{array}{l}\text { Up-to-date immunisation } \\
\text { status at } 6 \text { months of age for } \\
\text { Hib, PCV13, DTaP-IPV, HBV, } \\
\text { and rotavirus }\end{array}$ & Saitoh 2017 & $\begin{array}{l}6 \text { months } \\
\text { post-interven- } \\
\text { tion }\end{array}$ & 22 & 51 & 21 & 45 & $\begin{array}{l}\text { Three 5-minute sessions } \\
\text { Figures adjusted to account } \\
\text { for clustering (original inter- } \\
\text { vention } N=100 \text {; control } N= \\
88 \text { ) }\end{array}$ \\
\hline & Receipt of DPT3 & Usman 2009 & $\begin{array}{l}90 \text { days post- } \\
\text { intervention }\end{array}$ & 242 & 375 & 205 & 375 & One 2- to 3-minute session \\
\hline & Receipt of DPT3 & Usman 2011 & $\begin{array}{l}90 \text { days post- } \\
\text { intervention }\end{array}$ & 228 & 376 & 149 & 378 & One 2- to 3-minute session \\
\hline \multirow[t]{3}{*}{$\begin{array}{l}\text { Longer ses- } \\
\text { sions (11 } \\
\min +)\end{array}$} & Receipt of MMR vaccine & $\begin{array}{l}\text { Jackson } \\
2011\end{array}$ & $\begin{array}{l}3 \text { months } \\
\text { post-interven- } \\
\text { tion }\end{array}$ & 18 & 19 & 18 & 25 & $\begin{array}{l}\text { One 2-hour session } \\
\text { Figures adjusted to account } \\
\text { for clustering (original inter- } \\
\text { vention } \mathrm{N}=29 \text {; control } \mathrm{N}= \\
37 \text { ) }\end{array}$ \\
\hline & $\begin{array}{l}\text { Up-to-date status at } 12 \\
\text { months of age ( } 1 \text { dose BCG, } \\
3 \text { doses HepB, } 3 \text { doses OPV, } \\
3 \text { doses DTP, } 1 \text { dose MR, } 1 \\
\text { dose JEV) }\end{array}$ & Hu 2017 & $\begin{array}{l}12 \text { months } \\
\text { post-interven- } \\
\text { tion }\end{array}$ & 376 & 418 & 359 & 433 & One 15-minute session \\
\hline & $\begin{array}{l}\text { Up-to-date immunisation } \\
\text { status at } 3 \text { months of age } \\
\text { (BCG, > } 2 \text { doses diphtheria } \\
\text { and pertussis vaccine, OPV) }\end{array}$ & Bolam 1998 & $\begin{array}{l}3 \text { months } \\
\text { post-interven- } \\
\text { tion }\end{array}$ & $\begin{array}{l}\text { Groups A + B } \\
=179\end{array}$ & $\begin{array}{l}\text { Groups A + B } \\
=205\end{array}$ & $\begin{array}{l}\text { Groups C }+ \\
D=169\end{array}$ & $\begin{array}{l}\text { Groups C }+ \\
D=198\end{array}$ & $\begin{array}{l}\text { One } 20 \text {-minute session } \\
\text { Groups } A+B=\text { education at } \\
\text { birth }\end{array}$ \\
\hline
\end{tabular}




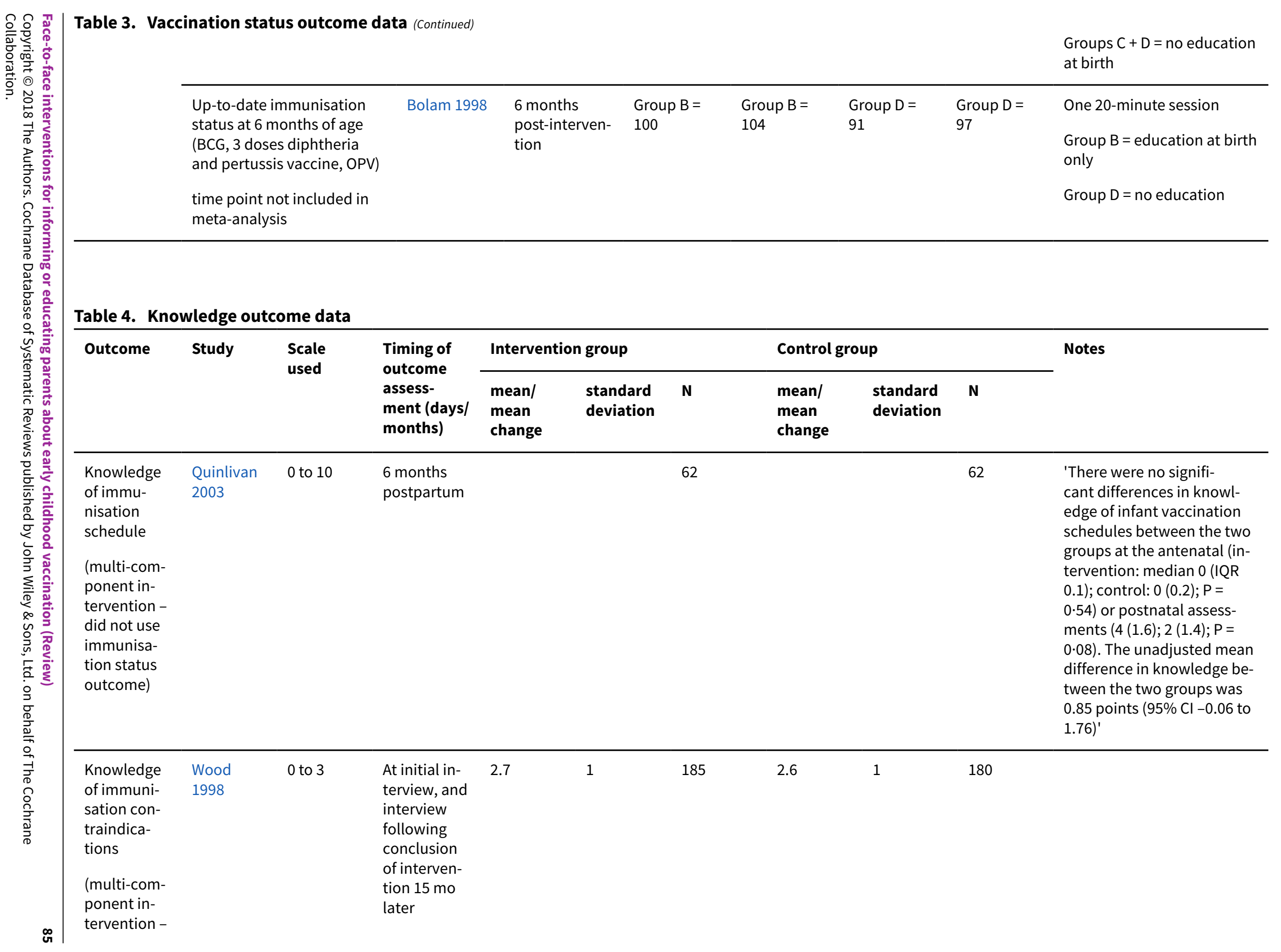




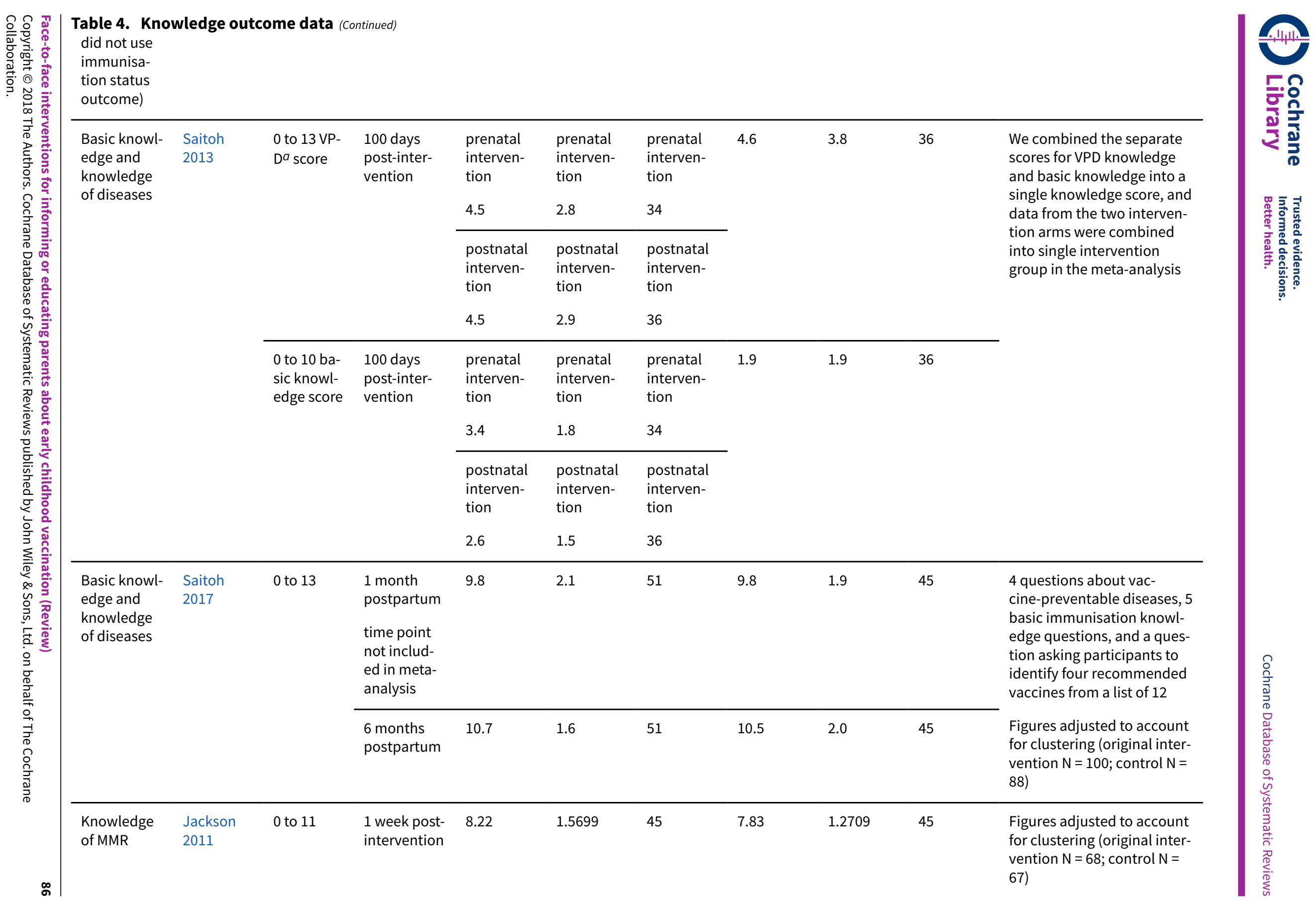




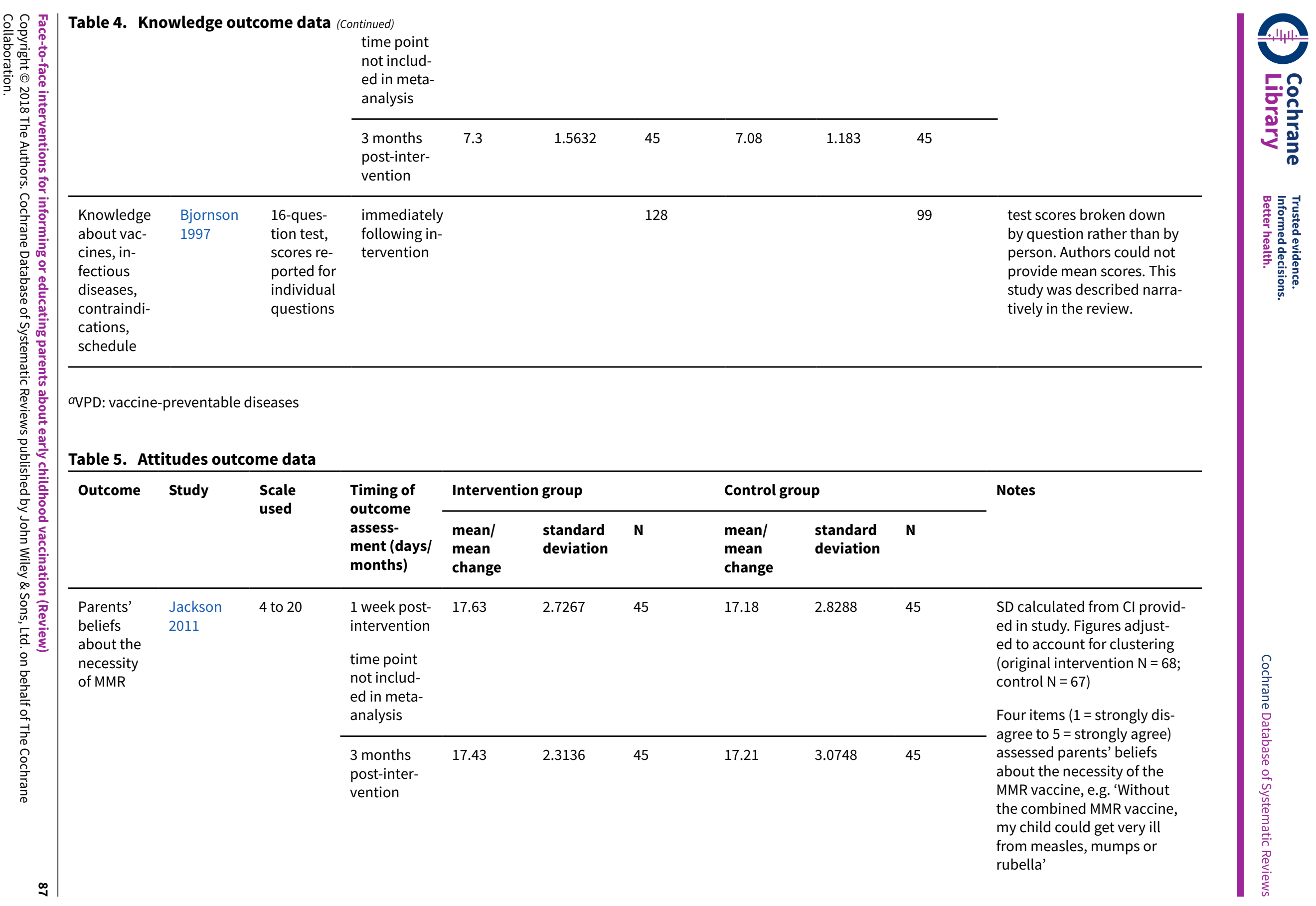




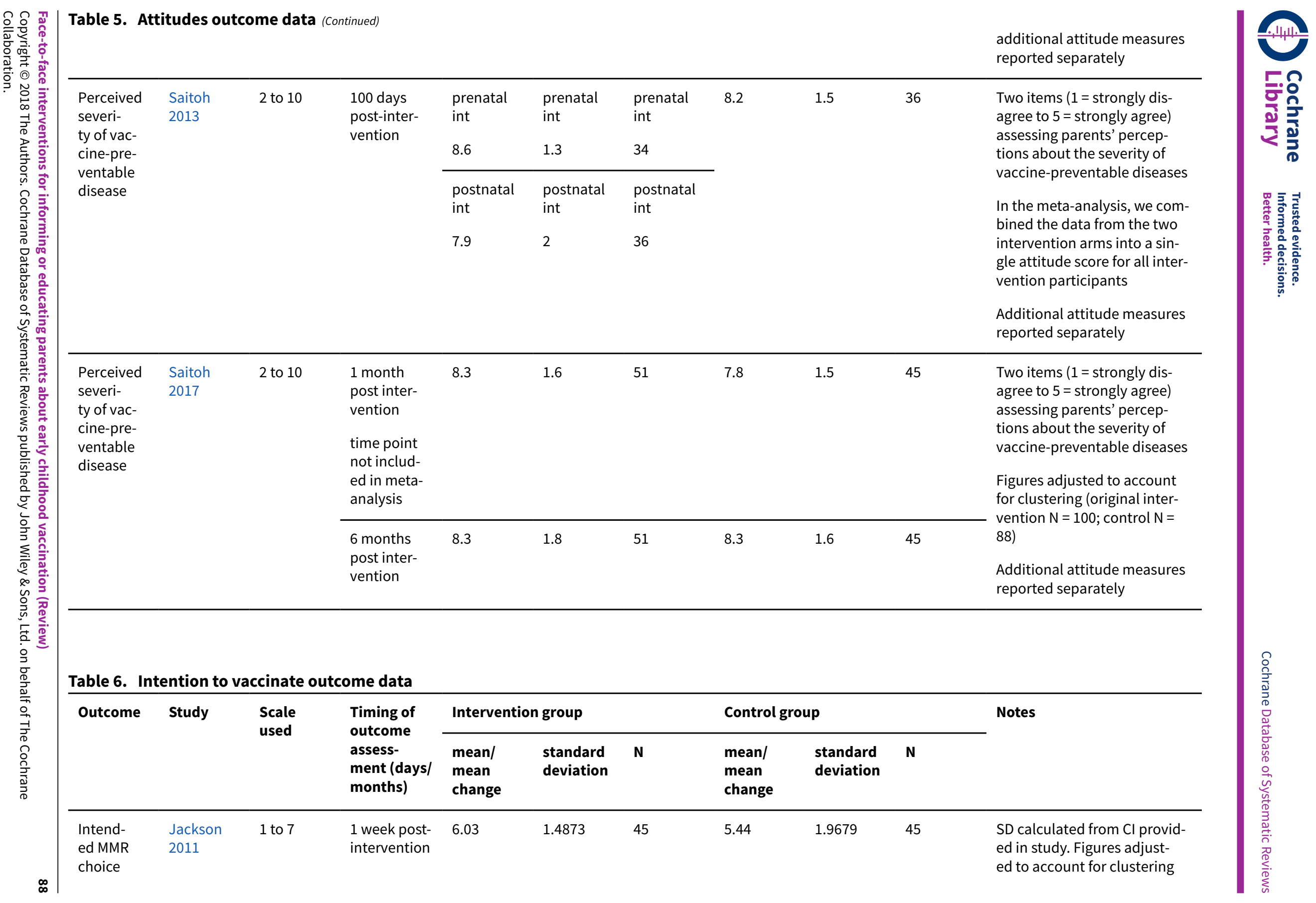


Table 6. Intention to vaccinate outcome data (Continued)

time point

not includ-

(original intervention $\mathrm{N}=68$;

ed in meta-

control $\mathrm{N}=67$.

analysis

Three items measured on a

7-point scale e.g. "I intend to

3 month

6.34

1.4047

45

5.58

2.1319

45

give my child the combined

post-inter-

vention

mended ages' (definitely do

not to definitely do). Respons-

es averaged over the three

items.

\begin{tabular}{|c|c|c|c|c|c|c|c|c|c|c|}
\hline $\begin{array}{l}\text { Intent to } \\
\text { immunise }\end{array}$ & $\begin{array}{l}\text { Saitoh } \\
2013\end{array}$ & 1 to 4 & $\begin{array}{l}100 \text { days } \\
\text { post-inter- } \\
\text { vention }\end{array}$ & 3.7288 & 0.4484 & 59 & 3.4 & 0.4983 & 30 & $\begin{array}{l}\text { Four-point scale where } 1=\text { no, } \\
2=\text { undecided, } 3=\text { yes, for a } \\
\text { specific vaccine, and } 4=\text { yes. }\end{array}$ \\
\hline
\end{tabular}

Study authors presented the data for this outcome with both intervention arms combined. Rather than provid-

ing mean and SD, the authors reported the number of participants who selected each scale rating. For the metaanalysis, we transformed these data into mean and SD, with $\mathrm{N}=$ total respondents for this question.

Table 7. Adverse effects outcome data

\begin{tabular}{|c|c|c|c|c|c|c|c|c|c|c|}
\hline \multirow[t]{2}{*}{ Outcome } & \multirow[t]{2}{*}{ Study } & \multirow{2}{*}{$\begin{array}{l}\text { Scale } \\
\text { used }\end{array}$} & \multirow{2}{*}{$\begin{array}{l}\text { Timing of } \\
\text { outcome } \\
\text { assess- } \\
\text { ment (days/ } \\
\text { months) }\end{array}$} & \multicolumn{3}{|c|}{ Intervention group } & \multicolumn{3}{|c|}{ Control group } & \multirow[t]{2}{*}{ Notes } \\
\hline & & & & $\begin{array}{l}\text { mean/ } \\
\text { mean } \\
\text { change }\end{array}$ & $\begin{array}{l}\text { standard } \\
\text { deviation }\end{array}$ & $\mathbf{N}$ & $\begin{array}{l}\text { mean/ } \\
\text { mean } \\
\text { change }\end{array}$ & $\begin{array}{l}\text { standard } \\
\text { deviation }\end{array}$ & $\mathbf{N}$ & \\
\hline Anxiety & $\begin{array}{l}\text { Jackson } \\
2011\end{array}$ & 20 to 80 & $\begin{array}{l}1 \text { week post- } \\
\text { intervention }\end{array}$ & 30.89 & 11.9396 & 45 & 33.78 & 13.7341 & 45 & $\begin{array}{l}\text { SD calculated from } \mathrm{Cl} \text { pro- } \\
\text { vided in study. Figures ad- } \\
\text { justed to account for clus- } \\
\text { tering (original intervention } \\
\mathrm{N}=68 \text {; control } \mathrm{N}=67 \text { ). }\end{array}$ \\
\hline
\end{tabular}




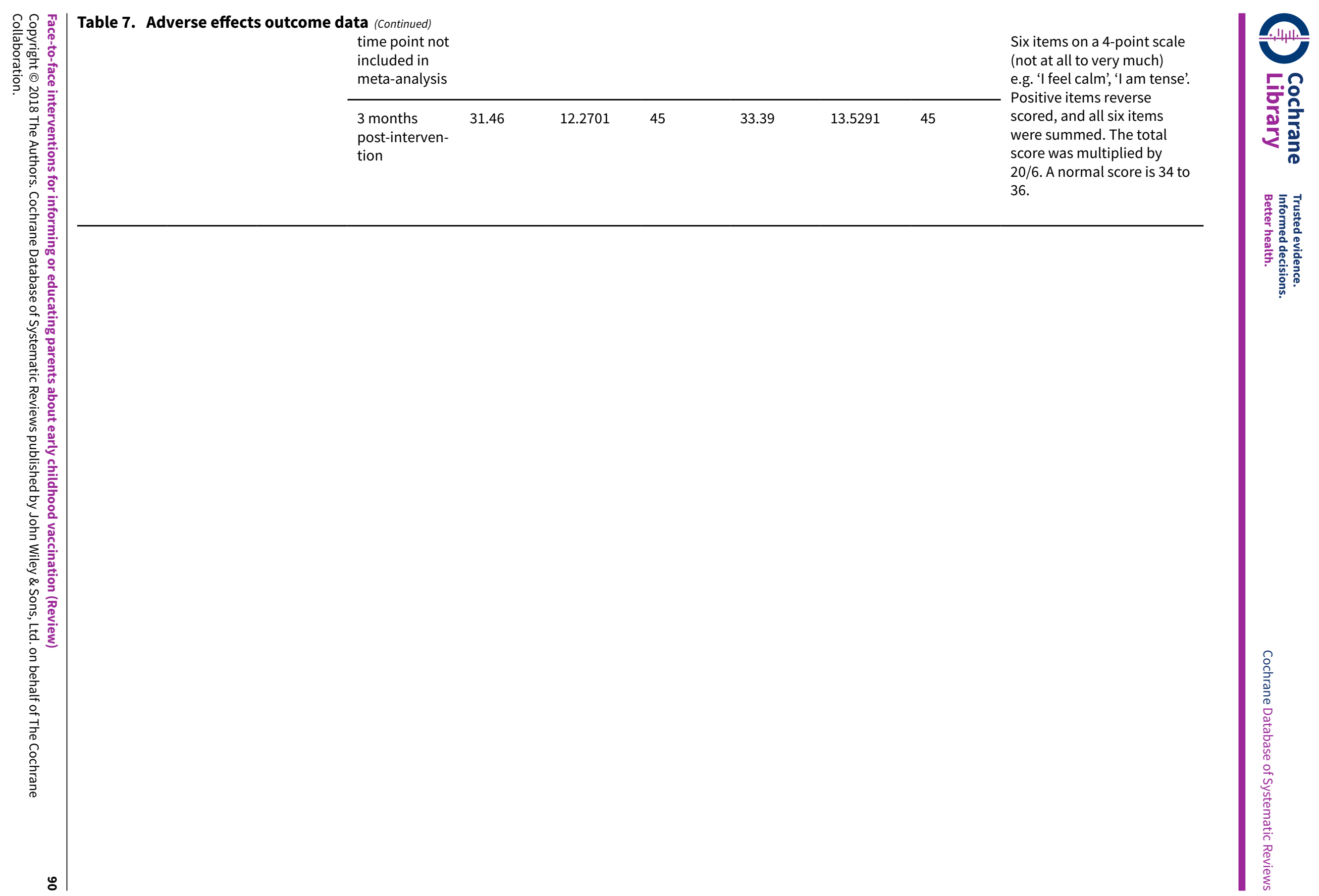




\section{AP PE N D I C E S}

\section{Appendix 1. Definitions of 'inform' and 'educate' from original 2013 review \\ Defining the intervention}

We examined the literature to see if information was defined differently from education, as this may have affected the methods of the review. To do this, we searched the following sources: major health agency websites, grey literature reports describing immunisation campaign strategies, and literature about general patient education. We conducted a content analysis to see how these terms were used, described and defined in practice.

Our main conclusion was that there was no agreement about the difference between informing and educating. From the content analysis, four things became clear:

1. It is acknowledged that informing may be different from educating, however the ways in which they might differ are rarely explained;

2. Both of the interventions are described and operationalised in many different ways, and with varying degrees of overlap;

3. Information delivery is frequently described as a component of education, rather than an intervention in its own right;

4. interventions are not often labelled as 'informing' or 'educating'. A plethora of terms is used to describe informing or educating interventions. For example, interpersonal communication, program communication, and behaviour change communication are all terms that can be applied to education interventions (UNICEF 2005).

There were some consistencies in the ways agencies and publications described interventions to inform and to educate, but overall, our main conclusion was that there was not sufficient agreement as to how they differed from one another. Due to a lack of detailed description, and inconsistent language, there was no reliable way to determine which type of intervention a given trial described.

The implications for our review were that we included all interventions that aimed to inform or educate, without distinguishing between these two purposes.

\section{Our definition of the intervention}

Relevant interventions are those that make consumers aware of the practical or logistical factors associated with vaccination, or seek to enable them to understand the meaning and relevance of vaccination for themselves, their family or community (Willis 2013) The goal of these interventions could be to achieve outcomes, such as improved vaccination coverage; appropriate timeliness of vaccination; or increased knowledge of vaccines, vaccine-preventable diseases, or service delivery. Interventions may be tailored to address low literacy levels or misinformation.

\section{Descriptions of 'inform' and 'educate' from different sources}

\begin{tabular}{lll}
\hline Organisation & 'Inform' definition and description & 'Educate' definition and description \\
\hline UNICEF/WHO & - Increasing or disseminating information & - Can lead to greater awareness and motivation \\
(UNICEF 2005) & - Reaching many people & - There is a partnership between the parent and \\
& - Reinforcing messages & - An empowering process \\
& - Timited interaction & - Can incorporate community participation \\
& - Awareness is increased & - Can facilitate learning \\
& Examples include: mass media interventions, \\
& such as radio, TV and newspapers, posters, ad- & - Spreases comprehension \\
vertisements, public service announcements, & reach \\
banners, promotion by radio, drama, news cov- & - Educational materials give information on vaccina- \\
erage, calendars. & tion
\end{tabular}

Also referred to as educational tools, health education, educational materials; can be delivered through meetings or individual contact, or by media, such as radio or TV programs, drama, talk shows, counselling cards, flip charts, pictures. 
(Continued)

\section{CDC (USA)}

(CDC 2012)
- Parent information website covering a very comprehensive list of vaccination topics, such as describing vaccine-preventable diseases, the schedule, and making vaccination decisions
- To learn
- Receipt and provision of tailored, up-to-date, and accurate information, advice, and support

- Information is promoted and disseminated
- Opportunities (e.g. home visits) to discuss concerns or issues

(NICE 2009)

- Raising awareness

- Interventions include: posters, distributing educational material, including information in church bulletins, information booths and displays in public areas

- Information can be solicited from parents (e.g. have 'story hours' at local libraries with people who have suffered from infectious disease to come and talk about their experiences)

\section{- Involves a process of learning}

(Health Canada 2012)
- Can be written and verbal (Johnson 2003)

Cochrane Consumers and Communication Review Group
- Can increase knowledge and encourage positive healthcare choices (Sawmynaden 2012)
- Interactive, structured and formal (Foster 2007)

- Verbal communication, sometimes supplemented with written materials; increases knowledge and skill levels; helps people to understand (Stacey 2017)

IUHPE • Information provision

(IUHPE 2009)
- Can improve health and well-being

- 'Efforts that enable and support people to exert control over the determinants of health and to create environments that support health

- Empowering individuals and communities to improve their health
Patient education academic literature
- Information provision is the most basic level of health education (Nutbeam 1998)

- Can improve knowledge (Coulter 2007)

- Written information is a useful adjunct to encounters with the health professional (Coulter 2007)

- Mass media campaigns are used to inform the public (Coulter 2007)

- Information provision interventions administered on their own are largely unsuccessful (Coulter 2007)
- Promotes self care and improves patient compliance (Ling 2012)

- Includes the provision of information, instructions, or advice. Advice and discussion are common components (Söderlund 2011)

- Incorporates the development of skills and self-efficacy (Nutbeam 1998)

- Enhanced to include features beyond the delivery of information (Nutbeam 2000; Pálsdóttir 2008)

- Promotes understanding (Coulter 2007)

- There is a partnership between the patient and healthcare professional; can be called shared decision making (Coulter 2007)

- Educational interventions are designed to increase the participation of patients in treatment decisions (Coulter 2007)

- There is communication between health providers and patients (Hoving 2010)

- To enable decision making (Hoving 2010)

- Actively involves people 'in the process of setting their own goals and priorities for behavior related to health' (Green 1990) 
(Continued)

\section{Grey literature}

- Giving information can occur during a clinician-patient encounter, using tools, such as posters (Williams 2002)

- Increasing awareness, reinforcing a message (Sheedy 2011)

- An acronym is used incorporating both terms; Information, Education, and Communication (IEC). IEC activities are described as one-onone and mass media (Clift 2001)
- Education materials can supplement conversations clinicians have with parents

- Addresses misinformation (Sheedy 2011)

\section{Appendix 2. Behaviour change theories and their application to vaccination}

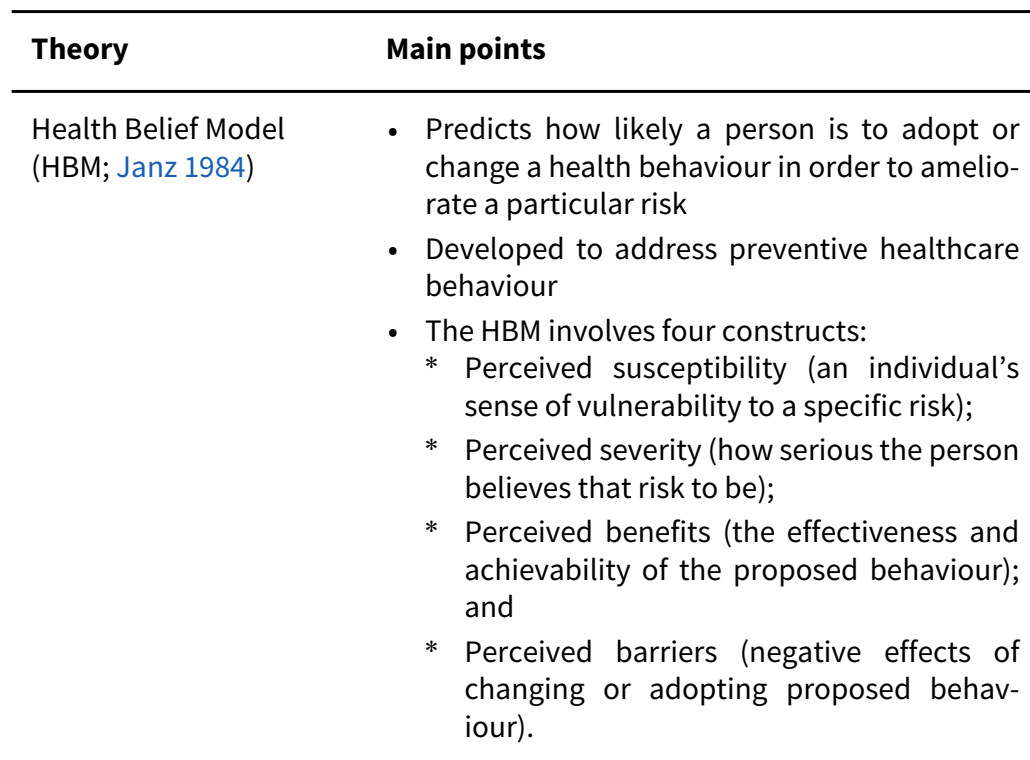

Theory of Reasoned Action (TRA; Ajzen 1985)
- The likelihood of behaviour change or uptake can be predicted based on three components: * Behavioural intention (BI);

* Attitude (AB): personal beliefs about the behaviour;

* Subjective norms (SN): the influence of others in a person's environment.

- A person is likely to change their behaviour if they have the intention to change.

\section{Application to vaccination}

- Interventions can be targeted at any of the four levels of the model in order to influence behaviour, for example providing images and stories of children experiencing serious effects from vaccine-preventable diseases increases perceived severity, while education describing the effectiveness of vaccines influences the perceived benefits of vaccination.

- A face-to-face intervention to inform or educate parents about vaccination is likely to target the parents' attitude toward vaccination, in order to influence their intention to vaccinate. However, if their subjective norm is highly contradictory to their personal attitudes (e.g. they live in a community where vaccination is not approved of), then positively influencing their attitude may not result in a change in vaccination behaviour. Receiving information from a trusted and respected source may help overcome negative subjective norms.
Theory of Planned Behaviour (TPB; Ajzen 1991)
- An extension of the TRA

- Addresses behaviours that are influenced by factors beyond a person's control

- The TPB adds the element of 'perceived behavioural control' (PBC), which is an individual's confidence in their ability to perform the behaviour
- Information intended to influence parental attitudes towards vaccination might differ from information to influence perceived behavioural control. PBC might be improved through provision of logistical information, such as where, how, or when to vaccinate. Attitudes might be more affected by information about risks or benefits, or information delivered in an emotive manner. 
(Continued)

Integrated Behavioral Model (IBM; Montaño 2008)
- Integrates TRA and TPB

- Most important determinant of behaviour is intention

- Intention is determined by attitudes, perceived norms, and personal agency

- Four other components directly affect behavior: knowledge and skill; environmental constraints; salience of the behaviour; habit
- To influence parents' intentions to vaccinate, information or education could target their attitudes, perceptions about what their peers are doing, or perceived ability to act. If parents already have an intention to vaccinate, it is important that they also have sufficient knowledge about how and when to vaccinate. Vaccinations should also be made salient, or cued through a reminder, to ensure parents remember to access them.
Transtheoretical Model (TTM; Prochaska 1994)
- A model incorporating the concept of self-efficacy to predict an individual's readiness or likelihood of acting on a behaviour.

- The TTM is a staged model, with five stages:

* Precontemplation (the person is not intending to take action);

* Contemplation (the person intends to change within the next 6 months);

* Preparation (the person intends to act within the immediate future);

* Action (the person has made some specific changes within the past 6 months); and

* Maintenance (the person is working to avoid relapse).

- Depending on which stage a person falls into, different interventions may be more or less effective at moving them closer to behaviour change.
- Interventions may be tailored to the stage of readiness of the proposed audience. Informative or educational interventions, explaining where to receive vaccines, may be appropriate for people who are in the preparation stage, but people who are completely unaware of, or uninterested in vaccination (pre-contemplation), may be influenced more by information about vaccine-preventable diseases, and the risks and benefits of vaccines. Reinforcement or reminders may be a feature of an intervention targeting people in the maintenance stage.
Social Cognitive Theory (Bandura 1986)
Behaviour, environment, and knowledge are intertwined, and act upon one another. People acquire knowledge, and change their behaviour, based on observing their environment and the behaviour of others in their social context. Selfefficacy, a person's belief in their ability to perform a task, also affects their behaviour.
The vaccination behaviour of parents is influenced by their knowledge (which they have developed, based on available and understandable information), as well as their social environment (the attitudes and behaviour of their peers or community). Vaccination messages delivered face-to-face allow for interaction, and information can be tailored to address specific social, environmental, or personal self-efficacy concerns.

\section{Appendix 3. Sources searched in original review}

In the original review, we searched the following databases and additional sources (Kaufman 2013).

\section{Electronic searches}

We searched the following international and regional sources:

- Cochrane Central Register of Controlled Trials (CENTRAL; 2012, issue 7) in the Cochrane Library

- MEDLINE Ovid (1946 to July 2012)

- Embase Ovid (1947 to July 2012)

- CINAHL EBSCO HOST (1981 to July 2012)

- PsycINFO Ovid (1806 to July 2012)

- Global Health (CAB; 1910 to July 2012)

- Global Health Library (WHO; includes WHOLIS, LILACS, other regional WHO databases; searched July 2012)

We tailored strategies to each database. There were no language or date restrictions.

\section{Searching other resources}

Face-to-face interventions for informing or educating parents about early childhood vaccination (Review) 
- We searched for ongoing trials in the International Clinical Trials Registry Platform (ICTRP; searched August 2012) and contacted authors to obtain further information or eligible data if available.

- We searched for grey literature in:

1. The Grey Literature Report (searched August 2012): www.nyam.org/library/online-resources/grey-literature-report/

2. OpenGrey (searched August 2012): www.opengrey.eu/

- We searched the reference lists of all included papers and any key papers in the field. We also searched the ISI Web of Science (both the Social Science Citation Index and the Science Citation Index; searched September 2012) and Google Scholar (searched September 2012) for papers that cited the studies included in the review. We contacted authors of included studies and vaccination experts from the COMMVAC project advisory group and asked for additional references.

- We also asked authors of included studies to identify any economic evaluations conducted alongside the studies.

\section{Appendix 4. Glossary}

\begin{tabular}{ll}
\hline Abbreviation & Definition \\
\hline BCG & Bacillus Calmette-Guérin (tuberculosis vaccine) \\
\hline DP & Diphtheria and pertussis combined vaccine \\
\hline DPT (or DTP) & $\begin{array}{l}\text { Diphtheria, pertussis, and tetanus combined vaccine (numbers 1 to 3 following the acronym refer } \\
\text { to the dose) }\end{array}$ \\
\hline EPI & Expanded programme on limmunization \\
\hline HBV & Hepatitis B vaccine \\
\hline Hep B & Hepatitis B \\
\hline Hib & Haemophilus influenzae type b \\
\hline HPV & Human papillomavirus \\
\hline MMR & Measles, mumps, and rubella combined vaccine \\
\hline OPV & Oral polio vaccine \\
\hline PCV7 & Pneumococcal conjugate vaccine \\
\hline
\end{tabular}

\section{Appendix 5. CENTRAL search strategy}

3 July 2017

ID Search

$\# 1$ [mh communication]

\#2 ( ${ }^{\star}$ communicat $^{\star}$ or messag* or face-to-face or verbal* or nonverbal* or written or writing or read* or language* or speech ${ }^{\star}$ or speak ${ }^{\star}$ or spoken or talk* or conversation* or listen* or negotiat* or narrat ${ }^{\star}$ or dialog ${ }^{\star}$ or question $^{\star}$ or promot ${ }^{\star}$ or market ${ }^{\star}$ or adverti $^{\star}$ or persua* $^{\star}$ or signage or cartoon $^{\star}$ or humo* or music ${ }^{\star}$ or interpreter ${ }^{\star}$ or translator $\left.^{\star}\right):$ ti, ab,kw

\#3 readability or intelligibility or credibility

\#4 trust* or truth* or deceiv* or deception

\#5 [mh "interpersonal relations"]

\#6 ("human relation*" or interpersonal):kw 
\#7 [mh "hospital-patient relations"]

\#8 [mh "community-institutional relations"]

\#9 (professional or physician or doctor or clinician or nurse or provider or practitioner or pediatrician) near/1 (patient or client or family or parent)

\#10 (improv* or increas* or enhanc* or rais*) near/3 (knowledge or understanding or comprehension or aware*)

$\# 11$ (health or patient* or client*) near/2 knowledge

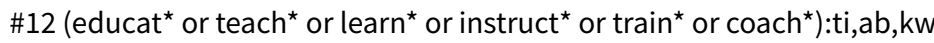

\#13 (community or family or office or work* or school or faith or church) next based

\#14 information* near/1 (service* or disseminat* or seek* or transfer* or campaign* or provid* or provision or aid* or material* or sheet* or pack $\left.{ }^{\star}\right)$

\#15 (patient ${ }^{\star}$ or client ${ }^{\star}$ or health or medical or written or print ${ }^{\star}$ or visual $^{\star}$ or provid ${ }^{\star}$ or present ${ }^{\star}$ or vaccin or immuni $^{\star}$ ) near $/ 2$ inform ${ }^{\star}$

\#16 (oral or text or data or dynamic or numerical or statistical or visual or graphic ${ }^{\star}$ or pictorial or audio*) next (format* or presentation* or display*)

\#17 counsel $^{\star}$ or advis ${ }^{\star}$ or advice* or "social support" or psychosocial or ((social or pastoral or spiritual) next care)

\#18 (support* or peer ${ }^{\star}$ ) near/2 (intervention* or group* or program or project*)

\#19 (social or community) near/2 network*

\#20 ((print* next (material or media or feedback or based)) or paper-based or postal or mail* or letter ${ }^{\star}$ or correspondence or (paper near/2 pen $^{\star}$ ) or publication* or newsletter ${ }^{\star}$ or brochure* or booklet* or pamphlet* or leaflet ${ }^{\star}$ or flyer ${ }^{\star}$ or handout ${ }^{\star}$ or poster $^{\star}$ or billboard $^{\star}$ or illustrat* or picture* or pictogram* or graphic* or icon*):ti,ab,kw

\#21 (home* near/3 visit ${ }^{\star}$ ) or interview* or session* or lecture* or meeting ${ }^{\star}$ or presentation ${ }^{\star}$

\#22 cultural ${ }^{\star}$ near/3 (service* or care or intervention* or appropriate* or sensitiv*)

\#23 [mh "informed consent"]

\#24 "parental consent"

\#25 informed next (consent or choice* or decision*)

\#26 "choice behavior":kw

\#27 decision next (making or support* ${ }^{\star}$ or aid $^{\star}$ or tool ${ }^{\star}$ )

\#28 (patient or person or family or client) next (cent ${ }^{\star}$ red or focus*ed or oriented)

\#29 (shared or joint) near/3 decision*

$\# 30\{$ or \#1-\#29\}

\#31 [mh immunization]

\#32 [mh vaccines]

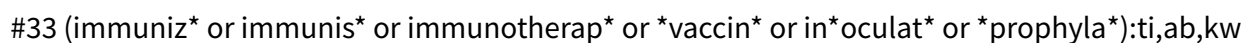

\#34 \#31 or \#32 or \#33

$\# 35$ \#30 and \#34

\#36 [mh child]

\#37 [mh infant]

\#38 [mh parents]

Face-to-face interventions for informing or educating parents about early childhood vaccination (Review) 
\#39 perinatal or peri-natal or postnatal or post-natal

\#40 (child ${ }^{\star}$ or infan ${ }^{\star}$ or toddler ${ }^{\star}$ or newborn or neonat ${ }^{\star}$ or baby or babies or preschool* or pre-school ${ }^{\star}$ or kindergarten* or boy ${ }^{\star}$ or girl ${ }^{\star}$ or schoolchild $^{\star}$ or pediatric ${ }^{\star}$ or paediatric ${ }^{\star}$ or parent ${ }^{\star}$ or mother ${ }^{\star}$ or father ${ }^{\star}$ or maternal or paternal):ti,ab,kw

\#41 \{or \#36-\#40\}

\#42 \#35 and \#41 Publication Year from 2012 to 2017

\section{Appendix 6. MEDLINE Ovid search strategy}

1. immunotherapy/

2. exp immunization/

3. Immunization Programs/

4. exp vaccines/

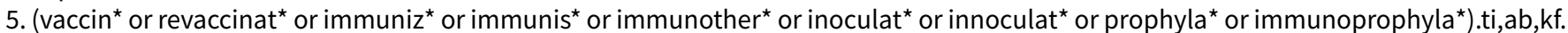

6. or/1-5

7. exp child/

8. exp infant/

9. exp perinatal care/

10. exp parents/

11. (child ${ }^{\star}$ or infan ${ }^{\star}$ or toddler ${ }^{\star}$ or newborn or neonat ${ }^{\star}$ or baby or babies or preschool ${ }^{\star}$ or pre-school ${ }^{\star}$ or kindergarten ${ }^{\star}$ or boy ${ }^{\star}$ or girl $^{\star}$ or schoolchild $^{\star}$ or pediatric ${ }^{\star}$ or paediatric ${ }^{\star}$ or parent ${ }^{\star}$ or $_{\text {mother }}^{\star}$ or father ${ }^{\star}$ or maternal or paternal).mp.

12. or $/ 7-11$

13.6 and 12

14. exp communication/

15. (communicat* or messag* or face to face or verbal ${ }^{\star}$ or nonverbal ${ }^{\star}$ or written or writing or reading or language* or speech* or speak ${ }^{\star}$ or spoken or talk* or conversation* or listen ${ }^{\star}$ or negotiat* or narrat* or dialog* or question* or promot* or marketing or adverti* or persua* or signage* or cartoon ${ }^{\star}$ or humo? $r^{\star}$ or music ${ }^{\star}$ or interpreter ${ }^{\star}$ or translator $\left.{ }^{\star}\right) . \mathrm{mp}$.

16. (readability or intelligibility or credibility).mp.

17. (trust* or truth $^{\star}$ or deceiv ${ }^{\star}$ or deception or misinform $\left.{ }^{\star}\right)$.mp.

18. exp interpersonal relations/

19. hospital patient relations/

20. community institutional relations/

21. ((professional or physician or doctor or clinician or nurse or provider) adj1 (patient or client or family)).mp.

22. ((improv or increas $^{\star}$ or enhanc ${ }^{\star}$ or rais $\left.{ }^{\star}\right)$ adj3 (knowledge or understanding or comprehension or aware $\left.{ }^{\star}\right)$ ).ti,ab,kf.

23. ((health or patient* or client $\left.^{\star}\right)$ adj2 knowledge).mp.

24. (educat ${ }^{\star}$ or teach ${ }^{\star}$ or instruct ${ }^{\star}$ or train ${ }^{\star}$ or coach $^{\star}$ or learn $\left.^{\star}\right)$.mp.

25. ((community or family or office or work* or school or faith or church) adj based).ti,ab,kf.

26. (information ${ }^{\star}$ adj (service* or disseminat ${ }^{\star}$ or seek ${ }^{\star}$ or transfer ${ }^{\star}$ or campaign ${ }^{\star}$ or provid ${ }^{\star}$ or provision or aid or material* or sheet ${ }^{\star}$ or pack $)) \cdot \mathrm{mp}$.

27. ((patient or client or health or medical or written or print ${ }^{\star}$ or visual ${ }^{\star}$ or provid ${ }^{\star}$ or present ${ }^{\star}$ or vaccin* or immuni $\left.{ }^{\star}\right)$ adj2 inform*).mp.

28. ((oral or text ${ }^{\star}$ or data or numerical or statistical or visual or graphic $\left.{ }^{\star}\right)$ adj (format ${ }^{\star}$ or presentation* or display $\left.{ }^{\star}\right)$ ).mp.

29. (counsel ${ }^{\star}$ or advis ${ }^{\star}$ or advice* or social support or psychosocial or ((social or pastoral or spiritual) adj care)).mp.

30. ((support or peer) adj2 (intervention* or group* or program*)).mp.

31. ((social or community) adj2 network $\left.{ }^{\star}\right) . \mathrm{mp}$.

32. ((print ${ }^{\star}$ adj (material ${ }^{\star}$ or based or media)) or paper-based or (paper adj1 pen ${ }^{\star}$ ) or publication ${ }^{\star}$ or newsletter ${ }^{\star}$ or brochure ${ }^{\star}$ or booklet $^{\star}$ or pamphlet* or leaflet $^{\star}$ or flyer ${ }^{\star}$ or handout ${ }^{\star}$ or poster $^{\star}$ or illustrat ${ }^{\star}$ or picture* or pictogram $^{\star}$ ).mp.

33. ((home* adj3 visit $\left.^{\star}\right)$ or interview* or session* $^{\star}$ or lecture ${ }^{\star}$ or meeting ${ }^{\star}$ or presentation* $\left.{ }^{\star}\right) . m p$.

34. (cultural ${ }^{\star}$ adj3 (service* or care or intervention ${ }^{\star}$ or appropriate* or sensitiv $\left.^{\star}\right)$ ).mp.

35. choice behavior/

36. (decision adj (making or support or aid*)).mp.

37. exp informed consent/

38. (informed adj (consent or choice* or decision*)).ti,ab,kf.

39. ((patient or person or family or client) adj (cent ${ }^{\star}$ red or focus ${ }^{\star}$ ed or oriented)).mp.

40. or/14-39

41.13 and 40

42. randomized controlled trial.pt.

43. controlled clinical trial.pt.

44. randomized.ab.

45. placebo.ab.

46. drug therapy.fs.

47. randomly.ab. 
48. trial.ab.

49. groups.ab.

50. or/42-49

51.41 and 50

52. limit 51 to $y r=" 2012$-current"

53.51 and $\left(201207^{\star}\right.$ or $201208^{\star}$ or $201209^{\star}$ or $201210^{\star}$ or $201211^{\star}$ or $201212^{\star}$ or $2013^{\star}$ or $2014^{\star}$ or $2015^{\star}$ or $2016^{\star}$ or $\left.2017^{\star}\right)$.ed,ep,dc.

54.52 or 53

\section{Appendix 7. Embase search strategy}

1. exp immunization/

2. exp Immunotherapy/

3. exp vaccine/

4. (vaccin* or revaccinat $^{\star}$ or immuniz ${ }^{\star}$ or immunis ${ }^{\star}$ or immunother $^{\star}$ or inoculat* or innoculat $^{\star}$ or prophyla* or immunoprophyla*).ti,ab,kw.

5. or/1-4

6. exp child/

7. exp perinatal care/

8. exp parent/

9. (child* or infan* or toddler* or newborn or neonat* or baby or babies or preschool* or pre-school ${ }^{\star}$ or kindergarten* or boy ${ }^{\star}$ or girl ${ }^{\star}$ or schoolchild $^{\star}$ or pediatric ${ }^{\star}$ or paediatric ${ }^{\star}$ or parent ${ }^{\star}$ or mother $^{\star}$ or father ${ }^{\star}$ or maternal or paternal).mp.

10. or/6-9

11.5 and 10

12. exp interpersonal communication/

13. (communicat* or messag* or face to face or verbal ${ }^{*}$ or nonverbal* or written or writing or reading or language* or speech* or speak ${ }^{\star}$ or spoken or talk* or conversation ${ }^{\star}$ or listen ${ }^{\star}$ or negotiat ${ }^{\star}$ or narrat ${ }^{\star}$ or dialog ${ }^{\star}$ or question ${ }^{\star}$ or promot ${ }^{\star}$ or marketing or adverti* or persua ${ }^{\star}$ or signage or cartoon $^{\star}$ or humo? $r^{\star}$ or music ${ }^{\star}$ or interpreter ${ }^{\star}$ or translator $\left.{ }^{\star}\right) . \mathrm{mp}$.

14. (readability or intelligibility or credibility).mp.

15. (trust ${ }^{\star}$ or truth $^{\star}$ or deceiv ${ }^{\star}$ or deception or misinform $\left.{ }^{\star}\right) . \mathrm{mp}$.

16. exp human relation/

17. ((professional or physician or doctor or clinician or nurse or provider) adj1 (patient or client or family)).mp.

18. ((improv* or increas $^{\star}$ or enhanc* or rais*) adj3 (knowledge or understanding or comprehension or aware $\left.{ }^{\star}\right)$ ).ti,ab,kw.

19. (educat ${ }^{\star}$ or teach ${ }^{\star}$ or instruct ${ }^{\star}$ or train ${ }^{\star}$ or coach $^{\star}$ or learn $\left.^{\star}\right)$.mp.

20. ((community or family or office or work* or school or faith or church) adj based).ti,ab,kw.

21. ((health or patient ${ }^{\star}$ or client $\left.^{\star}\right)$ adj2 knowledge).mp.

22. exp information/

23. (information ${ }^{\star}$ adj (service* or disseminat* or seek ${ }^{\star}$ or transfer ${ }^{\star}$ or campaign* or provid $^{\star}$ or provision or aid or material ${ }^{\star}$ or sheet ${ }^{\star}$ or pack*)).mp.

24. ((patient or client or health or medical or written or print ${ }^{\star}$ or visual ${ }^{\star}$ or provid ${ }^{\star}$ or present ${ }^{\star}$ or vaccin ${ }^{\star}$ or immuni $\left.{ }^{\star}\right)$ adj2 inform $\left.{ }^{\star}\right) . \mathrm{mp}$.

25. ((oral or text ${ }^{\star}$ or data or numerical or statistical or visual or graphic $\left.{ }^{\star}\right)$ adj (format ${ }^{\star}$ or presentation ${ }^{\star}$ or display $\left.\left.^{\star}\right)\right)$.mp.

26. (counsel ${ }^{\star}$ or advis* or advice* or social support or psychosocial or ((social or pastoral or spiritual) adj care)).mp.

27. ((support or peer) adj2 (intervention ${ }^{\star}$ or group* or program*)).mp.

28. ((social or community) adj2 network*).mp.

29. ((print ${ }^{\star}$ adj (material ${ }^{\star}$ or based or media)) or paper-based or (paper adj1 pen ${ }^{\star}$ ) or publication* or newsletter ${ }^{\star}$ or brochure* or booklet* or pamphlet ${ }^{\star}$ or leaflet ${ }^{\star}$ or flyer ${ }^{\star}$ or handout ${ }^{\star}$ or poster $^{\star}$ or illustrat $^{\star}$ or picture ${ }^{\star}$ or pictogram $\left.^{\star}\right)$.mp.

30. ((home* adj3 visit $\left.^{\star}\right)$ or interview* or session $^{\star}$ or lecture ${ }^{\star}$ or meeting ${ }^{\star}$ or presentation $\left.{ }^{\star}\right) \cdot \mathrm{mp}$.

31. (cultural ${ }^{\star}$ adj3 (service ${ }^{\star}$ or care or intervention* or appropriate ${ }^{\star}$ or sensitiv $\left.{ }^{\star}\right)$ ).mp.

32. (decision adj (making or support or aid*)).mp.

33. parental consent/

34. (informed adj (consent or choice* or decision*)).mp.

35. ((patient or person or family or client) adj (cent ${ }^{\star}$ red or focus ${ }^{\star}$ ed or oriented)).mp.

36. or/12-35

37.11 and 36

38. randomized controlled trial/

39. controlled clinical trial/

40. single blind procedure/ or double blind procedure/

41. crossover procedure/

42. random ${ }^{\star}$.tw.

43. placebo*.tw.

44. ((singl ${ }^{\star}$ or doubl $\left.{ }^{\star}\right)$ adj $\left(\right.$ blind $^{\star}$ or mask $\left.\left.{ }^{\star}\right)\right)$.tw.

45. (crossover or cross over or factorial ${ }^{\star}$ or latin square).tw.

46. (assign* or allocat $^{\star}$ or volunteer $\left.{ }^{\star}\right)$.tw.

47. or/38-46

Face-to-face interventions for informing or educating parents about early childhood vaccination (Review) 
48. 37 and 47

49. limit 48 to $y r=" 2012$-current"

50.48 and $\left(201207^{\star}\right.$ or $201208^{\star}$ or $201209^{\star}$ or $201210^{\star}$ or $201211^{\star}$ or $201212^{\star}$ or $2013^{\star}$ or $2014^{\star}$ or $2015^{\star}$ or $2016^{\star}$ or $\left.2017^{\star}\right)$.dc.

51.49 or 50

\section{Appendix 8. CINAHL search strategy}

S1 child* or infan* or toddler* or newborn or neonat* or baby or babies or preschool ${ }^{\star}$ or pre-school ${ }^{\star}$ or kindergarten ${ }^{\star}$ or boy ${ }^{\star}$ or girl ${ }^{\star}$ or schoolchild $^{\star}$ or pediatric ${ }^{\star}$ or paediatric ${ }^{\star}$ or parent ${ }^{\star}$ or $_{\text {mother }}{ }^{\star}$ or father ${ }^{\star}$ or maternal or paternal

S2 perinatal or peri-natal or postnatal or post-natal

$\mathrm{S} 3 \mathrm{~s} 1$ or $\mathrm{s} 2$

S4 mh immunization+

$\mathrm{S} 5 \mathrm{mh}$ vaccines+

S6 immuniz or immunis $^{\star}$ or immunotherap ${ }^{\star}$ or vaccin ${ }^{\star}$ or revaccinat ${ }^{\star}$ or inoculat ${ }^{\star}$ or innoculat ${ }^{\star}$ or prophyla* or immunoprophyla*

$\mathrm{S} 7 \mathrm{~s} 4$ or $\mathrm{s} 5$ or $\mathrm{s} 6$

$\mathrm{S} 8 \mathrm{~s} 3$ and $\mathrm{s} 7$

S9 communicat* or messag* or face-to-face or verbal* or nonverbal* or written or writing or read* or language* or speech* or speak* or spoken or talk* or conversation* or listen* or negotiat ${ }^{\star}$ or narrat ${ }^{\star}$ or dialog* or question $^{\star}$ or promot ${ }^{\star}$ or market $^{\star}$ or adverti $^{\star}$ or persua* $^{\star}$ or signage or cartoon $^{\star}$ or humo* or music* or interpreter ${ }^{\star}$ or translator*

S10 readability or intelligibility or credibility or trust ${ }^{\star}$ or truth $^{\star}$ or deceiv* or deception or misinformation

S11 (professional or physician or doctor or clinician or nurse or provider or practitioner or pediatrician) N1 (patient or client or family or parent)

S12 (improv* or increas* or enhanc* or rais*) N3 (knowledge or understanding or comprehension or aware ${ }^{\star}$ )

S13 (health or patient* or client ${ }^{\star}$ ) N2 knowledge

S14 educat ${ }^{\star}$ or teach ${ }^{\star}$ or learn ${ }^{\star}$ or instruct ${ }^{\star}$ or train ${ }^{\star}$ or coach ${ }^{\star}$

S15 (community or family or office or work ${ }^{\star}$ or school or faith or church) N1 based

S16 information ${ }^{\star}$ N1 (service* or disseminat ${ }^{\star}$ or seek ${ }^{\star}$ or transfer* or campaign* or provid* or provision or aid* or material* or sheet ${ }^{\star}$ or $\left.\operatorname{pack}^{\star}\right)$

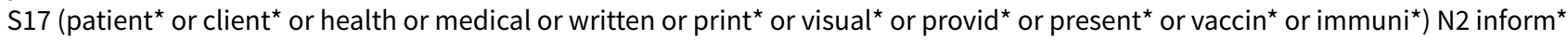

S18 (oral or text or data or dynamic or numerical or statistical or visual or graphic ${ }^{\star}$ or pictorial or audio*) N1 (format ${ }^{\star}$ or presentation* or display*)

S19 counsel $^{\star}$ or advis* or advice* or "social support" or psychosocial or ((social or pastoral or spiritual) N1 care)

S20 (support* or peer $\left.{ }^{\star}\right)$ N2 (intervention* or group* or program* or project ${ }^{\star}$ )

S21 (social or community) N2 network*

S22 (print ${ }^{\star}$ N1 (material or media or feedback or based)) or paper-based or postal or mail* or letter ${ }^{\star}$ or correspondence or (paper N2 pen*) or publication ${ }^{\star}$ or newsletter ${ }^{\star}$ or brochure or booklet $^{\star}$ or pamphlet ${ }^{\star}$ or leaflet ${ }^{\star}$ or flyer ${ }^{\star}$ or handout ${ }^{\star}$ or poster ${ }^{\star}$ or billboard $^{\star}$ or illustrat $^{\star}$ or picture* or pictogram* or graphic* or icon*

S23 (home* N3 visit*) or interview* or session* or lecture* or meeting ${ }^{\star}$ or presentation ${ }^{\star}$

S24 cultural $^{\star}$ N3 (service $^{\star}$ or care or intervention* or appropriate ${ }^{\star}$ or sensitiv ${ }^{\star}$ )

S25 (informed N1 (consent or choice* or decision*)) or "parental consent" or (decision N1 (making or support* or aid* or tool*))

S26 (patient or person or family or client) N1 (cent*red or focus ${ }^{\star} e d$ or oriented)

$\mathrm{s} 27 \mathrm{~s} 9$ or $\mathrm{s} 10$ or $\mathrm{s} 11$ or $\mathrm{s} 12$ or $\mathrm{s} 13$ or $\mathrm{s} 14$ or $\mathrm{s} 15$ or $\mathrm{s} 16$ or $\mathrm{s} 17$ or $\mathrm{s} 18$ or $\mathrm{s} 19$ or $\mathrm{s} 20$ or $\mathrm{s} 21$ or $\mathrm{s} 22$ or $\mathrm{s} 23$ or $\mathrm{s} 24$ or $\mathrm{s} 25$ or $\mathrm{s} 26$

$\mathrm{S} 28 \mathrm{~s} 8$ and $\mathrm{s} 27$

S29 "randomi?ed controlled trial" or PT randomized controlled trial

S30 PT Clinical Trial

S31 MH Clinical Trials+

S32 MH Random Assignment

S33 MH Placebos

S34 MH Quantitative Studies

$\mathrm{S} 35 \mathrm{AB}$ (random* or trial or placebo*) or TI (random* or trial or placebo*)

S36 AB (singl ${ }^{\star}$ or doubl ${ }^{\star}$ or tripl ${ }^{\star}$ or trebl $l^{\star}$ ) and AB (blind ${ }^{\star}$ or mask ${ }^{\star}$ )

S37 TI (singl* or doubl ${ }^{\star}$ or tripl* or trebl $l^{\star}$ ) and TI (blind ${ }^{\star}$ or mask ${ }^{\star}$ )

$\mathrm{S} 38 \mathrm{~S} 29$ or S30 or S31 or S32 or S33 or S34 or S35 or S36 or S37

S39 s28 and s38

S40 PY 2012-2017

S41 s39 and s40

S42 s41 Limiters - Exclude MEDLINE records

\section{Appendix 9. PsycINFO search strategy}

1. exp immunotherapy/

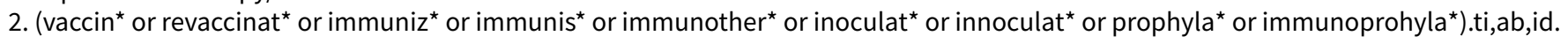

3. or $/ 1-2$

Face-to-face interventions for informing or educating parents about early childhood vaccination (Review) 
4. exp parents/

5. (child* or infan* or toddler* or newborn or neonat* or baby or babies or preschool* or pre-school* or kindergarten* or boy* or girl ${ }^{\star}$ or schoolchild $^{\star}$ or pediatric ${ }^{\star}$ or paediatric ${ }^{\star}$ or parent ${ }^{\star}$ or mother ${ }^{\star}$ or father $^{\star}$ or maternal or paternal).mp.

6. or/4-5

7.3 and 6

8. exp interpersonal communication/

9. exp verbal communication/

10. exp nonverbal communication/

11. (communicat* or messag* or face to face or verbal ${ }^{\star}$ or nonverbal ${ }^{\star}$ or written or writing or reading or language* or speech ${ }^{\star}$ or speak $^{\star}$ or spoken or talk* or conversation ${ }^{\star}$ or listen* or negotiat ${ }^{\star}$ or narrat ${ }^{\star}$ or dialog* or question* or promot* or marketing or adverti* or persua* or signage or cartoon $^{\star}$ or humo? $r^{\star}$ or music or interpreter $^{\star}$ or translator $\left.{ }^{\star}\right) . \mathrm{mp}$.

12. (readability or intelligibility or credibility).mp.

13. (trust* ${ }^{\star}$ or truth ${ }^{\star}$ or deceiv ${ }^{\star}$ or deception or misinform ${ }^{\star}$ ).mp.

14. interpersonal.mp.

15. ((professional or physician or doctor or clinician or nurse or provider) adj1 (patient or client or family)).mp.

16. ((improv* or increas* or enhanc ${ }^{\star}$ or rais $\left.{ }^{\star}\right)$ adj3 (knowledge or understanding or comprehension or aware $\left.{ }^{\star}\right)$ ).ti,ab,id.

17. ((health or patient* or client $\left.{ }^{\star}\right)$ adj2 knowledge).mp.

18. (educat ${ }^{\star}$ or teach ${ }^{\star}$ or instruct ${ }^{\star}$ or train ${ }^{\star}$ or coach $^{\star}$ or learn $\left.{ }^{\star}\right) . \mathrm{mp}$.

19. ((community or family or office or work* or school or faith or church) adj based).ti,ab,id.

20. (information* adj (service* or disseminat* or seek* or transfer* or campaign* or provid* or provision or aid or material* or sheet* or pack $)) \cdot \mathrm{mp}$.

21. ((patient or client or health or medical or written or print ${ }^{\star}$ or visual ${ }^{\star}$ or provid ${ }^{\star}$ or present ${ }^{\star}$ or vaccin ${ }^{\star}$ or immuni $\left.{ }^{\star}\right)$ adj2 inform*).mp.

22. ((oral or text* or data or numerical or statistical or visual or graphic $\left.{ }^{\star}\right)$ adj (format ${ }^{\star}$ or presentation ${ }^{\star}$ or display $\left.^{\star}\right)$ ).mp.

23. (counsel ${ }^{\star}$ or advis ${ }^{\star}$ or advice* or social support or psychosocial or ((social or pastoral or spiritual) adj care)).mp.

24. ((support or peer) adj2 (intervention* or group* or program*)).mp.

25. ((social or community) adj2 network*).mp.

26. ((print ${ }^{\star}$ adj (material ${ }^{\star}$ or based or media)) or paper-based or (paper adj1 pen ${ }^{\star}$ ) or publication ${ }^{\star}$ or newsletter ${ }^{\star}$ or brochure or booklet $^{\star}$ or pamphlet* or leaflet* or flyer ${ }^{\star}$ or handout $^{\star}$ or poster $^{\star}$ or illustrat ${ }^{\star}$ or picture* or pictogram*).mp.

27. ((home ${ }^{\star}$ adj3 visit $\left.{ }^{\star}\right)$ or interview* or session $^{\star}$ or lecture* or meeting ${ }^{\star}$ or presentation $\left.{ }^{\star}\right) . \mathrm{mp}$.

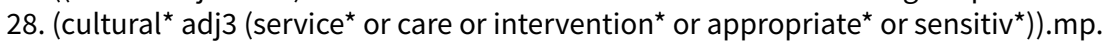

29. (decision adj (making or support or aid $\left.\left.^{\star}\right)\right)$.mp.

30. choice behavior/

31. (informed adj (consent or choice ${ }^{\star}$ or decision*)).mp.

32. ((patient or person or family or client) adj (cent ${ }^{\star}$ red or focus ${ }^{\star}$ ed or oriented)).mp.

33. or/8-32

34.7 and 33

35. random*.ti,ab,hw,id.

36. trial ${ }^{\star}$.ti,ab,hw,id.

37. controlled stud*.ti,ab,hw,id.

38. placebo*.ti,ab,hw,id.

39. ((singl ${ }^{\star}$ or doubl ${ }^{\star}$ or trebl ${ }^{\star}$ or tripl $\left.{ }^{\star}\right)$ and (blind ${ }^{\star}$ or mask $\left.\left.^{\star}\right)\right)$.ti,ab,hw,id.

40. (cross over or crossover or factorial ${ }^{\star}$ or latin square).ti,ab,hw,id.

41. (assign ${ }^{\star}$ or allocat ${ }^{\star}$ or volunteer $\left.{ }^{\star}\right) . t i, a b, h w, i d$.

42. treatment effectiveness evaluation/

43. mental health program evaluation/

44. exp experimental design/

45. "2100".md.

46. or $/ 35-45$

47. 34 and 46

48. limit 47 to $y r=" 2012$-current"

49.47 and $\left(201207^{\star}\right.$ or $201208^{\star}$ or $201209^{\star}$ or $201210^{\star}$ or $201211^{\star}$ or $201212^{\star}$ or $2013^{\star}$ or $2014^{\star}$ or $2015^{\star}$ or $2016^{\star}$ or $\left.2017^{\star}\right)$.up.

50.48 or 49

\section{Appendix 10. Additional database search strategies}

\section{The International Clinical Trials Registry Platform (ICTRP) search strategy}

Review authors searched for any planned or ongoing trials in the WHO International Clinical Trials Registry Platform (ICTRP) on 24 July 2017. Using the "Advanced search" function, the following was used in each field:

Title: vaccin* OR immuniz* OR immunis*

Intervention: educate OR educat* OR inform * OR promot* OR knowledge OR attitude OR teach* OR instruct* OR train* OR session* OR face to face OR communication OR communicat* 
Recruitment status: ALL

Date: since 16/7/2012

\section{ClinicalTrials.gov search strategy}

Date searched: $24 / 7 / 2017$

Other terms: (vaccine OR vaccination OR immunise OR immunize OR immunizing OR immunization) AND child AND (educate OR education OR teach OR train OR instruction OR inform OR promotion OR communication OR knowledge OR attitude OR session OR face to face)

Study type: Interventional Studies

\section{Open Grey search strategy}

Date searched: $24 / 7 / 2017$

Search strategy: (vaccin ${ }^{\star} O R$ immunis ${ }^{\star} O R$ immuniz ${ }^{\star}$ OR immunotherap ${ }^{\star} O R$ inoculat ${ }^{\star}$ ) AND (child ${ }^{\star}$ OR infant ${ }^{\star}$ OR parent $^{\star}$ ORmother ${ }^{\star}$ or $^{\star}$ father ${ }^{\star}$ OR famil ${ }^{\star}$ ) AND (educat ${ }^{\star}$ OR teach ${ }^{\star}$ OR train* OR instruct* OR inform* OR promot* OR persua* OR influenc* OR explain* OR advis* OR counsel ${ }^{\star}$ OR communicat* OR knowledge OR understand ${ }^{\star}$ OR attitude* OR session* OR campaign ${ }^{\star}$ OR messag* OR adverti^ OR visit ${ }^{\star}$ OR

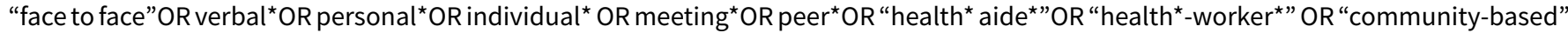
OR "family-based” OR "school-based" OR “work*-based” OR "church-based” OR intervention") AFTER 2010

\section{WHAT'S NEW}

\begin{tabular}{lll}
\hline Date & Event & Description \\
\hline 4 May 2018 & $\begin{array}{l}\text { New citation required and conclusions } \\
\text { have changed }\end{array}$ & Findings for all outcomes have changed. \\
\hline 12 December 2017 & New search has been performed & $\begin{array}{l}\text { All aspects of this review have been updated since its original } \\
\text { publication in 2013. We have included four additional studies } \\
\text { and the findings for all outcomes have changed. }\end{array}$ \\
\hline
\end{tabular}

\section{CONTRIBUTIONS OF AUTHORS}

\section{Review Update}

Drafting updated review: JK

Searching for trials: JK

Selecting trials: JK, LW, RR

Data entry: JK, LW

Analysis: JK, RR, DH

Interpreting analysis: All

Commenting on and finalising updated review: All

\section{DECLARATIONS OF INTEREST}

JK received funding to undertake this review update from a La Trobe University, Building Health Communities Research Focus Area grant. Additional funding for JK was provided by the Centre for Health Communication and Participation. She is an editor with the CCC.

$\mathrm{SH}$ is the Coordinating Editor of the CCC and her contribution to this review was funded in part by a Cochrane Infrastructure Grant provided by the National Health and Medical Research Council (NHMRC).

RR is the Deputy Coordinating Editor of the CCC, and receives funding from a Cochrane Infrastructure Grant provided by the National Health and Medical Research Council (NHMRC). 
$\mathrm{DH}$ is an editor with the CCC.

JL received funding from the Sydney Children's Hospital Network for work in developing a vaccination communication intervention.

No authors with editorial roles in the CCC were involved in the editorial or peer review process for this review.

\section{SOURCES OF SUPPORT}

\section{Internal sources}

- NHMRC, Australia.

Infrastructure funding for Cochrane Collaboration activities (SH and RR)

\section{External sources}

- No sources of support supplied

\section{DIFFERENCES BETWEEN PROTOCOL AND REVIEW}

\section{Differences between original review and update}

The following features or methods were changed from the original review (Kaufman 2013):

Outcomes: We changed the outcomes to reflect the development of research in this field. We added 'attitudes or beliefs' and moved 'intention to vaccinate' and 'adverse effects' to the primary outcomes.

Inclusion criteria: We excluded studies evaluating maternal support and educational interventions in which immunisation was not a primary component of the intervention content and where only immunisation coverage was measured. If immunisation knowledge was measured, we included the studies.

Time points: Changed relevant time point from first and last to just last.

Comparisons: We changed the comparisons to face-to-face vs usual care, and face-to-face A vs face-to-face B (removing group and individual distinction, as this was deemed not to be a meaningful distinction).

Search: In the update, we did not search Grey Literature Report because this database has been discontinued. We also did not search Global Health (CAB), or Global Health Library (WHO), as we determined they were low yield databases.

Selection of outcome when multiple outcomes within one category (attitudes or beliefs) were measured: We developed a process to select one outcome when multiple outcomes from a single category were measured and none were identified as the primary outcome. This plan involved comparing the outcome assessment tools to identify the most comparable measure across studies, as different choices of scales measured different aspects of attitudes.

Heterogeneity: We did not set an acceptable heterogeneity threshold for meta-analysis.

Subgroup analyses: We added two post hoc formal subgroup analyses to investigate sources of heterogeneity among the studies reporting vaccination status. The two subgroups were based on intervention session length and number of vaccines received. These subgroups were identified by vaccination experts as relevant to practice and decision making. Session length has direct cost and time implications. Receipt of a single vaccine may be considerably less 'demanding' to achieve, as an outcome, than receipt of multiple or all required vaccines.

\section{N DEX TERMS}

\section{Medical Subject Headings (MeSH)}

${ }^{\star}$ Vaccination; Health Education [ ${ }^{*}$ methods]; Mothers [education]; Parents [*education]; Randomized Controlled Trials as Topic

\section{MeSH check words}

Child; Child, Preschool; Humans; Infant 